九州大学学術情報リポジトリ

Kyushu University Institutional Repository

\title{
Taxonomic Study of the Japanese Species of the Genus Sphecodes (Hymenoptera, Halictidae)
}

Mitai, Katsushi

Kyushu University Museum

Tadauchi, Osamu

Department of Biological Science, Faculty of Sciences, Kyushu University

https://doi.org/10.5109/26914

出版情報: ESAKIA. 53，pp.21-78，2013-03-29. Entomological Laboratory，Faculty of Agriculture， Kyushu University

バージョン：

権利関係 : 


\title{
Taxonomic Study of the Japanese Species of the Genus Sphecodes (Hymenoptera, Halictidae)
}

\author{
Katsushi MitaI $^{1)}$ and Osamu TADAuCHI ${ }^{2)}$ \\ 1) Kyusyu University Museum, Fukuoka, 812-8581 Japan \\ 2) Department of Biological Science, Faculty of Sciences, Kyushu University, Fukuoka, \\ 812-8581 Japan
}

\begin{abstract}
The genus Sphecodes comprised of twenty species in Japan is taxonomically revised. Two new species are described: $S$. ikudomei and S. nagasei. The following thirty-three synonymies are proposed: $S$. tsunekii Haneda, 1995 = S. amakusensis Yasumatsu et Hirashima, 1951: S. kamafuse Tsuneki, 1983, S. ohtsukius Tsuneki, 1984, and S. chichibuensis Tsuneki, $1986=$ S. coptis Tsuneki, 1983; S. baratonis Tsuneki, 1983 and S. sudai Tsuneki, 1983=S. hanedai Tsuneki, 1983; S. chibaensis Tsuneki, 1984 and S. izumindus Tsuneki, $1986=$ S. koikensis Tsuneki, 1983; S. convergens Tsuneki, $1983=$ S. maruyamanus Tsuneki, 1983; S. kaiensis Tsuneki, 1983, S. akitanus Tsuneki, 1984, S. maetai Tsuneki, 1984, and S. mutsuoides Tsuneki, 1984 = S. murotai Tsuneki, 1983; S. aino Tsuneki, 1983 and S. awaensis Tsuneki, 1983= S. nippon Meyer, 1922; S. iwatensis Tsuneki, 1983, S. kisukei, Tsuneki, 1983, S. itidyo Tsuneki, 1983, and S. rikuchu Tsuneki, 1983=S. nipponicus Yasumatsu et Hirashima, 1951; S. breviclypeatus Tsuneki, 1983, S. duplipunctatus Tsuneki, 1983, S. hasshanus Tsuneki, 1983, and S. sapporoensis Tsuneki, $1983=S$. okuyetsu Tsuneki, 1983; S. japonicus Cockerell, 1911, S. utinamius Tsuneki, 1983, S. taicho Tsuneki, 1983, and S. daisi Tsuneki, 1983 = S. scabricollis Wesmael, 1885; S. kitamius Tsuneki, 1983 and S. shirozui Tsuneki, 1983 = S. silvicola Tsuneki, 1983; S. mutsu Tsuneki, 1983 and S. fukuiensis Tsuneki, 1983, S. fudzi Tsuneki, 1983, and S. chichibuus Tsuneki, 1983 = S. tanoi Tsuneki, 1983.
\end{abstract}

Key words: Sphecodes, taxonomy, Hymenoptera, Halictidae, Sphecodes, cleptoparasitic, new species, new synonymies.

\section{Introduction}

Sphecodes Latreille, 1804 is a large genus of Halictidae distributed worldwide except in the Polar Regions. Most Sphecodes species are cleptoparasites of Lasioglossum, but some attack nests of other pollen-collecting bees, Andrena (Andrenidae), Colletes (Colletidae) etc. (Michener, 2007).

Sphecodes are relatively not abundant among the Japanese bees, and can be distinguished among Japanese Halictidae by the lack of the specialized pollen-collecting apparatus, the third submarginal cell which is much smaller than the first, and the non-metallic, wholly black body or with partially red-colored abdomen.

In Japan, the first record of Sphecodes was by F. Smith
(1873) describing $S$. simillimus as a new species, then followed by Vachal (1903), Cockerell (1911), Meyer (1922) and Yasumatsu and Hirashima (1951). Tsuneki revised Sphecodes of Japan and enumerated 44 species in 1983, and later he added nine species to the Japanese fauna, but placed two species as synonyms $(1984,1986)$. However, some taxonomic problems involving taxonomic identity and combinations of female and male are still unsolved. The descriptions of quite a few species by Tsuneki were based on single specimen, and the interspecific discriminations are subtle differences of the sculpture and shape of the pygidial plate, which may to some extent vary intraspecifically. Subsequently nearly thirty years since his work, little progress has been made on the taxonomy of the genus, and much taxonomic work still needs to be

E-mail: mkatusi@agr.kyushu-u.ac.jp 
done to promote their biological and bee diversity studies.

The purpose of this paper is to describe two new species, redescribe 18 species, synonymize 33 species, and provide a key for distinguish the Japanese species.

We were not able to examine the type of Sphecodes oriundus Vachal, 1903, which was described based on a male specimen from Tokyo and had not been recorded ever since. We, therefore, excluded it in the systematics and the key below.

\section{Materials and Methods}

Terminology for the structures follows Michener (2007). In the case of species where both females and males are known, only differences compared to females are given in the male description.

The hosts of most Sphecodes species in Japan are unknown. Fragmental biological data, if present, are contained in the description of each species, but most of the labels of the examined specimens do not contain biological information. As for the species with many specimens, namely S. coptis, nipponicus, okuyetsu, scabricollis, silvicola, and simillimus, the phenologies are represented in Tables.

Male genitalia were figured after being cleared in a $10 \%$ solution of $\mathrm{KOH}$.

Abbreviations used in the text are as follows: FL, flagellar segment; T, metasomal tergum; S, metasomal sternum.

The examination is based on approximately 3,700 dried, pinned specimens. They are comprised of about 900 specimens from Hokkaido, 2,500 from Honshu, 40 from Shikoku, 250 from Kyushu, and two from the Nansei Islands. Depositories of examined specimens are abbreviations as follows: APM, Aomori Prefectural Museum, Aomori, Japan; EBSU, Division of Environmental Biology, Faculty of Life and Environmental Science, Shimane University, Matsue, Japan; ELKU, Entomological Laboratory, Faculty of Agriculture, Kyushu University, Fukuoka, Japan; FFPRI, Forestry and Forest Products Research Institute, Tsukuba, Japan; MNHAH, Museum of Nature and Human Activities, Sanda, Japan; SEHU, Systematic Entomology, Faculty of Agriculture, Hokkaido University, Sapporo, Japan. Specimens without a depository listed belong to the private collections of the respective collectors.

\section{Systematics \\ Genus Sphecodes}

\section{Key to females of Japan}

1 Vertex with a longitudinal carina S. simillimus

- Vertex without such carina ......................................... 2

2 Area from top of head to upper margin of lateral ocellus about twice as wide as lateral ocellar diameter S. nippon

- Vertex not such developed, area from top of head to upper margin of lateral ocellus about as wide as lateral ocellar diameter

... 3

3 Gena flat; outer orbit of compound eye furrowed; lateral ridge of pronotum produced anteriorly beyond anterolateral margin of pronotum ... 4

- Gena roundly swollen; outer orbit of compound eye not furrowed; lateral ridge of pronotum rounded and low, not produced anteriorly beyond anterolateral margin of pronotum 5

4 Median carina on interantennal elevation usually gradually fading out ventrally, top of interantenal elevtion higher than median carina; punctures on T1-2 distinct and dense; basal (usually hidden under T1) and apical depression areas of T2 deep S. nipponicus

- Median carina on interantennal elevation usually abruptly ends ventrally, top of interantenal elevtion lower than median carina; punctures on T1-2 less distinct and slightly sparser; basal and apical depression areas of T2 moderate S. scabricollis

5 Hind femur slender with the maximum width 0.25 0.28 times as wide as the length ............................. 6

- Hind femur with maximum width as least 0.35 times as wide as the length. 7

6 Mandible without an inner tooth .... S. nagasei sp. nov

- Mandible with an inner tooth ........... S. maruyamanus

7 Mandible without an inner tooth ........ S. amakusensis

- Mandible with an inner tooth ...................................... 8

8 Pygidial plate wide, more than twice the width of FL2 …............................................. S. laticaudatus

- Pygidial plate usually less than the width of FL2, at most 1.2 times as wide as it ..................................... 9

9 Upper margin of posterior vertical face of propodeum (immediately below transverse carina) smooth transversely without sculpture ......................... S. sulcifera

- Posterior vertical face of propodeum without such smooth area .............................................................. 10

10 Punctures on clypeus dense, interpunctual space narrower than or as wide as a puncture diameter ....... See table 2

- Punctures on clypeus sparser, interpunctual space usually over twice wider than a puncture diameter 11 
11 Hind femur with the maximum width about 0.35 times as the length; labrum semicircular, length 0.5 times as long as width S. silvicola

- Hind femur with the maximum width about 0.4 times as the length; labrum nearly trapezoid, length 0.7 times as long as width S. ohdeyamanus

\section{Key to males of Japan}

1 Vertex with a longitudinal carina S. simillimus

- Vertex without such carina . .2

2 Frist tergum with distinct punctures ......................... 3

- First tergum with sparse, microscopic punctules or nearly impunctate

S. nipponicus

3 All terga black 6

- First to 3rd terga at least partially red... ... 4

4 Gena roundly swollen; area from top of head to upper margin of lateral ocellus about twice as wide as lateral ocellar diameter S. nippon

- Gena flat; vertex not so developed, area from top of head to upper margin of lateral ocellus about as wide as lateral ocellar diameter

5 Each flagellar segment from 2nd with velvet-like areas, which are band-shaped, at most occupying basal one-fourth of segment; vestiture on face silvery white in color S. scabricollis

- Each flagellar segment from FL2 with velvet-like area which surrounding medial hairless area. Velvet-like area on FL2 confined peripherally; velvet-like areas on more following segments gradually wider; vestiture on face golden in color ....... S. ikudomei sp. nov.

- Each flagellar segment from FL2 with velvet-like area. Velvet-like area on FL2 confined peripherally; velvetlike area on more following segments gradually much wider, hairless area surrounded by velvet-like area, becoming one or a pair of small spot on last several segment; vestiture on face golden in color ... S. nambui

6 Flagellar segments wholly covered with short hairs without hairless area ................................................ 7

- Every flagellar segments from 2nd with distinct hairless areas and velvet-like areas on underside ............ 9

7 Frontal face with very sparse, weakly plumose hairs, hence the integument below can be seen clearly

S. maruyamanus

- Frontal face obscured by dense, plumose hairs ......... 8

8 Scutellum areolate; apical margin of 7th tergum very weakly produced but gently curved and upturned highly....

S. murotai

- Scutellum punctate as scutum with distinct interpunctural spaces; apical margin of 7th tergum moderately produced and upturned weakly S. silvicola
9 Velvet-like areas on flagellar segments narrow, extending from base to basal one-fourth of each segment or

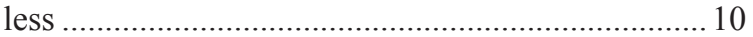

- Velvet-like areas on flagellar segments wide, usually extending from base to the middle of each segment, or at least to basal one-third .14

10 Propodeal triangle enclosed by semicircular carina, which surrounds smaller semicircular carina; these two carinae connected by four to six ridges; longitudinal, straight ridge present medially [scutum and scutellum very sparsely punctate; scutellum gently roundly convex] .......................... S. nagasei sp. nov.

- Propodeal triangle irregularly rugose ...................... 11

11 Scutum areolate on anterior half, changing posteriorly into punctate-reticulate [apical margin of T7 broad-triangularly produced; scutellum areolate].... S. laticaudatus

- Scutum sparsely or densely punctate, but not areolate

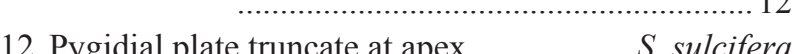

- Pygidial plate rounded at apex.................................. 13

13 Scutellum areolate; apical margin of 7 th tergum turned upward, semicircular or feebly angulate at apex

\section{S. hanedai}

- Scutellum punctate with distinct interpunctural spaces; apical margin of 7th tergum not turned upward, broadtriangularly produced .......................S. dyozankeanus

14 With following combination: small, body size 4-6mm; areas between lateral ocelli and compound eyes sparsely punctate; apical margin of 7 th broad-triangularly produced. S. amakusensis

- Without preceding combination ................................ 15

15 Body size 6-7 mm; FL 1.5 times as long as FL1; scutellum areolate S. tanoi

- Body size 5.5-7mm; FL twice as long as FL1; scutellum at least on anterior half distinctly punctate with flat interpunctural space. S. okuyetsu

\section{Descriptions}

\section{Sphecodes amakusensis Yasumatsu et Hirashima, 1951}

[Japanese name: Amakusa-yadori-kohanabachi] (Figs. 1-2)

Sphecodes amakusensis Yasumatsu et Hirashima, 1951, Ins. Mats. , 7: 121-125 [Holotype: Female]; Tsuneki, 1983, Spec. Publ. Jap. Hymenopt. Assoc. (26): 58 [redescription].

Sphecodes sabulosus Tsuneki, 1983, Spec. Publ. Jap. Hymenopt. Assoc., (26): 39 [Holotype: Female], synonymized by Tsuneki, 1984: 7 . 
Sphecodes tsunekii Haneda, 1994, Jpn. J. Ent., 62: 640 [new name for S. crassicornis Tsuneki, 1983 (nec Smith, 1879)]. Syn. Nov.

\section{Redescription.}

\section{Female.}

Color: Head and mesosoma black except the following: labrum variably tinged with dark brown; mandibles brown basally, red apically; flagellar segments dark brown beneath, slightly paler apically. T1 and T2 basally, or T1-2 wholly and T3 basally red. Femora blackish brown, tibiae and tarsi slightly paler, sometimes nearly yellow.

Sculpture: Clypeus weakly convex without median furrow; punctures sparse, separated by three to four puncture diameters medially. Frons reticulate-punctate. Vertex with scattered, small punctures. Vertex near occipital ridge and genal area costate with fine, irregular rugosity among costae; costae subobsolete near outer orbits of

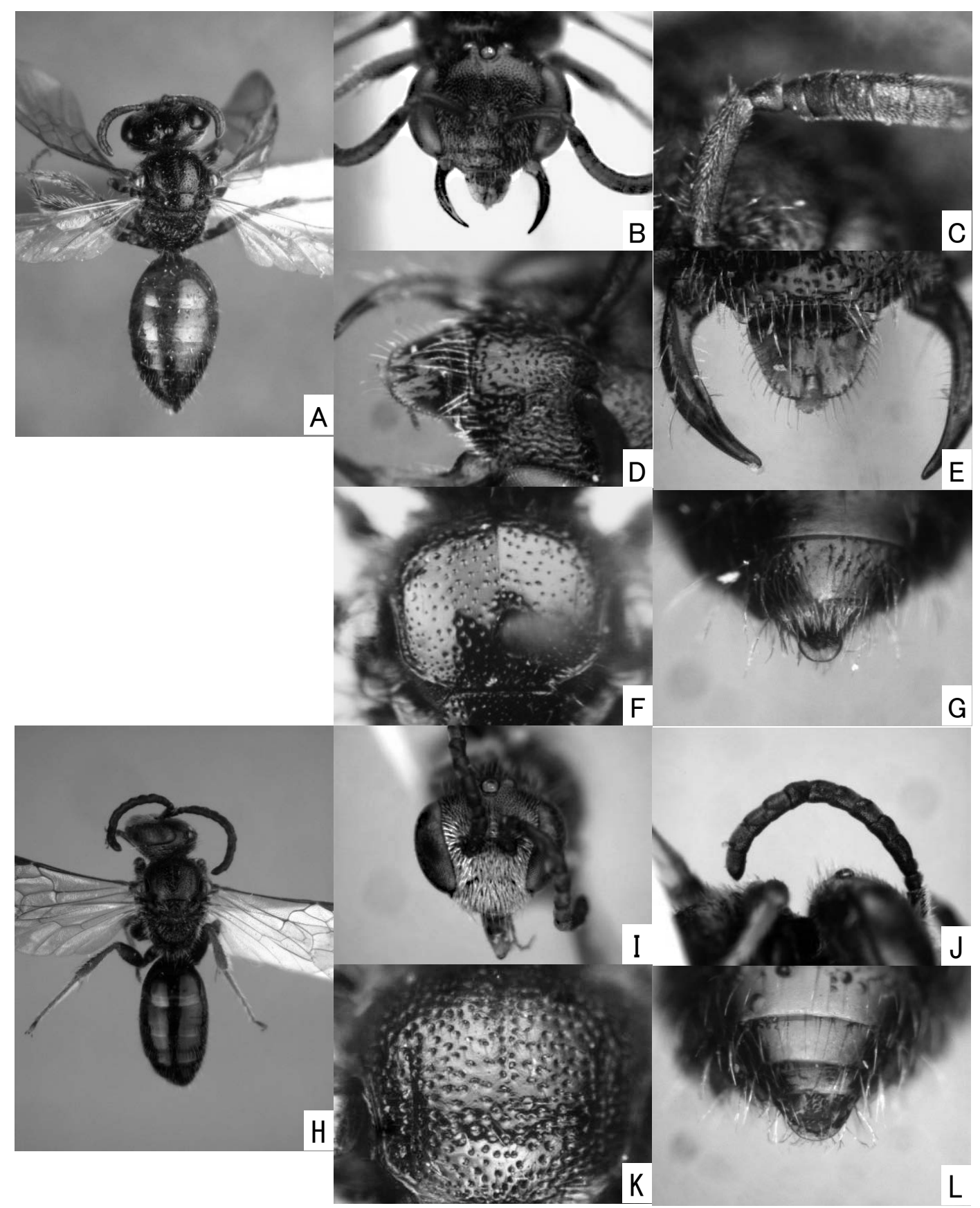

Fig. 1. Sphecodes amakusensis Yasumatsu et Hirashima. Female: A-G. Male: H-L. A, H: habitus, dorsal view. B, I: head. C, J: antenna. D: clypeus. E: labrum. F, K: scutellum. G, L: pygidial plate. 

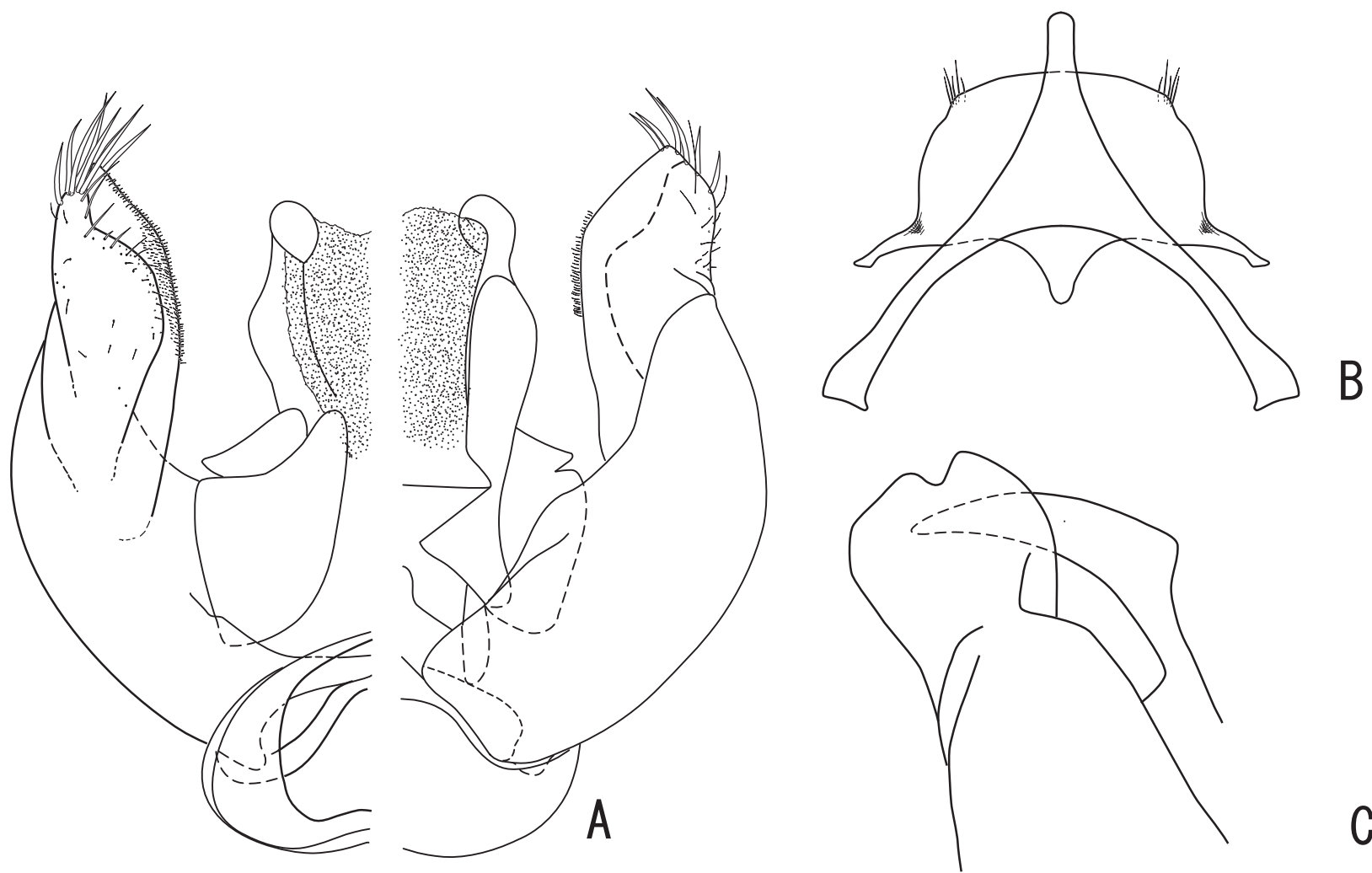

C

Fig. 2. Sphecodes amakusensis Yasumatsu et Hirashima, male. A: genital capsule (left, ventral view; right, dorsal view). B: 7th and 8th metasomal sterna, ventral view. C: gonostylus, lateral view (vestiture omitted).

compound eyes. Scutum sparsely punctate; punctures separated by up to five puncture diameters; interpunctural surface scattered with punctules on peripheral area. Scutellum punctate generally as scutum, but much denser on posterior margin. Mesepisternum areolate shallowly. T1-4 shiny with scattered, fine punctules basally; punctures denser gradually on succeeding tergum. Apical depressed areas of terga indistinctly indicated and impunctate. T5 with setigerous punctures more densely than preceding terga. Pygidial plate 1.25 times as wide as width of FL3, with indistinct longitudinal raised line medially, apex broadly rounded; surface faintly shagreen in some direction of light.

Vestiture: Vestiture on face white or slightly yellowish, very short; that on clypeus, frons and vertex rather sparse, simple or slightly plumose; that on supraclypeal area and lower paraocular area densely plumose, but not so dense to conceal integument.

Structure: Body length 5.5-6 mm. Head about 0.80 times as long as wide. Labrum about 0.5 times as long as wide with medial longitudinal furrow; apex deeply emarginate. Vertex behind lateral ocelli not extended upward beyond lateral ocelli in frontal view. Genal area distinctly narrower than compound eye in lateral view, about 0.5 times as wide as compound eye. Exposed portion of pedicel much longer as FL1. Relative length of FL1 $: 2: 3$ $=1.0: 1.0: 1.6$. FL1 and F2 0.5 times as long as width, FL3 0.6 times, and remaining segment shorter than width. FL1-2 densely shagreen, matt. Undersides of FL3 and the following segments slightly shiny. Mandible simple without inner tooth. Collar sharply angulate between frontal and lateral sides. Pronotum with lateral ridge roundly and lowly raised. Scutellum flat. Hind femora slender, relative breadth to length of hind femur about 0.3 . Apical process of hind tibia broadly triangular. Hook on hind wing 5 in number.

Male.

Color: Body black except the following: mandible dark brown basally, yellowish brown medially, red apically, or wholly darker in some specimens; usually all terga tinged with dark red on apical margins. Femora black, tibiae slightly brown, tarsi yellowish brown.

Sculpture: Clypeus without median furrow; punctures dense without interpunctural space. Supraclypeal area punctate as clypeus. Frons reticulate-punctate. Vertex with scattered punctures, but more densely than that of 
female. Vertex near preoccipital ridge and genal area costate as those of female. Punctures on scutum larger and slightly denser than those of female. Mesepisternum areolate moderately. Terga similar to those of female but slightly denser and hairs longer. T7 well produced posteriorly; surface gently convex and smooth with sparse punctures, but in some specimens impunctate on exposed area.

Vestiture: Vestiture on lower face white, very dense, densely plumose and appressed, concealing integument completely.

Structure: Body length 4-6 mm. Head about 0.85 times as long as wide. Exposed portion of pedicel slightly longer than FL1. Relative length of FL1 : $2: 3=1.0$ : 2.0-2.1 : 1.8. FL1 0.7 times as long as width, FL2 1.5 times, FL3 1.2 times, and remaining segments longer than width. Each segment after FL2 weakly swollen medially. Undersides of FL3 and the following segments with velvet-like areas; velvet-like area variable in width individually, but wider successively on the more following segments. Often the area on FL3 occupies at least basal half of segment, and the area on FL10 reaches slightly before the top of segment. However, in some specimens the areas on FL3 and FL4 occupy basal one-third of segment, and the area on FL8 reaches the middle of segment. Apical process of hind tibia hardly produced. S7 arrow-shaped. S8 with posterior margin gently rounded; lateral margins feebly wavy; anterior margin with process tapering to narrow rounded apex. Gonocoxite striate without dorsal depression. Gonostylus thick, with long vestiture on top and with fine, very short vestiture on other surface; inner basal surface without distinct setae; basoventral lobe not recognized.

Distribution. JAPAN [Hokkaido, Honshu, Kyushu, Amami-Oshima].

Specimens examined. Holotype [ELKU] "[Amakusa]/ Tomioka-/ Shiki /19. vi. 1931/ Esaki \& Hori// Holotype/ Sphecodes/ amakusensis/ Yasumatsu et /Hirashima, '51// Property of/ Ent. Lab. / Kyushu Univ.”.

Other specimens: We have examined about 65 females and 20 males. Some of them are listed as follows: JAPAN [Hokkaido] 3, Wakasakinai, 7. vii. 1975 (H. Fukuda, ELKU). [Honshu] Aomori: 1ð̄, Hukutami, Kuroisi, 24. viii. 1984 (M. Yamada, APM); đ̃, Hohganzi , Kuroishi, 2. viii. 1985 (M. Yamada, APM); ㅇ, Amagamori, Misawa, 27. vii. 1986 (M. Yamada, APM). Iwate: q, Ashiro, 26. ix. 1973 (Y. Maeta, EBSU). Tochigi: + , Mine, Utsunomiya, 24. v. 1980 (K. Nakamura); Ō, Mt. Atago-Inubo, Chosi City, 14. ix. 1987 (H. Suda); đ̃, Ohwada, Yachiyo City, 2. x. 1991 (H. Suda). Gumma:, , Ogo-machi, 14. vii. 1974 (H. Kawano, FFPRI); + , Ayugawa, Nishi-hirai, Fujioka,
23. iv. 2001 (T. Nambu). Saitama: + , Konosu, 13. v. 1961 (T. Nambu); +, Kodama, 3. viii. 1964 (T. Nambu); 3, Arakawa River, Konosu, 28. vi. 1970 (T. Nambu); ㅇ, Hikawa Shrine, Konosu, 7. vi. 1972 (T. Nambu); + , Yorii, 2. v. 1976 (T. Nambu); ㅇ, Gongendo-tsutsumi, Gongendo, Satte, 27. vii. 1995 (T. Nambu); ㅇ, Yamazaki, Yorii, 30. iv. 1998 (T. Nambu); 2q, Nakagawasaki, Satte, 30. vi. 1998 (T. Nambu); + , Asama Shrine, Nishisekijiku, Satte, 30. vi. 1998 (T. Nambu); + , Nakagawasaki, Satte, 5. viii. 1998 (T. Nambu); +, Hie Shrine, Shitami, Hazo, 4. viii. 1999 (T. Nambu); +, Akahama, Yorii, 19. vii. 2000 (T. Nambu). Chiba: + , Usui, Sakura City, 22. x. 1975 (H. Suda); đ̂, Motosakura-Shisui, Inba, 17. x. 1979 (H. Suda); +, Iida, Sakura City, 14. vii. 1980 (H. Suda); ふ, Mt. Atago-Inubo, Chosi City, 14. ix. 1987 (H. Suda); ㅇ, Kurahashi, Unakami Town, 18. vi. 1995 (H. Suda); ㅇ, Tsuboi-cho, Funabashi City, 21. iv. 1997 (H. Suda); ㅇ, Namiki, Kouzaki, Katori, 29. iv. 1998 (H. Suda); 2q, Kamio Brige, Horinouchi, Yachiyo City, 9. v. 2000 (H. Suda); + , Shimoichiba, Yachiyo City, 15. iv. 2001 (H. Suda); $q$, Matsuho Brige, Horinouchi, Yachiyo City, 20. v. 2001 (H. Suda); +, Miyauchi Bridge, Kayada, Yachiyo City, 3. vi. 2001 (H. Suda); + , Shinkawa-Ohashi Bridge, Kayadamachi, Yachiyo City, 21. vii. 2001 (H. Suda); ㅇ, Torami, Ichinomiya-machi, 26. v. 2002 (K. Kubo). Tokyo: 2ᄋ, Tama Cemetery, Fuchyu, 30. vii. 1994 (T. Nambu); , Tama Cemetery, Momijigaoka, Futyu, 13. viii. 1996 (T. Nambu). Kanagawa: q, Kamakura, 7. iv. 1954 (H. Nagase); đ̄, Ebina, 17. iv. 1994 (H. Nagase); 2へ, Ebina, 16. viii. 1994 (H. Nagase); ठิ, Atsugi, 2. х. 1999 (H. Nagase). Niigata: + , Shidaihama, 21. viii. 1983 (H. Itami); ㅇ, Senami, N-Echigo, 12. vii. 1985 (K. Baba); 운, Senami, N-Echigo, 25. vii. 1985 (K. Baba); 2q, Senami, N-Echigo, 28. x. 1985 (K. Baba); + , Senami, N-Echigo, 31. x. 1985 (K. Baba). Fukui: , Sanrihama, 14. vi. 1976 (T. Murota); +, Asojima, Ohno, 23. vii. 1984 (Y. Haneda); ふૈ, Katsuyama, Shimoarai, 4. vii. 1984 (Y. Haneda); ふ̂, Maruoka T., Naruka, 6. viii. 1984 (Y. Haneda); q, Matsugazaki, Ashihara-cho, 9. x. 1997 (Y. Haneda); §̂, Mt. Tezutuyama, Tsuruga-city, 25. xi. 1999 (C. Nozaka); §, Egamicho, Fukuishi, 21. ix. 2000 (H. Kurokawa); + , Egamicho, Fukuishi, 6. v. 2003 (H. Kurokawa); $q$, Matugasaki, Awara-cho, 4. vii. 2004 (H. Kurokawa). Yamanashi: + , Mt. Kouyoudai-Mt. Ashiwadayama, 4. viii. 1976 ( Y. T. \& H. Suda); ㅇ, Kouyoudai-Mikodai, 17. viii. 1981 (Y. \& H. Suda). Nagano: 3 \%, Minamiminowa, Ina, 10. vii. 1962 (2) \& 9. vi. 1963 () (Y. Maeta, EBSU); Shimane: $\hat{\jmath}$, Inasa-hama, Taisya-cho, 5. viii. 1994 (Y. Maeta, EBSU). [Kyushu] Fukuoka: đ̂, Hirao, 11. vii. 1929 (Esaki et al., ELKU); +, Fukuoka, 25. vi. 1952 (Y. Hirashima, ELKU); ㅇ, Fukuoka, 30. vi. 1954 (Maeda 
et Takahashi, ELKU); 9 , Nagahama-kaigan, Nishi-ku, Fukuoka-shi, 2. viii. 2009 (R. Murao, ELKU). Kumamoto: §, Kawayou, Choyo vill., 26. v. 2004, (T. Sugimoto, ELKU). Kagoshima: +, Miyanoura, Yakushima Is., 29. viii. 1952 (Takeya and Hirashima, ELKU); + , Ichikicho, 14. viii. 1978 (H. Nagase); + , Onoaida, 40-200m, Yakushima Is., 27. vii. 1982 (S. Ikudome); ㅇ, Kanoya-shi, 60-70m. 20. ix. 1982 (S. Ikudome). Kagoshima: +, Miyanoura, 0-60m, Yakushima Is., 26. ix. 1982 (S. Ikudome); ㅇ, Sakamine, Kikai, Ohshima, 29. vi. 2000 (H. Suda); 2へ, Amami Forest Polis, Amami-Oshima Is., 9. viii. 2007 (T. Tano).

Biology. The flight period for both sexes is April to November, primarily in June and July. Tsuneki (1983) redescribed this species based on seven female specimens, all of which were collected "at sandy area" at different localities. Haneda (1991) also commented that this species is often collected on seaside and river bed.

Remarks. This species is similar to $S$. longulus and $S$. puncticeps, but can be separated by the combination of the following characters: the much sparser puncture around vertex, the slender hind femur of the female, and the wide velvet-like area on the male antenna. Among the Japanese species, species with simple mandible in the females are only two: Sphecodes nagasei sp. nov. and the present species, whereas the latter species have unique sculpture on the propodeum in both sexes, and robust hind femur in female.

\section{Sphecodes coptis Tsuneki, 1983}

[Japanese name: Ouren-yadori-kohanabachi]

(Figs. 3; Table 1-2)

Sphecodes coptis Tsuneki, 1983, Spec. Publ. Jap. Hymenopt. Assoc., (26): 29 [Holotype: Female. Type locality: Koike, Fukui Pref., Honshu, Japan].

Sphecodes kamafuse Tsuneki, 1983, Spec. Publ. Jap. Hymenopt. Assoc., (26): 65 [Holotype: Female. Type locality: Ohminato, Mt. Kamafuse, Shimokita Peninsula, Aomori Pref., Honshu, Japan]. Syn. Nov.

Sphecodes shirozui (female): Tsuneki, 1983, Spec. Publ. Jap. Hymenopt. Assoc., (26): 66 [description of female].

Sphecodes ohtsukius Tsuneki, 1984, Spec. Publ. Jap. Hymenopt. Assoc., (30): 9 [Holotype: Female. Type locality: Tomihama, Ohtsuki City, Yamanashi Pref., Honshu, Japan]. Syn. Nov.

Sphecodes chichibuensis Tsuneki, 1986, Spec. Publ. Jap.

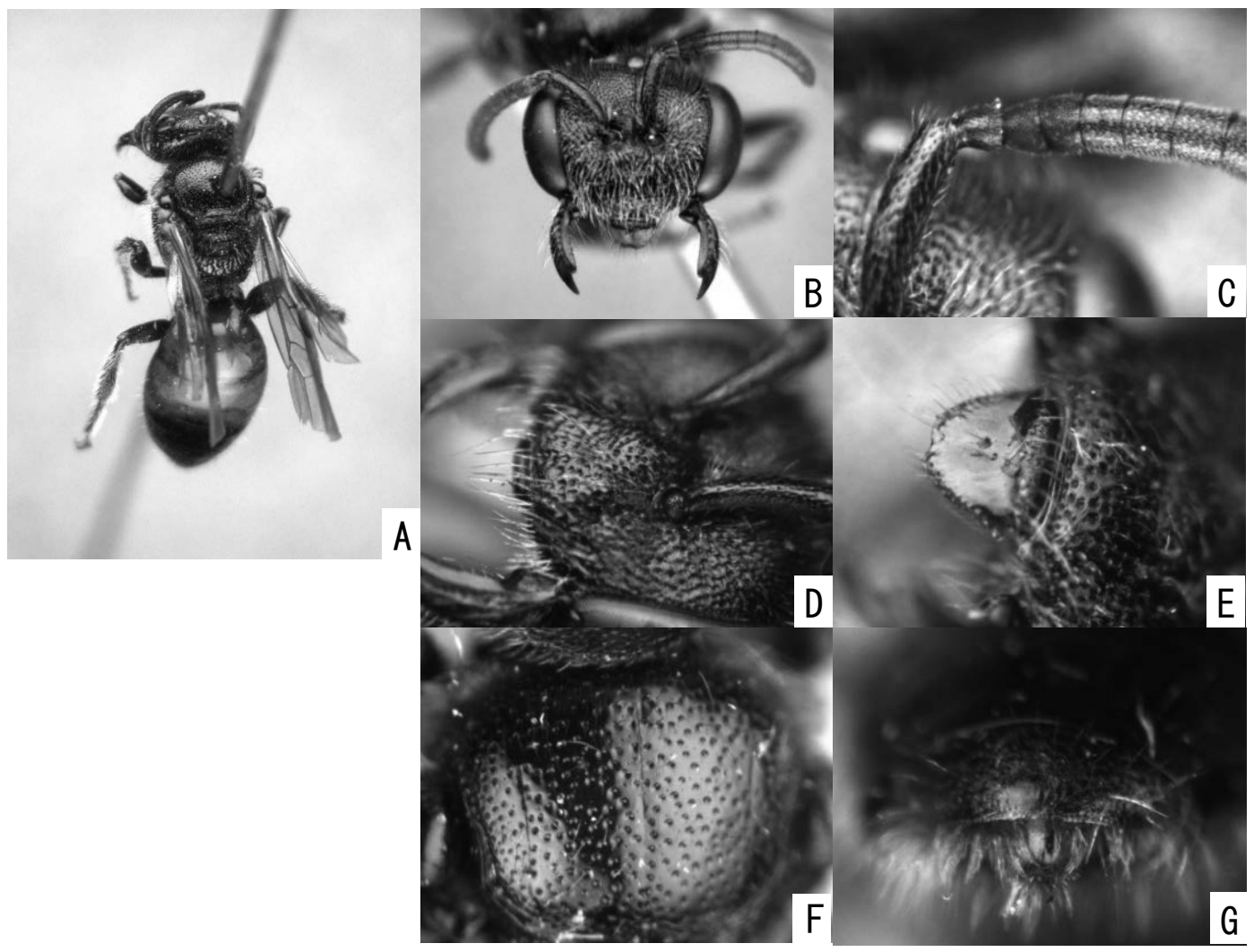

Fig. 3. Sphecodes coptis Tsuneki, female. A: habitus, dorsal view. B: head. C: antenna. D: Clypeus. E: Labrum. F: scutellum. G: Pygidial plate. 
Table 1. Seasonal change in number of the captured female individuals of S. coptis in Japan (E: early, M: mid, L: late).

\begin{tabular}{|c|c|c|c|c|c|c|c|c|c|c|c|c|c|c|c|c|c|c|c|c|c|c|c|c|c|}
\hline \multirow{2}{*}{ Main Island } & \multirow{2}{*}{ Prefecture } & \multicolumn{3}{|c|}{ March } & \multicolumn{3}{|c|}{ April } & \multicolumn{3}{|c|}{ May } & \multicolumn{3}{|c|}{ June } & \multicolumn{3}{|c|}{ July } & \multicolumn{3}{|c|}{ August } & \multicolumn{3}{|c|}{ September } & \multicolumn{3}{|c|}{ October } \\
\hline & & $\mathrm{E}$ & $\mathrm{M}$ & $\mathrm{L}$ & $\mathrm{E}$ & $\mathrm{M}$ & $\mathrm{L}$ & $\mathrm{E}$ & $\mathrm{M}$ & $\mathrm{L}$ & $\mathrm{E}$ & $\mathrm{M}$ & $\mathrm{L}$ & $E$ & $\mathrm{M}$ & $\mathrm{L}$ & $\mathrm{E}$ & $\mathrm{M}$ & $\mathrm{L}$ & $\mathrm{E}$ & $\mathrm{M}$ & $\mathrm{L}$ & $E$ & $\mathrm{M}$ & $\mathrm{L}$ \\
\hline Hokkaido & & & & & & & & 4 & 1 & 4 & 5 & & 8 & 3 & & 5 & 1 & 1 & 1 & 2 & & & & 1 & 1 \\
\hline $\begin{array}{l}\text { Honshu } \\
\quad \text { [Tohoku] }\end{array}$ & $\begin{array}{l}\text { Aomori } \\
\text { Iwate }\end{array}$ & & & & & 3 & 2 & $\begin{array}{l}1 \\
2\end{array}$ & $\begin{array}{l}1 \\
2 \\
\end{array}$ & 6 & & & & & 2 & $\begin{array}{l}2 \\
1\end{array}$ & 1 & 2 & 1 & & $\begin{array}{l}2 \\
1\end{array}$ & 8 & $\begin{array}{l}2 \\
1\end{array}$ & & \\
\hline [Kanto] & $\begin{array}{l}\text { Tochigi } \\
\text { Gumma } \\
\text { Saitama } \\
\text { Tokyo } \\
\text { Kanagawa }\end{array}$ & & & & $\begin{array}{l}1 \\
1\end{array}$ & 3 & $\begin{array}{c}10 \\
11 \\
2\end{array}$ & $\begin{array}{l}1 \\
2 \\
2\end{array}$ & $\begin{array}{l}1 \\
8 \\
1\end{array}$ & $\begin{array}{l}1 \\
2\end{array}$ & 5 & $\begin{array}{l}1 \\
3 \\
1\end{array}$ & $\begin{array}{l}2 \\
1\end{array}$ & 10 & $\begin{array}{l}4 \\
1\end{array}$ & $\begin{array}{l}1 \\
1\end{array}$ & $\begin{array}{l}3 \\
2\end{array}$ & 1 & & & & & & & \\
\hline [Chubu] & $\begin{array}{l}\text { Ishikawa } \\
\text { Fukui } \\
\text { Yamanashi } \\
\text { Nagano } \\
\text { Shizuoka }\end{array}$ & & & & $\begin{array}{l}9 \\
1 \\
1\end{array}$ & 1 & $\begin{array}{l}1 \\
3 \\
2\end{array}$ & $\begin{array}{l}2 \\
5 \\
1\end{array}$ & 2 & $\begin{array}{l}2 \\
4\end{array}$ & 4 & 2 & 1 & $\begin{array}{l}1 \\
1 \\
6\end{array}$ & $\begin{array}{l}1 \\
1\end{array}$ & 4 & $\begin{array}{l}1 \\
1\end{array}$ & $\begin{array}{l}1 \\
4\end{array}$ & 2 & 3 & 1 & 1 & & & \\
\hline [Kinki] & Kyoto & & & & & & & & 2 & & & & & & & & & & & & & & & & \\
\hline [Chugoku] & Hiroshima & & & & & 5 & & & & & & & & & & & & & & & & & & & \\
\hline Shikoku & $\begin{array}{l}\text { Tokushima } \\
\text { Ehime }\end{array}$ & & & & & $\begin{array}{l}2 \\
1 \\
\end{array}$ & & & & & & & & & & & & & & & & 1 & & & \\
\hline Kyushu & $\begin{array}{l}\text { Fukuoka } \\
\text { Nagasaki } \\
\text { Oita } \\
\text { Miyazaki }\end{array}$ & & & 1 & $\begin{array}{l}2 \\
1\end{array}$ & $\begin{array}{l}1 \\
1 \\
\end{array}$ & 1 & 1 & 1 & & $\begin{array}{l}1 \\
1\end{array}$ & & & & & & 1 & & & & & & & & \\
\hline Total & & 0 & 0 & 1 & 15 & 17 & 32 & 21 & 19 & 19 & 19 & 7 & 12 & 21 & 9 & 14 & 10 & 9 & 4 & 5 & 4 & 10 & 3 & 1 & 1 \\
\hline
\end{tabular}

Table 2. Differences among females of Sphecodes coptis, S. koikensis, and S. okuyetsu.

\begin{tabular}{llll}
\hline Feature & S. coptis & S. koikensis & S. okuyetsu \\
\hline Vertex & $\begin{array}{l}\text { Not developed above lateral ocelli } \\
\text { in front view }\end{array}$ & $\begin{array}{l}\text { Developed above lateral ocelli } \\
\text { in front view }\end{array}$ & $\begin{array}{l}\text { Not developed above lateral ocelli } \\
\text { in front view }\end{array}$ \\
Clypeus & $\begin{array}{l}\text { Apical margin not furrowed. Rarely } \\
\text { interpunctual area faintly rugose }\end{array}$ & $\begin{array}{l}\text { Apical margin not furrowed. Sometimes } \\
\text { interpunctual area faintly rugose }\end{array}$ & $\begin{array}{l}\text { Apical margin appears to be furrowed } \\
\text { by continuous punctures. Interpunctual } \\
\text { area always polished. }\end{array}$ \\
Fore wing vein & $\begin{array}{l}\text { First recurrent vein usually basad of 1st } \\
\text { transverse cubital by more than a vein } \\
\text { width }\end{array}$ & $\begin{array}{l}\text { First recurrent vein usually basad of 1st } \\
\text { transverse cubital by more than a vein } \\
\text { width }\end{array}$ & $\begin{array}{l}\text { First recurrent vein usually interstitial } \\
\text { with 1st transverse cubital }\end{array}$ \\
Pygidial plate & $\begin{array}{l}\text { Miximum width 0.8 times as wide as } \\
\text { 3rd flagellar segment }\end{array}$ & $\begin{array}{l}\text { Miximum width 0.9 times as wide as } \\
\text { 3rd flagellar segment }\end{array}$ & $\begin{array}{l}\text { Miximum width 1.2 times as wide as } \\
\text { 3rd flagellar segment }\end{array}$ \\
Body length & 6-7.5 mm & 7-9 mm & 5-8 mm
\end{tabular}

Hymenopt. Assoc., (32): 45 [Holotype: Female. Type locality: Tochimoto Village, Chichibu, Saitama Pref., Honshu, Japan]. Syn. Nov.

Redescription.

\section{Female.}

Color: Head and mesosoma black except the following: mandible paler medially with red apex; apical a few flagellar segments blackish slightly brown beneath; T1-T2, and T3 basally red. Femora and tibiae black, usually paler at apex of femora. Tarsi usually dark brown.

Sculpture: Clypeus without median furrow; punctures moderately dense, at most a puncture diameter apart; interpunctural surface sometimes faintly rugose. Supraclypeal area as clypeus. Frons reticulate-punctate. Vertex before lateral ocelli scattered with punctures. Vertex near preoccipital ridge and genal area costate with fine, irregular rugosity among costae; costae subobsolete near outer orbits of compound eyes. Scutum punctate sparsely, punctures separated generally by two-three puncture diameters; interpunctural surface scattered with punctules. Scutellum punctate generally as scutum, punctures much denser on posterior margin; sometimes most punctures shallow. Mesepisternum areolate moderately. T1-4 shiny with scattered, rather fine punctules basally; T5 punctate much denser than preceding terga with apical 
depressed area shagreen. Pygidial plate 0.8 times as wide as width of FL3, lateral margin nearly parallel; surface usually shiny with medial longitudinal elevation which variously develops.

Vestiture: Vestiture on face yollowish, short, sparse, not densely plumose.

Structure: Body length 6-7.5 mm. Head about 0.75 times as long as wide. Labrum about 0.6-0.7 times as long as wide without distinct medial furrow; apex broadly rounded or truncate, sometimes feebly emarginate. Vertex behind lateral ocelli not developed upward beyond lateral ocelli in frontal view. Genal area slightly narrower than compound eye in lateral view, about 0.9 times as wide as compound eye. Exposed portion of pedicel slightly longer than FL1. FL1-3 subequal in length and 0.7-0.8 times as long as width, and remaining segment slightly shorter than width. FL1-2 densely shagreen, matt. Undersides of FL3 and the following segments slightly shiny. Collar gently curved between frontal and lateral sides. Pronotum with lateral ridge lowly raised. Scutellum flat. Hind femora moderate in breadth, relative breadth to length of hind femur about 0.35 . Apical process of hind tibia shortly rounded. Hook on hind wing 6 in number. First recurrent vein usually basad of 1 st transverse cubital by more than a vein width, or sometimes nearly interstitial.

Male. unknown.

Distribution. JAPAN [Hokkaido, Honshu, Shikoku, Kyushu].

Specimens examined. Holotype [MNHAH], female with three labels as follows: "Koike [in Japanese]/ Fukui, Japan/ 26. VII. 1973/ K. Tsuneki [white rectangle with typed and handwritten letters]", "Sphecodes/ coptis/ Tsuneki 으 HOLOTYPE [red rectangle with handwritten letters]", and "B1-288244 [white rectangle with printed register-number of MNHAH and a bar-code]".

Other specimens: We have examined about 250 females. The localities and phenology are shown in Table 1.

Biology. The flight period is from April to late November, primarily in spring and early summer (see Table 1).

Remarks. Females of this species, S. koikensis Tsuneki, 1983, and S. okuyetsu Tsuneki, 1983 are very similar to each other. The table 2 distinguishes these three females. However, these differences are often obscured by a wide range of individual variation, and hence sometimes they cannot be reliably separated from each other.

\section{Sphecodes dyozankeanus Tsuneki, 1983}

[Japanese name: Jyouzan-yadori-kohanabachi]

(Figs. 4-5)

Sphecodes dyozankeanus Tsuneki, 1983, Spec. Publ. Jap. Hymenopt. Assoc., (26): 33 [Holotype: Male. Type locality: Dyozankei Valley, Sapporo, Hokkaido, Japan].

Redescription.

Male.

Color: Body black except the following: mandible narrowly black basally, yellowish brown medially, red apically; apical margins of T1 and T2 slightly tinged with dark red; Femora brown, tibiae brown and partially yellowish, tarsi wholly yellowish.

Sculpture: Clypeus minutely and densely punctatereticulate without median furrow. Supraclypeal area as clypeus. Frons areolate-rugose, somewhat punctate-reticulate in places. Vertex before lateral ocelli scattered punctures. Vertex near preoccipital ridge and genal area costate with fine, irregular rugosity among costae; costae subobsolete near outer orbits of compound eyes. Scutum sparsely punctate with punctures three or more puncture diameters apart medially. Scutellum punctate slightly denser than scutum with longitudinal line medially; puncture subobsolete medially, but distinct peripherally, much denser on posterior half of scutellum to appear areolate; interpunctural area faintly rugose. Mesepisternum areolate moderately to densely.

T1 and T2 smooth and shiny. T3-T6 indistinctly coriarious except apical margin. T1 with scattered fine punctules except apical impunctate area. T2 with scattered, but evidently denser than $\mathrm{T} 1$, fine punctules except apical impunctate area. T3-T5 impunctate on exposed areas, hairs not accompanied by punctures. T7 weakly produced; surface gently convex.

Vestiture: Vestiture on lower face white or slightly yellowish, rather dense, densely plumose and appressed, concealing integument, but not completely as that of $S$. amakusensis.

Structure: Body length 6-7 mm. Head about 0.85 times as long as wide. Vertex behind lateral ocelli developed upward beyond lateral ocelli in frontal view. Genal area narrower than compound eye in lateral view, about 0.5 times as wide as compound eye. Exposed portion of pedicel as long as FL1. Relative length of FL1 : $2: 3=1.0$ $: 2.4: 2.0$. FL1 0.8 times as long as width, FL2 1.6 times, FL3 1.3 times, and remaining segments slightly longer than width. Each segment after FL2 weakly swollen medially. Undersides of FL4 and the following segments with velvet-like areas; Velvet-like area on FL4 narrowly 


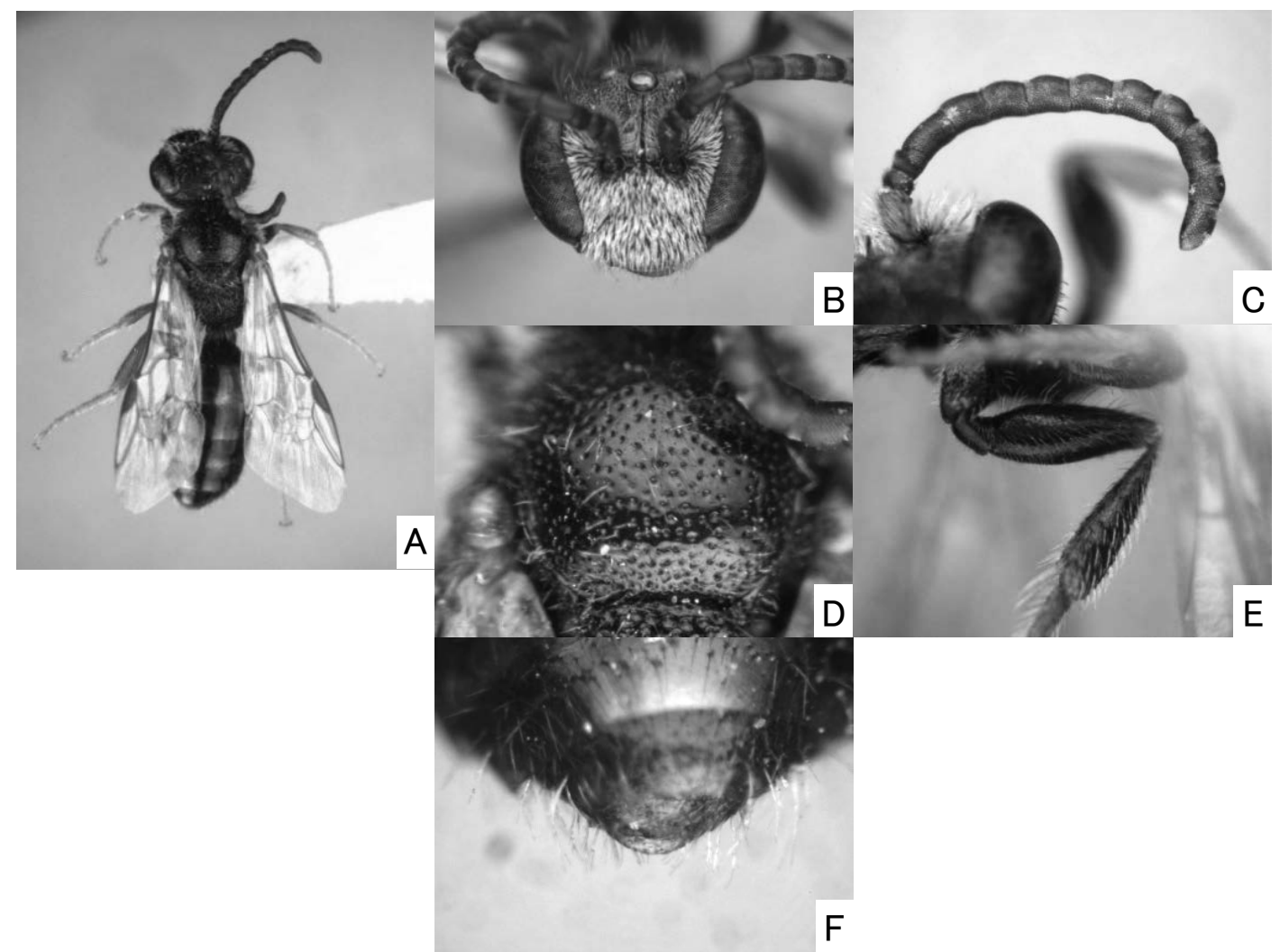

Fig. 4. Sphecodes dyozankeanus Tsuneki, male. A: habitus, dorsal view. B: head. C: antenna. D: scutellum. E: hind femur. F: pygidial plate.
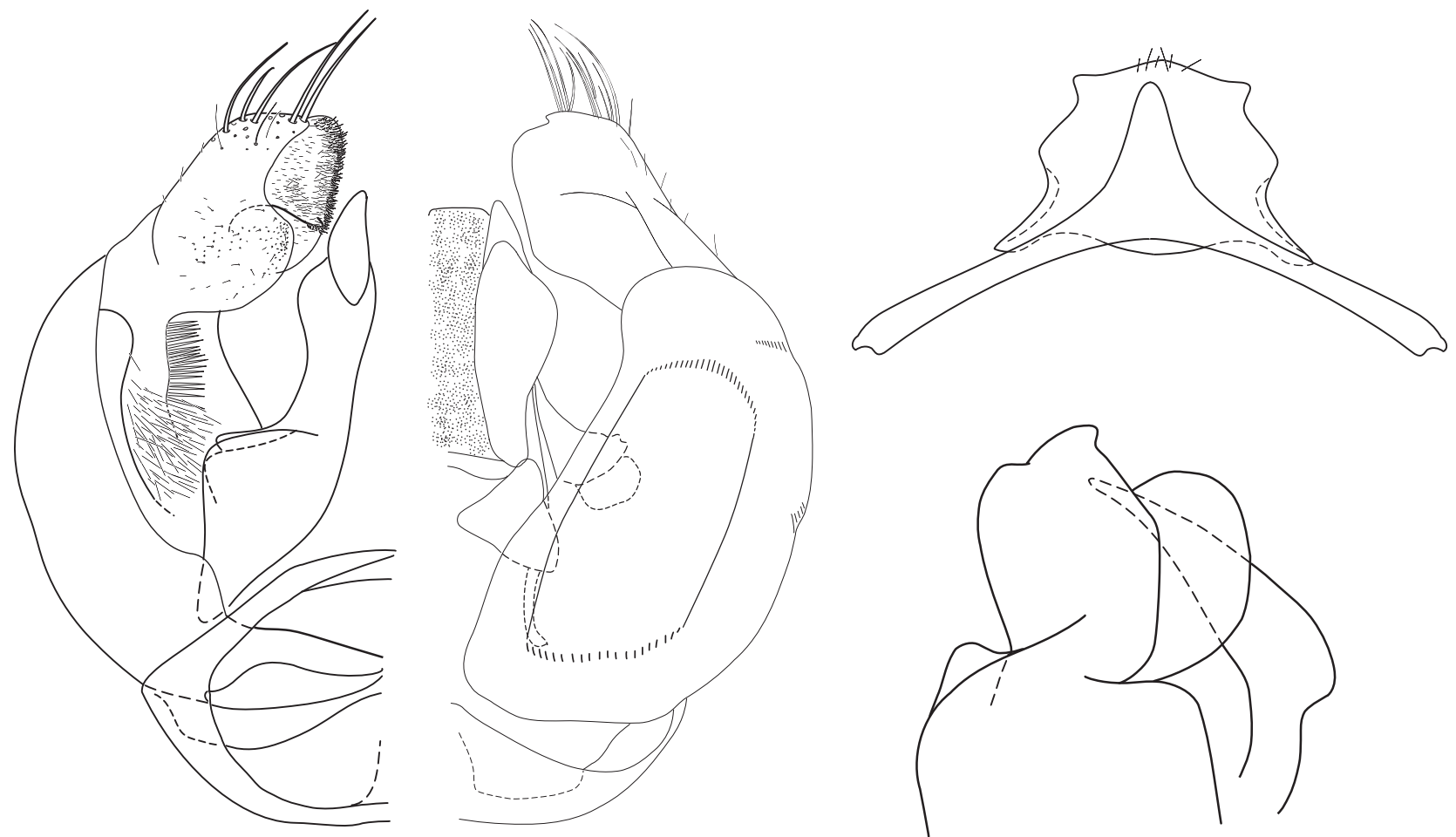

Fig. 5. Sphecodes dyozankeanus, male. A: genital capsule (left, ventral view; right, dorsal view). B: 7th and 8th metasomal sterna, ventral view. C: gonostylus, lateral view (vestiture omitted). 
band-shaped, reaching basal one-fourth of segment; velvet-like area slightly wider successively on the following segments or uniform in width. Collar gently curved between frontal and lateral sides. Pronotum with lateral ridge lowly raised. Scutellum flat. Hind femora moderate in breadth, relative breadth to length of hind femur about 0.38-0.4. Apical process of hind tibia shortly triangular. Hook on hind wing 6 in number. S7 arrow-shaped. S8 with posterior margin gently rounded or slightly produced posteriorly; lateral margins strongly wavy; anterior margin roundly produced anteriorly. Gonocoxite striate with dorsal depression. Gonostylus with long vestiture near top; inner basal surface with dense setae, which finer downwards; basoventral lobe carinate with several, very short, fine setae.

Female. Unknown.

Distribution. JAPAN [Hokkaido, Northern part of Honshu].

Specimens examined. Holotype [MNHAH], male with three labels as follows: "Zyozankei/ Hokkaido, Japan/ 9. IX. 1972/ Y. HANEDA [white rectangle with typed letters]", "Sphecodes/ dyozankeanus/ Tsuneki §/ HOLOTYPE [red rectangle with handwritten letters]", and "B1-288250 [white rectangle with printed registernumber of MNHAH and a bar-code]".

Other specimens: We have examined 22 males as follows: JAPAN [Hokkaido] ${ }^{\lambda}$, Piuka (Teshio), 22. vii. 1952 (T. Shirozu, ELKU); ð̃, Nishiashoro (Tokachi), 9. viii. 1953 (Y. Hirashima, ELKU); 今ે, Botanical Garden, Sapporo, 8. vii. 1959 (Sakagami); Ò, Tsukisappu, 2. ix. 1965 (collector unknown, ELKU); $\partial^{\lambda}$, Nokanan, 20. ix. 1967 (collector unknown, ELKU); 20, Soranuma, 30. viii. 1968 (collector unknown, ELKU); Ô, Inosawa, Asahikawa, 26. viii. 1969 (collector unknown, ELKU);

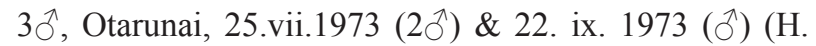
Fukuda, ELKU); 4ð, Urausu, 17. vii. 1974 (3ठ) \& 24.

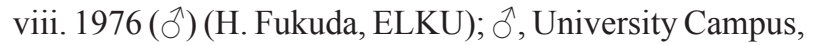
Sapporo, 30. vii. 1979 (Toda, FFPRI). [Honshu] Aomori: §ิ, Hohganzi (Kuroishi), 2. viii. 1985 (M. Yamada, APM); ふૈ, Yudan (Iwaki), 20. viii. 1988 (M. Yamada, APM); ภ, Hiratakinuma (Kizukuri), 22. vii. 1989 (M. Yamada, APM); đ’, Nonai (Aomori-shi), 28. vii. 1989 (M. Yamada, APM); đ, Yudan (Iwaki), 12. viii. 1990 (M. Yamada, APM). Iwate: ô, Kuzakai, 8. ix. 1963 (Y. Maeta, EBSU).

Biology. The flight period is from early July to late September.

Remarks. The male, like that of S. amakusensis Yasumatsu et Hirashima, 1951, has the narrow velvet-like area on the antenna and the sparsely punctate scutum. The latter species has the characteristic pattern of ridges on propodeum, whereas S. dyozankeanus has normal pattern of ridges as for Sphecodes.

\section{Sphecodes hanedai Tsuneki, 1983}

[Japanese name: Haneda-yadori-kohanabachi] (Figs. 6-7)

Sphecodes hanedai Tsuneki, 1983, Spec. Publ. Jap. Hymenopt. Assoc., (26): 35 [Holotype: Male. Type locality: Koike, Fukui Pref., Honshu, Japan].

Sphecodes baratonis Tsuneki, 1983, Spec. Publ. Jap. Hymenopt. Assoc., (26): 34 [Holotype: Male. Barato, Sapporo, Hokkaido, Japan]. Syn. Nov.

Sphecodes sudai Tsuneki, 1983, Spec. Publ. Jap.

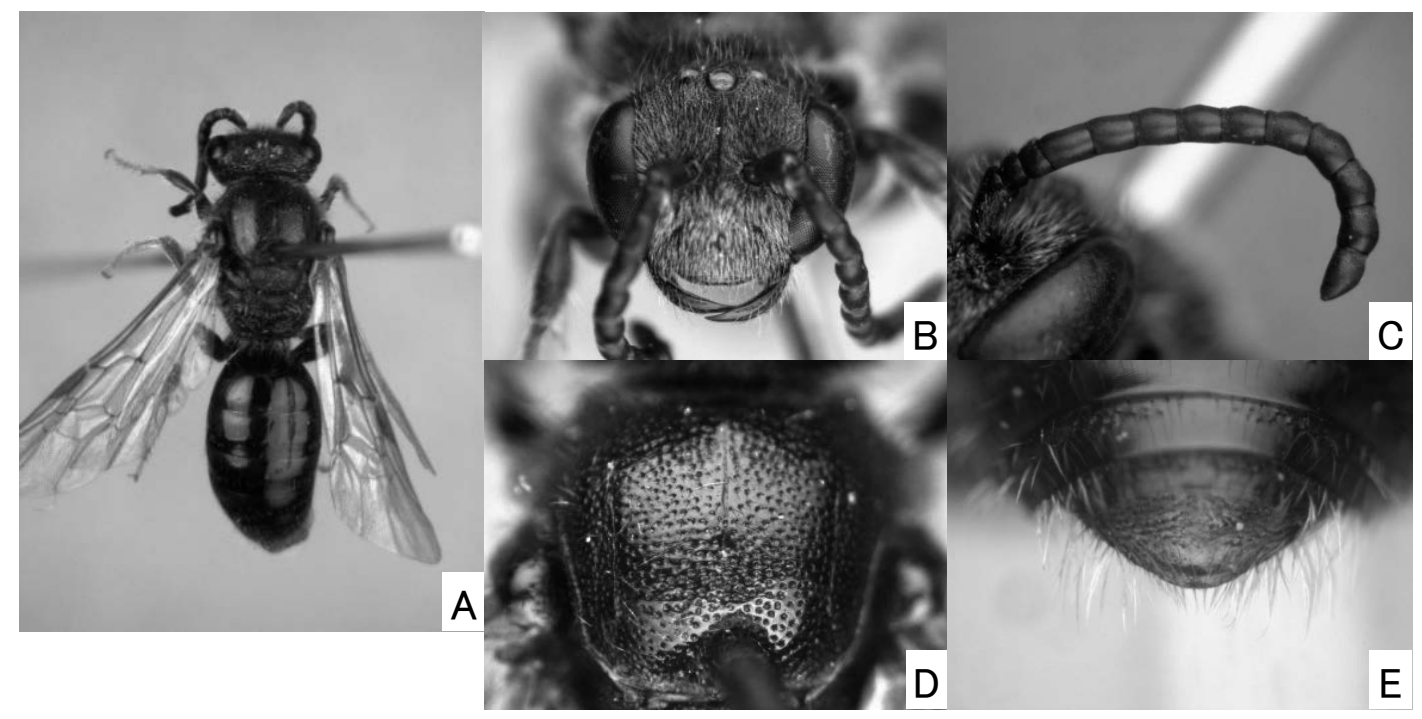

Fig. 6. Sphecodes hanedai Tsuneki, male. A: habitus, dorsal view. B: head. C: antenna. D: scutellum. E: pygidial plate. 

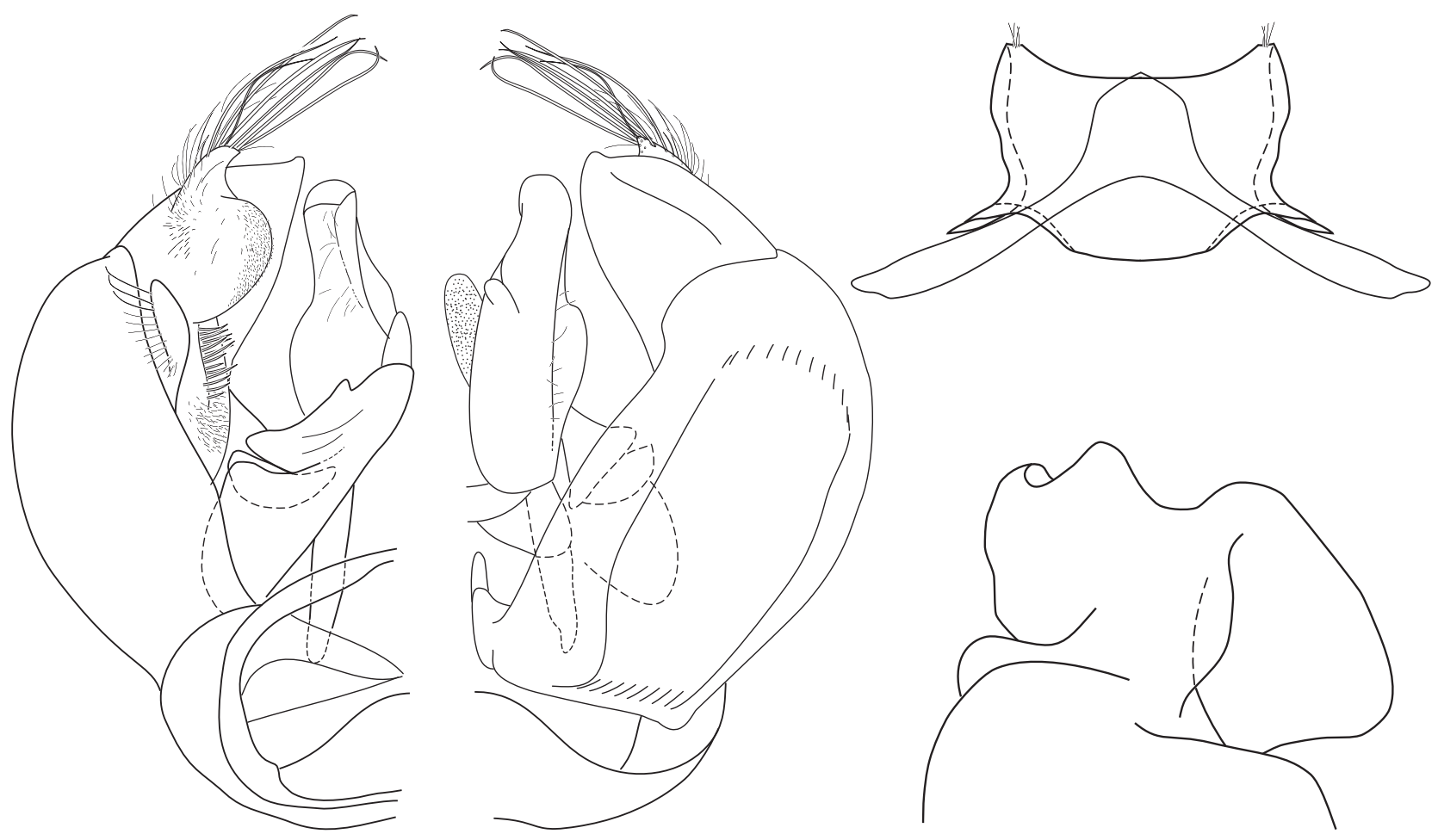

Fig. 7. Sphecodes hanedai, male. A: genital capsule (left, ventral view; right, dorsal view). B: 7th and 8th metasomal sterna, ventral view. C: gonostylus, lateral view (vestiture omitted).

Hymenopt. Assoc., (26): 38 [Holotype: Male. Mt. Tennyozan, Yamanashi Pref., Honshu, Japan]. Syn. Nov.

\section{Redescription.}

\section{Male.}

Color: Head and mesosoma black except mandible red apically. Terga wholly black, or T1-2, and T3 basally red. Legs black except tarsi blackish brown.

Sculpture: Clypeus minutely and densely punctatereticulate without median furrow. Supraclypeal area as clypeus. Frons areolate-rugose before lateral ocelli. Vertex near preoccipital ridge and genal area rugose, partially costate. Scutum densely punctate; puncture shallow and subobsolete, but distinct peripherally; interpunctural area generally up to one puncture diameter and weakly rugose. Scutellum coarsely and irregularly rugose. Mesepisternum areolate densely. T1 and T2 smooth and shiny. T3-T6 indistinctly coriarious except apical margin. T1 with scattered fine punctules except apical impunctate area. T2 with scattered, but slightly denser than $\mathrm{T} 1$, fine punctules except apical impunctate area. T3-T5 only with setigerous punctules. T7 densely shagreen; apical margin turned upward and broadly rounded, or feebly angulate at apex.

Vestiture: Vestiture on face yellowish, dense, densely plumose and erect or suberect, not concealing integument, but obscuring that to some extent.

Structure: Body length 6-8 mm. Head about 0.82-0.85 times as long as wide.

Vertex behind lateral ocelli developed upward beyond lateral ocelli in frontal view. Genal area narrower than compound eye in lateral view, about 0.6 times as wide as compound eye. Exposed portion of pedicel roughly as long as FL1. Relative length of FL1 : $2: 3=1.0: 2.1: 1.9$. FL1 0.6 times as long as width, FL2 1.9 times, FL3 1.2 times, and remaining segments slightly longer than width. Each segment after FL2 distinctly swollen medially. Undersides of FL3 and the following segments with velvet-like areas. Velvet-like area on FL3-5 indistinct, narrow, interrupted medially, band-shaped basally; that on FL6 distinct, completely band-shaped, reaching basal one-fourth of segment; those on the more following segments wider successively or uniform in width. Collar angulate between frontal and lateral sides. Pronotum with lateral ridge moderately, sharply raised. Scutellum flat. Hind femora slender, relative breadth to length of hind femur about 0.3 . Apical process of hind tibia shortly rounded. Hook on hind wing 7 in number. Disc of S7 pentagonal. S8 with posterior margin broadly emarginated; posterolateral corner with a few short setae; anterior 
margin broadly produced anteriorly. Gonocoxite striate with dorsal depression, lateral rims of depression angulated. Gonostylus with long vestiture near top and with moderately dense vestiture on other surface; inner basal surface with dense setae finer downwards; basoventral lobe distinct, with several setae which slightly shorter than those on inner basal surface.

Female. Unknown.

Distribution. JAPAN [Hokkaido, Honshu, Shikoku].

Specimens examined. Holotype [MNHAH], male with three labels as follows: "Koike[in Japanese], Ohno/ Fukui, Japan/ 27. VIII. 1975/ Y. HANEDA [white rectangle with typed and handwritten letters]", and "Sphecodes/ hanedai $\delta /$ Tsuneki/ HOLOTYPE [red rectangle with handwritten letters]", and "B1-288257 [white rectangle with printed register-number of MNHAH and a bar-code]".

Other specimens: We have examined about 30 males. Some of them are listed as follows: JAPAN [Hokkaido] ô, Piuka (Teshio), 22. vii. 1952 (T. Shirozu, ELKU); $\partial^{\lambda}$, Sapporo, 14. vii. 1955 (K. Kamijo, SEHU); 5ภ, Atsunai, 3. ix. 1969 (ठ), 12. x. 1969 (ð), 14. ix. 1969 (ठ), 17. ix. 1969 (ð), 23. ix. 1969 (ð) (M. Wakayama); ð, Otarunai, 26. ix. 1973 (H. Fukuda, ELKU); đ̊, Yudonuma, Tokachi, 13. x. 1976 (M. Usui, ELKU). [Honshu] Tochigi: ${ }^{2}$, Iroha zaka, Nikko, 1. ix. 1980 (K. Nakamura); ô, Nikko Nat. Park, Odashirogahara, 13. ix. 1982 (K. Nakamura). Saitama: J, Green School, Ootaki, 8. vii. 2000 (T. Nambu). Fukui: 3ð̂, Izumi V., Maezaka, 12. vii. 1984 (Y. Haneda); đ̊, Fukui, Koike, Ohno, 1. ix. 1986 (Y. Haneda); Ô, Suwara, Ohno, 3. viii. 1987 (Y. Haneda). Yamanashi: 3̊̉, Panoramadai, Kamikuisshiki V., 19. ix. 1976 (Y. T. \& H. Suda); ${ }^{2}$, Mt. Kyotodai- Ashi., Narusawa Village, 19. viii. 1985 (H. Suda); đ̃, Kouyoudai, Narusawa-mura, 7. vii. 1991 (H. Takahashi); Oૈ, Kouyoudai- Sankodai, 19. vii. 1992 (H. Takahashi). [Shikoku] Ehime: 3ð̂, Mt. Kamegamori, 26. ix. 1999 (Y. Maeta, EBSU).

Biology. The flight period is early July to mid October.

Remarks. The females of this species show striking variation in the color of abdomens from wholly black terga to red basal three terga. Although the examined species are about only thirty in number, this variation shows no intermediate state except a few specimens whose basal three terga are partially red. However, any structural differences are not recognized between the two color types. Hence, we recognized at present that the abdomen color is not distinguishing character, and these color types are conspecific. The holotypes of Sphecodes murotai and $S$. sudai have wholly black abdomens, whereas the one of Sphecodes baratonis has partially red basal three terga.

\section{Sphecodes ikudomei Mitai et Tadauchi, sp. nov.}

[Japanese name: Ikudome-yadori-kohanabachi] (Figs. 8-9)

\section{Description.}

Male.

Color: Head and mesosoma black except the following: mandible dark red apically; $\mathrm{T} 1$ apically, $\mathrm{T} 2$ basally or wholly red; S2 wholly, S3 basally dark red. Legs black except fore tibiae beneath yellowish.

Sculpture: Clypeus densely punctate-reticulate without median furrow. Supraclypeal area and vertex densely

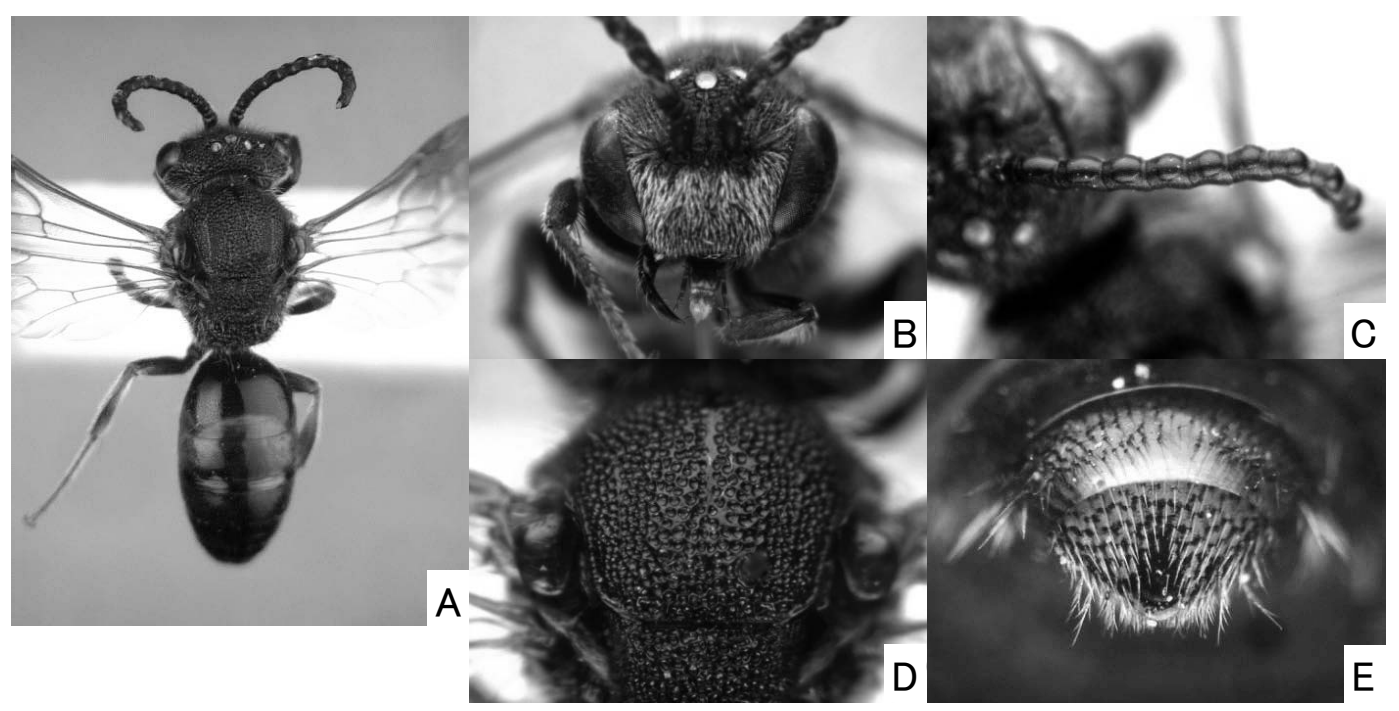

Fig. 8. Sphecodes ikudomei Mitai et Tadauchi, sp. nov., male. A: habitus, dorsal view. B: head. C: antenna. D: scutellum. E: pygidial plate. 

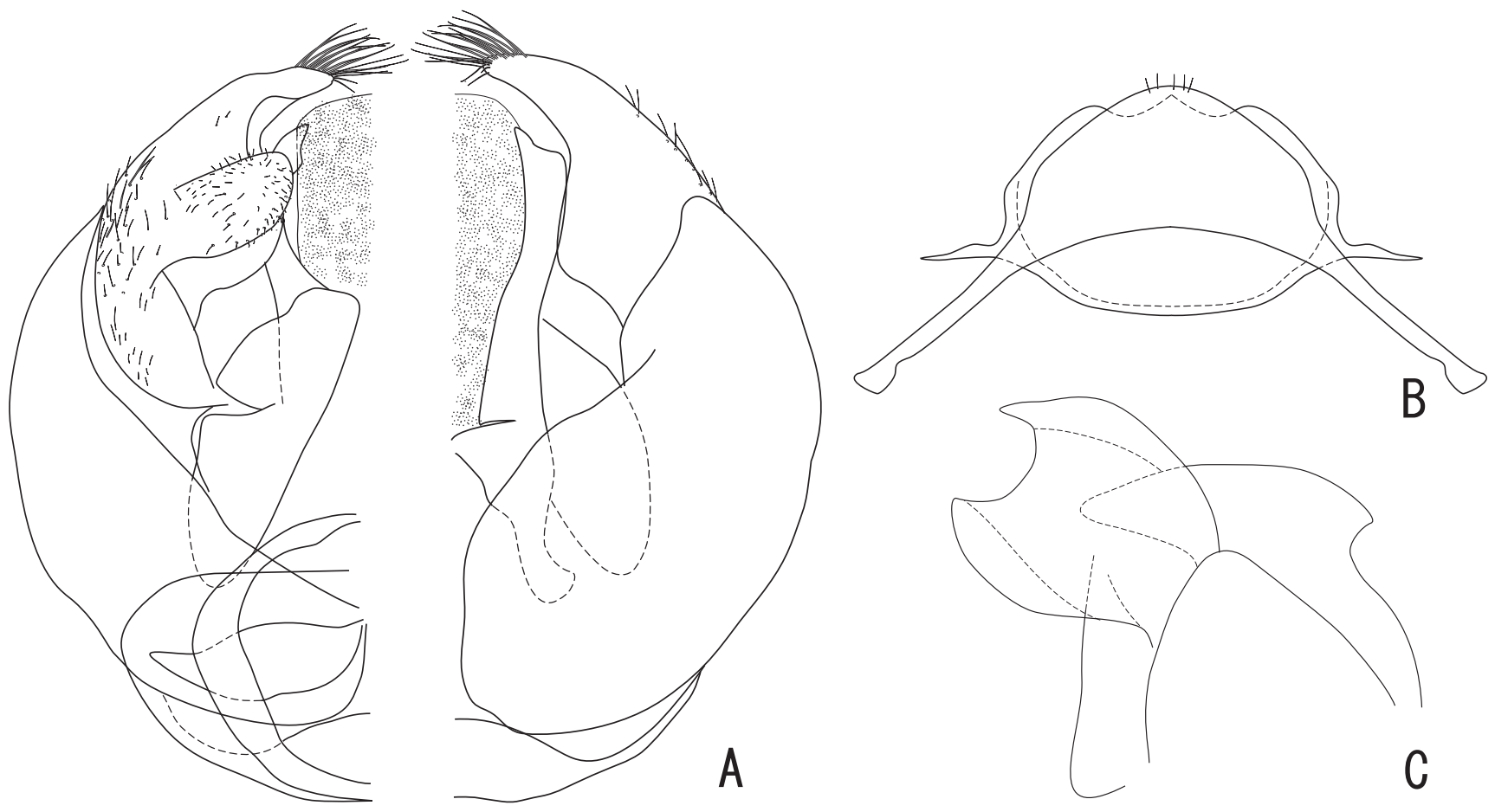

Fig. 9. Sphecodes ikudomei sp. nov., male. A: genital capsule (left, ventral view; right, dorsa view). B: 7th and 8th metasomal sterna, ventral view. C: gonostylus, lateral view (vestiture omitted)

areolate with partitions of convexity highly raised. Frons before lateral ocelli deeply and coarsely areolate-rugose. Genal area rugose; outer orbit of compound eye furrowed. Scutum punctate-reticulate. Scutellum areolate. Mesepisternum areolate coarsely. T1-2 polished, T3-6 faintly coriarious. T1 with apical half scattered small distinct punctures intermixed with much smaller punctules nearly up to margin. T2 and T3 punctate as T1, apical depressed area impunctate. T4-6 only with setigerous punctules. Apical portion polished and widely produced with apical margin obtuse-angled.

Vestiture: Vestiture on lower face golden in color, dense, densely plumose and largely appressed, not concealing integument, but obscuring that to some extent.

Structure: Body length 7.5-8.5 mm. Head about 0.80 times as long as wide. Interantennal elevation low with median carina abruptly ends apically. Vertex behind lateral ocelli well developed upward much beyond lateral ocelli in frontal view. Genal area much narrower than compound eye in lateral view, about 0.5 times as wide as compound eye. Exposed portion of pedicel as long as FL1. Relative length of FL1 : $2: 3=1.0: 2.8: 2.8$. FL1 0.5 times as long as width, FL2 and FL3 1. 6 times, and remaining segments distinctly longer than width. Each segment after FL2 swollen medially. Undersides of FL2 and the following segments with velvet-like area which surrounding medial hairless area. Velvet-like area on FL2 confined peripherally; velvet-like area gradually wider on the more following segments. Collar sharply angulate between frontal and lateral sides. Pronotum with lateral ridge highly raised and produced anteriorly. Scutellum flat. Hind femora slender, relative breadth to length of hind femur 0.32 . Apical process of hind tibia shortly rounded. Hook on hind wing 7-8 in number. Disc of S7 oblong pentagonal; apex with several setae medially. S8 with posterior margin shallowly tridentate; lateral margin shallowly wavy; anterior margin widely produced anteriorly. Gonocoxite very weakly striate without dorsal depression. Gonostylus with a loose row of long setae on top; basolateral sides of gonostylus with long setae; inner basal surface without setae; basoventral lobe rounded ridge-shaped, then being sharply carinate obliquely upwards with loose row of setae which are longer upwards.

Distribution. JAPAN [Kyushu].

Specimens examined. Holotype (Type No. 3324. ELKU), male with two labels as follows: "(KYUSHU) 490m/ Kotani Makizono/ Kagoshima Pref./A.M., 21. IX. 1980/ S. Ikudome leg./ Otokoeshi" [white rectangle with typed and handwritten letters]". Paratypes: [Kyushu] Miyazaki: 3ð̂, Ebino Highland, Ebino-shi, 16. ix. 2003 
(K. Mitai, ELKU). Kagoshima: đิ. Okuchi City, 7. ix. 1980 (H. Nagase); $2 \hat{\jmath}$, same data as the holotype.

Biology. The flight period is from early to late September.

Remarks. Sphecodes ikudomei differs from S. nambui only by the antennal structure, and differs from $S$. scabricollis by the color of hair on face as well as the antennal structure.

\section{Sphecodes koikensis Tsuneki, 1983}

[Japanese name: Koike-yadori-kohanabachi] (Figs. 10)

Sphecodes koikensis Tsuneki, 1983, Spec. Publ. Jap. Hymenopt. Assoc., (26): 27 [Holotype: Female. Type locality: Koike, Fukui Pref., Honshu, Japan].

Sphecodes chibaensis Tsuneki, 1984, Spec. Publ. Jap. Hymenopt. Assoc., (30): 8 [Holotype: Female. Type locality: Dyonai, Sakura, Chiba Pref., Honshu, Japan]. Syn. Nov.

Sphecodes izumindus Tsuneki, 1986, Spec. Publ. Jap. Hymenopt. Assoc., (32): 45 [Holotype: Female. Type locality: Maezaki, Izumi-mura, Fukui Pref., Honshu, Japan]. Syn. Nov.
Redescription.

Female.

Color: Head and mesosoma black except mandible tinged with red apically. T1-2, and usually T3 basally red. S1 and S2 red. Femora and tibia black. Tarsi also nearly black or some apical segments dark yellowish.

Sculpture: Clypeus without median furrow; punctures moderately dense, at most a puncture diameter apart; interpunctural surface sometimes faintly rugose. Supraclypeal area as clypeus. Frons areolate-rugose medially, becoming punctate-reticulate laterally and dorsally until level of posterior margin of lateral ocelli. Vertex behind lateral ocelli and genal area irregularly rugose, partially costate. Scutum scattered with small punctures; punctures generally up to six puncture diameters apart. Punctures on scutellum larger and slightly denser than those of scutum, especially on posterior half. Mesepisternum areolate shallowly. T1 polished with scattered, rather fine punctules basally; apical depressed margin not indicated. T2-4 feebly coriarious with apical polished margin. T2 punctate as T1. T3 and T4 impunctate on exposed areas with hairs not accompanied by punctules. T5 basally coriarious but nearly smooth on apical margin. Pygidial plate 0.9 times as wide as width of FL3 with medial longitudinal elevation; surface shiny

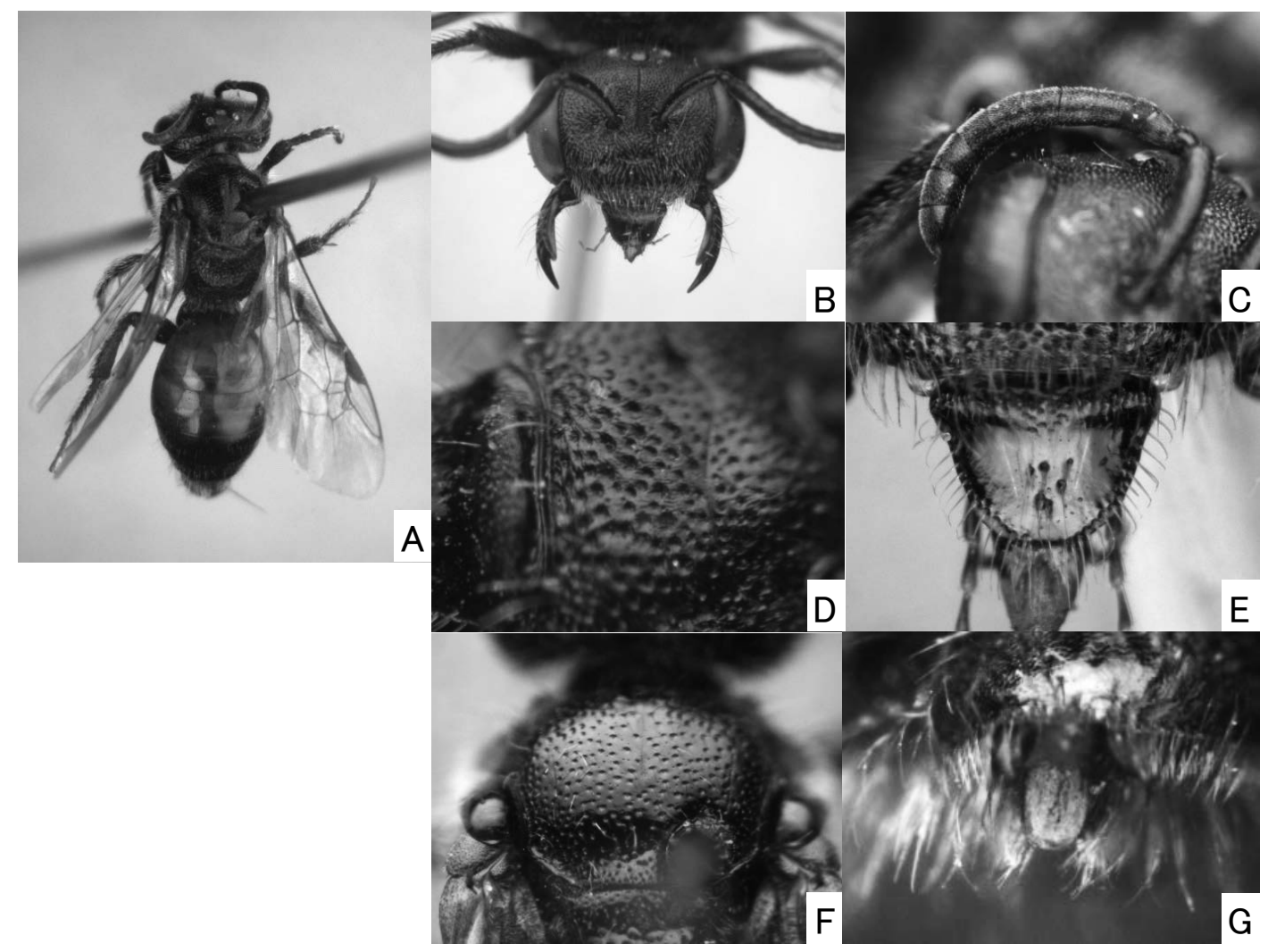

Fig. 10. Sphecodes koikensis Tsuneki, female. A: habitus, dorsal view. B: head. C: antenna. D: clypeus. E: labrum. F: scutellum. G: pygidial plate. 
peripherally.

Vestiture: Vestiture on face yellowish, short, sparse, weakly plumose.

Structure: Body length 7-9 mm. Head about 0.80 times as long as wide. Labrum about 0.6-0.7 times as long as wide without distinct medial furrow; apex variable from truncate to distinctly emarginate. Vertex behind lateral ocelli well developed upward slightly beyond lateral ocelli in frontal view. Genal area slightly narrower than compound eye in lateral view, about 0.9 times as wide as compound eye. Exposed portion of pedicel slightly longer than FL1. Relatively length of FL1 : $2: 3$ $=1.0: 1.2-1.3: 1.4$, and F1 0.7-0.8 times as long as width, FL2 0.8 times, FL3 0.8-0.9 times, and remaining segment slightly longer than width. FL1-2 densely shagreen, matt. Undersides of FL3 and the following segments slightly shiny. Collar gently curved between frontal and lateral sides. Pronotum with lateral ridge moderately raised. Scutellum flat, sometimes with shallow median furrow. Hind femora moderate in breadth, relative breadth to length of hind femur about 0.35 . Apical process of hind tibia shortly rounded. Hook on hind wing 7 in number. First recurrent vein usually basad of 1 st transverse cubital by more than a vein width, or rarely interstitial.

Male. Unknown.

Distribution. JAPAN [Hokkaido, Honshu, Shikoku, Kyushu].

Specimens examined. [MNHAH], female with three labels as follows: "Koike[in Japanese],/ Fukui, Japan/ 26. VII. 1973/ K. Tsuneki [white rectangle with typed and handwritten letters]", and "Sphecodes/ koikensis/ Tsuneki + / HOLOTYPE [red rectangle with handwritten letters]", and "B1-288272 [white rectangle with printed registernumber of MNHAH and a bar-code]".

Other specimens: We have examined about 70 females. Some of them are listed as follows: JAPAN [Hokkaido] ㅇ, Botanical Garden, 9. v. 1957 (Hayashida); 3 , , Atsunai, 11 (). \& \& 15 (). \& 24 (ㅇ). vi. 1969 (M. Wakayama); ㅇ, Kami-otoineppu, 13. vii. 1972 (Fukuda, ELKU); 3ㅇ, Otarunai, 26. v (29). \& 22. ix ()). 1973 (H. Fukuda, ELKU); 5, Wakkanai, 6 (3ㅇ). \& 24 (29). vi. 1974 (Y. Kusui); 2q, Obihiro, Tokachi, 23. v. 1976 (M. Usui); 오, Fushimi Senkyo, Tokachi, 16. vi. 1976 (M. Usui); ㅇ, Mt. Teinekanayama, Teine, Sapporo, 29. vi. 1999 (H. Suda); †, Tamaura, Okushiri Is., 28. vii. 2000 (T. Nambu). [Honshu] Aomori: o, Mt. Tashiro (Kuroishi), 19. vi. 1991 (M. Yamada, APM). Iwate: $q$, Matsukawa Spa, Matsuo V., 3. x. 1992 (H. Chiba, FFPRI). Akita: ㅇ, Fukenoyu spa, Kazono City, 2. viii. 1974 (T. \& H. Suda). Yamagata: ㅇ, Yonezawa, 22. v. 1942 (Y. K., ELKU): Tochigi: 2q, Nikko Nat. Park, Odashirogahara, 10. \& 25. viii. 1982 (K.
Kubota, K. Nakamura's coll.); 2 q, Nikko Nat. Park, Yumoto Spa, 4. vi. 1983 (T. Matsumura, K. Nakamura's coll.); + , Yumoto Skiing Ground, Nikko, 15. vii. 1997 (T. Ono, K. Nakamura's coll.); 5 q, Yoichi Park, Ohtawara, 8 (4). \& 15 (). vi. 1999 (E. Katayama). Saitama: $q$, Taiyoji, 16. vii. 1971 (T. Nambu); +, Karisaka Jizo, Otaki, 30. vii. 1976 (T. Nambu); q, Green School, Ootaki, 10. vii. 1999 (T. Nambu); , Teshiro Shrine, Yoshida, Ranzan, 12. iv. 2000 (T. Nambu). Chiba: + , Sanrizuka, Narita City, 9. x. 1967 (T. \& H. Suda); 29, Jonai, Sakura City, 3. \& 7. iv. 1974 (H. Suda); 9 , Shimizu park, Noda City, 31. v. 1976 (T. \& H. Suda); 9 q, Sakurajyoshi, Sakura City, 6 (q). \& 17 (3). iv. 1977, 9 (3) \& 19 (2q). iv. 1978 (Y. \& H. Suda, or H. Suda); q, Iida, Sakura City, 11. vi. 1980 (H. Suda); +, Sakurajoshi, Sakura City, 29. v. 1990 (H. Suda). Fukui: , Shiomi, Oono-gun, 7. vi. 1968 (Y. Haneda); 3 q, Izumi V., Maezaka, 12. vii. 1984 (2q) \& 30. v. 1985 (q) (Y. Haneda); +, Suwara, Ohno, 7. vi. 1987 (Y. Haneda); +, Mt. Hozukiyama, Rokusoshi, Ohno, 29. vii. 1995 (Y. Haneda); +, Riverside of Kuzuryu River, Futsukaichi, Fukui-shi, 16. vii. 1997 (T. Shimizu, Y. Haneda's coll.). Yamanashi: + , Masutomi, 28. vii. 1975 (J. Emoto, ELKU); + , Hikage, Yamato Vill., 16. v. 1978 (H. Suda); +, Kouyoudai-Sankodai, 19. vii. 1992 (H. Takahashi); 29, Tenjouyama, Kawaguchiko, 11. v. 1993 (H. Takahashi); +, Mt. Amariyama, Nirasaki City, 25. viii. 1993 (H. Suda); , Zaoh-chuohkougen, Yamagata City, 27. vii. 1996 (H. Suda); ㅇ, Yunosawaguchi, Ohtsuki City, 21. v. 1998 (H. Suda). Nagano: q, Togakushi, 13. ix. 1936 (S. Miyamoto, ELKU); 2ᄋ, Shiranone, 19. vii. 1956 (S. Kimoto, ELKU). [Shikoku] Ehime: †, Mt. Kamegamori, 26. ix. 1999 (Y. Maeta, EBSU). [Kyushu] Nagasaki: †, Izuhara-Ariakeyama, Tsushima Is., 9. vi. 1941 (T. Shirozu, ELKU).

Biology. The flight period is from early April to early October. Maeta et al. (1996) reported Lasioglossum vulsum (Vachal, 1903) is a host of this species, based on an identification of a Sphecodes adult which eclosed from a pupa excavated from a nest of $L$. vulsum, although we were not able to examined this specimen.

Remarks. For the discrimination from two similar species, S. coptis and S. okuyetsu, refer to the table in section of $S$. coptis.

\section{Sphecodes laticaudatus Tsuneki, 1983}

[Japanese name: Siribiro-yadori-kohanabachi] (Figs. 11-12)

Sphecodes laticaudatus Tsuneki, 1983, Spec. Publ. Jap. Hymenopt. Assoc., (26): 58 [Holotype: Female. Type locality: Shiramine, Ishikawa Pref., Honshu, Japan]. 


\section{Redescription.}

\section{Female.}

Color: Head and mesosoma black except the following: labrum variously tinged with dark brown; mandibles black basally, apex red; flagellar segments black wholly or blackish brown beneath, slightly paler apically. T1-2 and T3 basally red. Legs black or slightly paler.

Sculpture: Clypeus without median furrow; punctures large, moderately dense, at most two puncture diameters apart. Supraclypeal area as clypeus. Frons areolate-rugose medially, becoming punctate-reticulate laterally and dorsally until level of posterior margin of lateral ocelli. Vertex behind lateral ocelli and genal area rugose or slightly costate with fine, irregular rugosity among costae. Scutum densely punctate or punctate-reticulate on anterior onethird, and sparser posteriorly; punctures generally two or three puncture diameters apart. Scutellum generally sparsely punctate medially, much more densely and coarsely peripherally, especially on posterior margin. Propodeal triangle irregularly rugose in examined specimens though its constancy is unclear. Mesepisternum areolate moderately to coarsely. T1 polished with scattered, rather fine punctules; apical depressed margin not indicated. T2-4 feebly coriarious with apical polished margin. T2 punctate slightly denser than T1. T3 and T4 impunctate on exposed areas with hairs not accompanied by punctules. T5 basally coriarious, but nearly smooth on apical margin. Pygidial plate wide, 2-2.1 times as wide as width of FL3, apex broadly rounded; surface dull widely.

Vestiture: Vestiture on face yellowish, short, sparse, not densely plumose.

Structure: Body length 7.5-9 mm. Head about 0.75 times as long as wide. Labrum about 0.6-0.7 times as long as wide without distinct medial furrow; apex broadly triangularly emarginate. Vertex behind lateral ocelli developed upward slightly beyond lateral ocelli in frontal view. Genal area narrower than compound eye in lateral view, about 0.8 times as wide as compound eye. Exposed portion of pedicel slightly longer than FL1. Relatively length of FL1 : $2: 3=1.0: 1.2-1.3: 1.4$, and F1 $0.7-0.8$ times as long as width, FL2 0.8 times, FL3 0.8-0.9 times, and remaining segment slightly longer than width. FL1-2 and underside of FL3 densely shagreen, matt. Undersides of FL4 and the following segments slightly shiny. Collar distinctly angulate between frontal and lateral sides. Pronotum with lateral ridge moderately, sharply raised. Scutellum flat with shallow median furrow. Hind femora moderate in breadth, relative breadth to length of hind femur about 0.35 . Apical process of hind tibia narrowly oblong. Hook on hind wing usually 5 in number, or 6 in one specimen.
Male.

Color: Body black except the following: mandible dark red apically; T1 tinged with dark red, or wholly black. Fore tibia beneath and all tarsi dark yellowish.

Sculpture: Clypeus punctate-reticulate with shallow median furrow; punctures dense, less a puncture diameter apart. Supraclypeal area as clypeus. Frons areolate-rugose before lateral ocelli, coarser than in female. Vertex near preoccipital ridge and genal area coarsely rugose. Scutum areolate on anterior half, posteriorly changing into punctate-reticulate. Scutellum as scutum. Propodeal triangle irregularly rugose. Mesepisternum areolate coarsely. T1 polished wholly with very scattered fine punctules, virtually impunctate; apical depressed margin not indicated. T2 polished with scattered punctules. T3-5 without punctules on exposed areas. T6 shagreen and superposed with indistinct, shallow punctures except apical narrow margin of T6. Apical margin of T7 well, broad produced.

Vestiture: Vestiture on face white, moderately dense, densely plumose, rather short, not concealing integument, but obscuring that to some extent.

Structure: Body length 7.5-8.5 mm. Head about 0.85 times as long as wide.

Genal area narrower than compound eye in lateral view, about 0.6 times as wide as compound eye. Exposed portion of pedicel as long as FL1. Relative length of FL1 $: 2: 3=1.0: 2.8: 2.2$. FL1 0.5 times as long as width, FL2 1.5 times, FL3 1.2 times, and remaining segments slightly longer than width. Each segment after FL2 distinctly swollen medially. Undersides of FL3 and the following segments with velvet-like areas. Velvet-like areas on FL3-4 indistinct, narrow, band-shaped basally; that on FL5 distinct, completely band-shaped, reaching basal one-fourth of the segment; those on the following segments roughly same in shape. Scutellum flat. Hind femora slender, relative breadth to length of hind femur 0.32 . Apical process of hind tibia shortly triangular. Hook on hind wing usually 5 in number. S7 with posterior median process long, tapering to rounded apex. S8 not observable. Gonocoxite striate with dorsal depression. Gonostylus short with long, simple setae on top and dorsal surface; inner basal surface widely with dense setae finer downwards; basoventral lobe weakly carinate with several long setae.

Distribution. JAPAN [central Honshu].

Specimens examined. Holotype [MNHAH], female with three labels as follows: "Shiramine/ Ishikawa, Japan/ 19. IV. 1982/Y. HANEDA [white rectangle with typed and handwritten letters]", "Sphecodes/ laticaudatus $\% /$ Tsuneki/ HOLOTYPE [red rectangle with handwritten letters]", and "B1-288274 [white rectangle with printed 


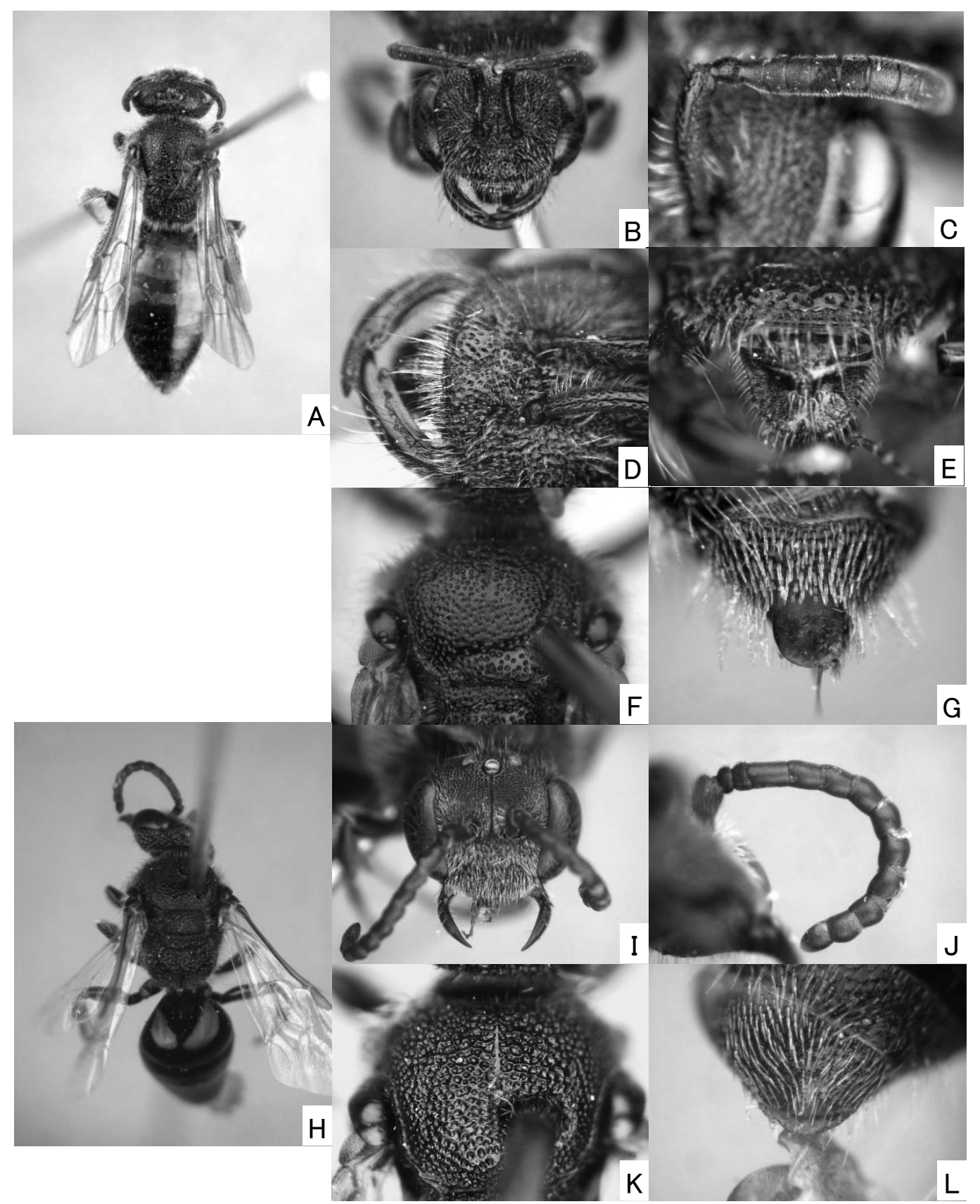

Fig. 11. Sphecodes laticaudatus Tsuneki. Female: A-G. Male: H-L. A, H: habitus, dorsal view. B, I: head. C, J: antenna. D: clypeus. E: labrum. F, K: scutellum. G, L: pygidial plate.

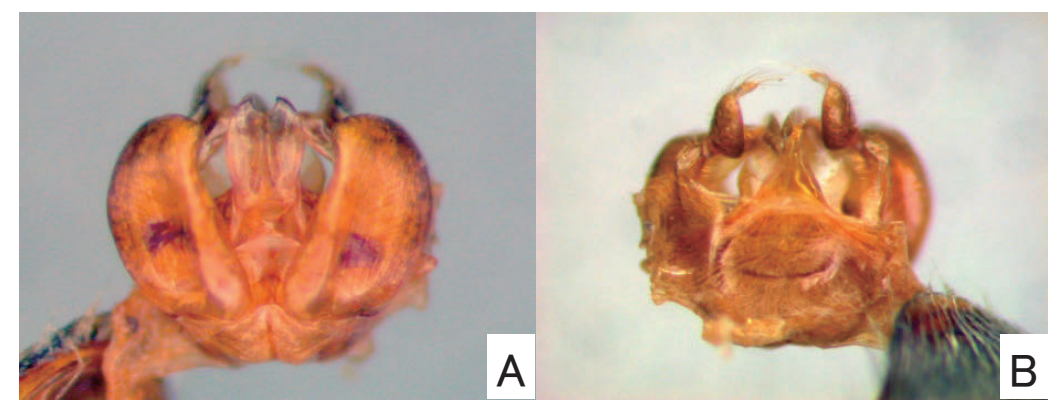

Fig. 12. Sphecodes laticaudatus Tsuneki. A: male genitalia, dorsal; B: the same, ventral. 
register-number of MNHAH and a bar-code]".

Other specimens: We have examined 8 females and 1 male as follows: JAPAN [Honshu] Tochigi: + , Kamikuwajima-machi, Utsunomiya-shi, 28. iii. 2003(K. Nakamura). Ishikawa: + , Kanazawa City, 21. v. 1949 (I. Togashi, ELKU). Fukui: + , Shimoyama, Izumi-mura, 12.

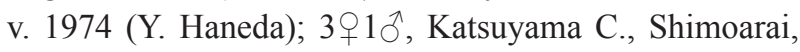
24. iv (2ㅇ)., 5. v (1ㅇ) . 17. vii (1 ઊ). 1984 (Y. Haneda); 우, Besshi-toge, Echizen-cho, 19. v. 1994 (C. Nozaka); , Matsugasaki, Awara-cho, 6. iv. 2001 (C. Nozaka).

Biology. The flight period is from late March to mid July.

Remarks. The female can be easily separated from the Japanese species by the wide pygidial plate. The female of Sphecodes simillimus is similar in having the wide pygidial plate, but that of $S$. simillimus is slightly narrower than that of $S$. laticaudatus. The male is similar to $S$. hanedai, $S$. dyozankeanus, and S. sulcifera, but can be separated from them by the densely punctate scutum.

\section{Sphecodes maruyamanus Tsuneki, 1983}

[Japanese name: Maruyama-yadori-kohanabachi] (Figs. 13-14)

Sphecodes maruyamanus Tsuneki, 1983, Spec. Publ. Jap. Hymenopt. Assoc., (26): 46 [Holotype: Female. Type locality: Maruyama, Sapporo, Hokkaido, Japan].

Sphecodes convergens Tsuneki, 1983, Spec. Publ. Jap. Hymenopt. Assoc., (26): 64 [Holotype: Female. Type locality: Ohno-Arashi, Fukui Pref., Honshu, Japan]. Syn. Nov.

\section{Redescription.}

\section{Female.}

Color: Head and mesosoma black except the following: labrum usually black, sometimes tinged with dark brown to brown; mandibles black basally, apex dark red; flagellar segments often blackish brown beneath. T1-2 wholly, and T3 basally red. Legs blackish brown or somewhat paler.

Sculpture: Clypeus with shallow median furrow on apical half; punctures dense, usually at most a puncture diameter apart, sometimes more sparser; interpunctural surface on apical margin minutely rugose, hence punctures indistinct. Supraclypeal area moderately dense as clypeus. Frons punctate-reticulate until frontal ocellus. Vertex behind lateral ocelli and genal area costate, the costae subobsolete near outer orbits of compound eyes. Scutum scattered with small punctures; punctures generally up to six puncture diameters apart medially. Scutellum generally as scutum, but denser on medial posterior margin. Mesepisternum areolate moderately. T1-4 polished, virtually impunctate with hairs not accompanied by distinct punctules; apical depressed area not indicated on T1. T5 basally coriarious but apical area smooth with sparse setigerous granules. Pygidial plate moderately wide, 0.9 times as wide as of FL3, flat or slightly turned upward peripherally; apex round or slightly truncate; surface faintly shagreen or shiny.

Vestiture: Vestiture on face white or slightly yellowish, short; that on clypeus, frons and vertex rather sparse, simple or slightly plumose; that on supraclypeal area and lower paraocular area densely plumose, but not so dense to obscure integument.

Structure: Body length 6-7.5 mm. Head about 0.6-0.7 times as long as wide. Labrum semicircular, short, 0.4 times as long as wide without median furrow Interantennal elevation roundly moderately raised. Vertex behind lateral ocelli not developed upward beyond lateral ocelli in frontal view. Genal area narrower than compound eye in lateral view, about 0.7 times as wide as compound eye. Exposed portion of pedicel slightly longer than FL1. Relatively length of FL1 $: 2: 3=1.0: 1.0: 1.3$, and F1 and F2 0.7 times as long as width, FL3 0.9 times, and remaining segment equal or slightly longer than width. FL1-2 densely shagreen, matt. Undersides of FL3 and the following segments slightly shiny. Collar gently curved between frontal and lateral sides. Pronotum with lateral ridge lowly raised. Scutellum flat. Hind femora slender, relative breadth to length of hind femur about 0.25-0.28. Apical process of hind tibia shortly rounded. Hook on hind wing usually 5 in number.

Male.

Color: Body black except the following: mandible paler apically; flagellar segment slightly paler beneath; terga sometimes tinged with dark red on apical margins. Legs dark brown, tarsi paler apically.

Sculpture: Clypeus with median furrow, which is shallower than that of female; punctures moderately dense, generally less a puncture diameter apart. Supraclypeal area punctate slightly more densely than clypeus, interpunctural surface minutely rugose. Scutum punctate more densely than in female, with punctures generally twothree puncture diameters apart; interpunctural area scattered with punctules. Scutellum coarsely areolate, cavities wider posteriorly. Mesepisternum areolate moderately. T1 and T2 smooth and shiny. T3-6 indistinctly coriarious except apical margin. T1 with scattered fine punctules except apical impunctate area. T2 with scattered fine punctules except apical impunctate area, but slightly denser than T1. T3-5 only with setigerous punctules. T7 densely shagreen; apical margin turned upward and pro- 
duced triangularly.

Vestiture: Vestiture on face yellowish, sparse, not densely plumose on paraocular area, so that not to obscuring integument.
Structure: Body length 6-7 mm. Head about 0.82-0.85 times as long as wide. Genal area narrower than compound eye in lateral view, about 0.5 times as wide as compound eye. Exposed portion of pedicel as long as or

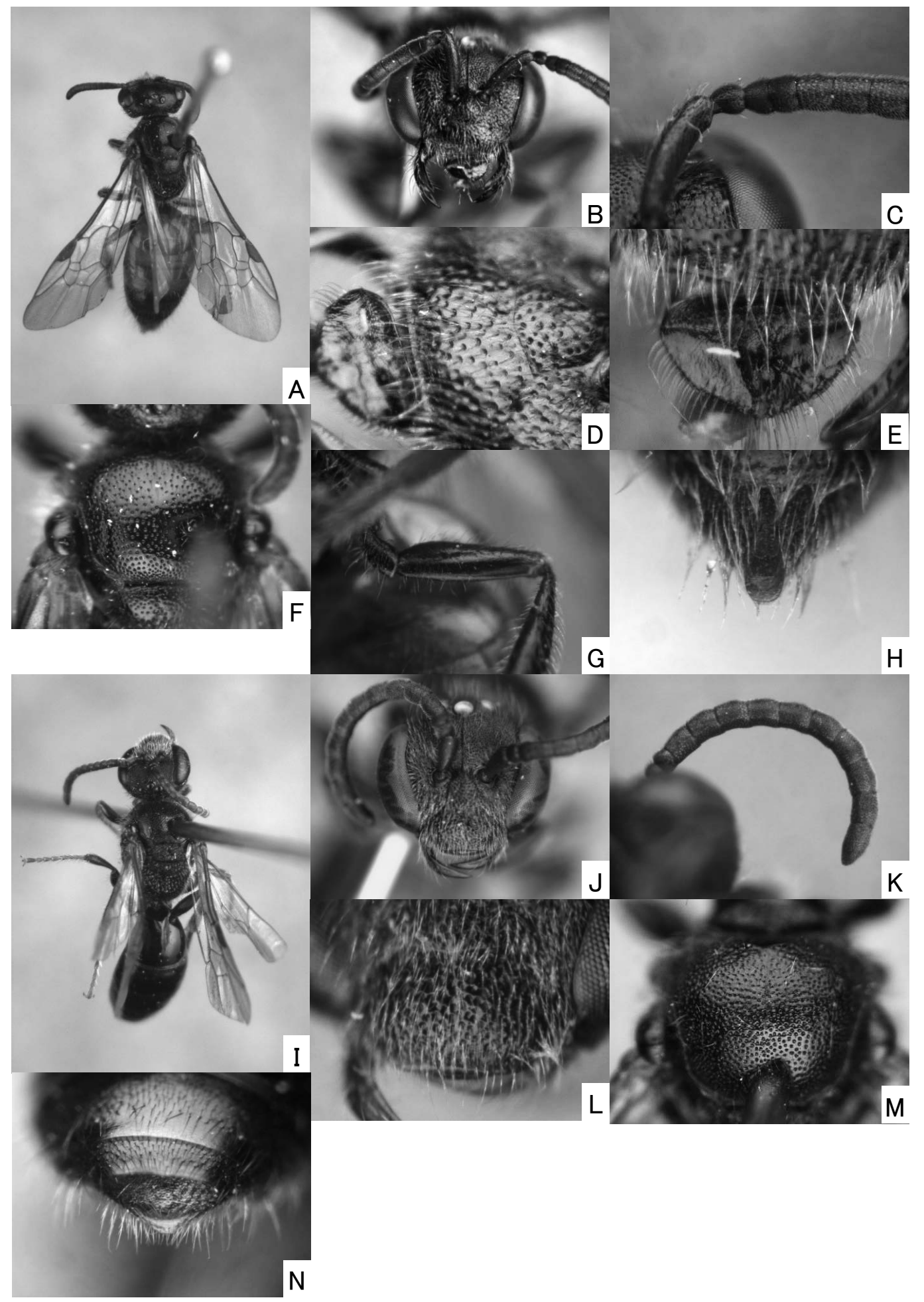

Fig. 13. Sphecodes maruyamanus Tsuneki. Female: A-H. Male: I-N. A, I: habitus, dorsal view. B, J: head. C, K: antenna. D, L: clypeus. E: labrum. F, M: scutellum. G: hind femur. H, N: pygidial plate. 

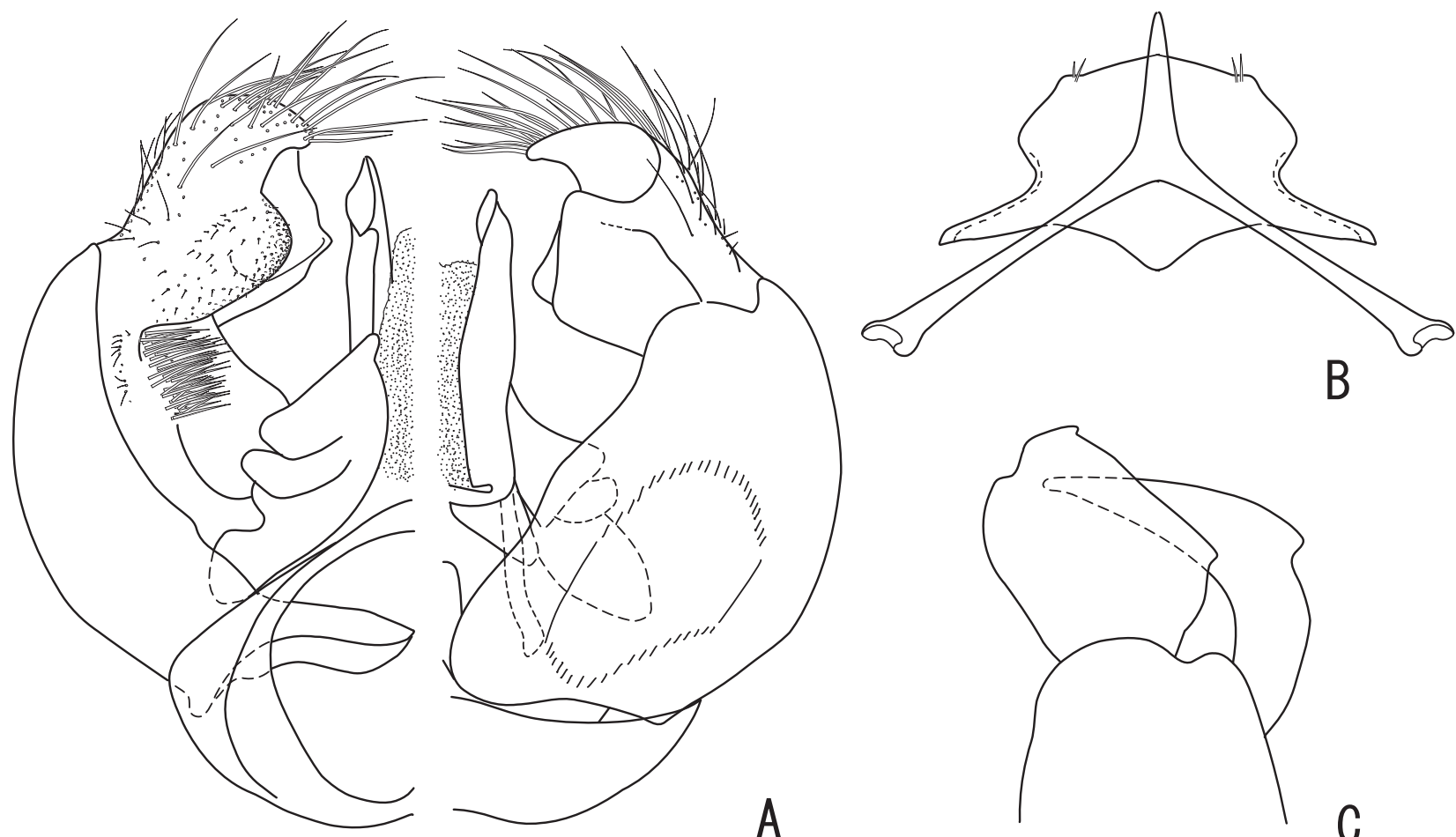

Fig. 14. Sphecodes maruyamanus, Tsuneki, male. A: genital capsule (left, ventral view; right, dorsa view) B: 7th and 8th metasomal sterna, ventral view. C: gonostylus, lateral view (vestiture omitted).

slightly longer than FL1. Relative length of FL1 : $2: 3=$ $1.0: 2.0-2.2: 1.6-1.8$. FL1 0.7 times as long as width, FL2 1.4-1.5 times, FL3 1.3-1.4 times, and remaining segments slightly longer than width. Flagellar segments simply cylindrical, not swollen medially, without velvet-like area. Hind femora slender as those of female, but sometimes relative breadth to length of hind femur reaching 0.3 . Apical process of hind tibia hardly produced. S7 slender, arrow-shaped. S8 with posterior margin rounded; posterolateral corners with a few short setae; lateral margin strongly wavy; anterior margin medially produced triangularly. Gonocoxite striate with dorsal depression. Gonostylus with long vestiture on lateral surface; inner basal surface with dense setae on relatively restricted area; dorsal lobe short; basoventral lobe hardly recognized, but a row of several setae presents on corresponding area.

Distribution. JAPAN [Hokkaido, Honshu].

Specimens examined. Holotype [MNHAH], female with three labels as follows: "Maruyama/ Sapporo, Japan/ 27. V. 1973/ K. Tsuneki [white rectangle with typed and handwritten letters]", "Sphecodes/ maruyamanus/ Tsuneki + / HOLOTYPE [red rectangle with handwritten letters]", and "B1-288277 [white rectangle with printed registernumber of MNHAH and a bar-code]".
Other specimens: We have examined about 70 females and 17 males. Some of them are listed as follows: JAPAN [Hokkaido] 9 , Shizukari, 30. vii. 1957 (T. Nambu); ㅇ, Atsunai, 11. vi. 1969 (M. Wakayama); +, Nopporo, 26. v. 1971 (H. Fukuda, ELKU); ふૈ, Zyozankei, 9. ix. 1972 (Y. Haneda); + , Otarunai, 6. ix. 1973 (H. Fukuda, ELKU); ठ̄, same locality, 22. ix. 1973 (H. Fukuda, ELKU); q, Botanical Garden, Sapporo, 16. v. 1989 (Sakagami, FFPRI); ㅇ, same locality, 16. v. 1989 (Sakagami, FFPRI). [Honshu] Aomori: 4, Hiraka- machi, Minami-tsuru-gun, 22. ix. 1957 (K. Shimoyama); +, Mt. Ohanabe, 15. vii. 1984 (M. Yamada, APM); 11ㅅ, Rangan-Mori (Nishimeya), 1. viii. 1984 (M. Yamada, APM); + , Hitotsumori (Azigasawa), 3. v. 1985 (M. Yamada, APM); ô, Mt. Kuromori (Takko), 15. ix. 1986 (M. Yamada, APM); ㅇ, Tsuta (Towadako), 31. v. 1987 (M. Yamada, APM); + , Yasumiya (Towadako), 1. vi. 1987 (M. Yamada, APM); , Mt. Tyohkeimori (Sohma), 15. ix. 1988 (M. Yamada, APM); + , same locality, 1. x. 1988 (M. Yamada, APM); §̂, Tugarutohge (Nisimeya), 18. ix. 1988 (M. Yamada, APM); , Mt. Azuma (Aomori), 8. vi. 1991 (M. Yamada, APM); Ô, Turubetohge (Nishimeya), 12. ix. 1993 (M. Yamada, APM); + , Ainaigawa (Sohma), 11. v. 1997 (M. Yamada, APM); q, Dake-Nojou (Mt. Iwaki), 24. v. 1997 (M. Yamada, APM); +, Dake-Onsen (Mt.Iwaki), 24. v. 
1997 (M. Yamada, APM); ふૈ, Nurukawa (Hiraka), 3. x. 1997 (M. Yamada, APM); q, Chohkeimori (Sohma), 7. vi. 1998 (M. Yamada, APM); ㅇ, Tsuta (Towadako), 30. v. 1999 (M. Yamada, APM). Iwate: , Ashiro, 16. ix. 1980 (Y. Maeta, EBSU); +, Isagozawa, Morioka C., 16. vi. 1991 (T. Chiba, FFPRI); q, same locality, 23. ix. 1991 (H. Chiba, FFPRI); , Yashikidai, Matsuo V., 6. v. 1991 (H. Chiba, FFPRI); 2 , Matsukawa Spa, Matsuo V., 3. x. 1992 (H. Chiba, FFPRI); +, Suesaki, Tamayama V., 14. vii. 1996 (T. Chiba, FFPRI). Fukushima: , Akaiwa, Fukushima City, 27. v. 1990 (H. Takahashi). Tochigi:

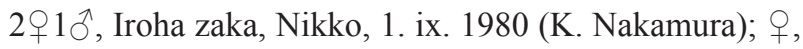
Takio Shrine, Nikko, 23. v. 1980 (K. Nakamura). Gumma: +, Nageishi Pass, Higashi-Mikabo, 28. viii. 1986 (T. Nambu). Saitama: + , Kawamata Karisaka, Otaki, 8. ix. 1973 (T. Nambu); 2ᄋ, Mt. Jyomine, 18. v. 1974 (T. Nambu); 2, Mt. Futagoyama, Ogano, 10. v. 1977 (T. Nambu); + , Nageishi Pass, Higashi-Mikabo, 28. viii. 1986 (T. Nambu). Kanagawa: ${ }^{\prime}$, Mikunitoge, Yamakitamachi, Ashigarakamigun, 16. viii. 1998 (H.

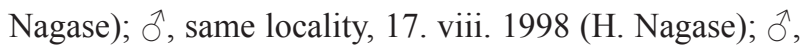
Komagatake 1100-1300m, Hakone, 30. viii. 2000 (H. Nagase). Ishikawa: + , Betto, Mt. Hakusan, 18. v. 1988 (Y. Haneda). Fukui: 4, Akausagi, 9. v. 1976 (T. Tano); ふૈ, Arashi, Ohno, 27. viii. 1976 (Y. Haneda); +, Mt. Akausagiyama, Ohno, 4. vi. 1976 (Y. Haneda); + Hatogayu, 28. v. 1977 (C. Nozaka); ふૈ, Suwara, Ohno, 5. ix. 1986 (Y. Haneda); , same locality, 7. vi. 1987 (Y. Haneda); 3 , , Mt. Takekurabeyama, Maruoka-cho, 8-9. v. 1994 (C. Nozaka); Ĵ, Suwara, Ohno, 22. viii. 1998 (Y. Haneda); + , Mt. Tezutsuyama, Tsuruga-City, 6. xi. 2000 (C. Nozaka, Y. Haneda's coll.); 39 , Mt. Ochisan, Fukuicity, 14. v. 2001 (C. Nozaka); 2 q, Kamikoike, Ono-shi, 14. v. 2002 (K. Mitai); $\hat{\jmath}$, Ohara $\sim$ Oharatouge, Katsuyamashi, 1. ix. 2002 (H. Kurokawa). Yamanashi: ô, Masutomi, 3. ix. 1975 (J. Emoto, ELKU); §̊, same locality, 11. ix. 1975 (J. Emoto, ELKU); + , KaneyamaKohgen, Sutama. Kitakoma, 28. v. 1979 (H. Suda); 2ㅇ, Nishizawakeikoku, Mitomi Vill., 28. v. 1980 (H. Suda); ภ, Nishizawakeikoku, Mitomi Village, 26. viii. 1985 (Y. T. \& H. Suda); + , Mt. Ohdenyama, Yamanakako V., 9. v. 1988 (H. Suda); 2 +, Zumizawa, Sasago, Ohtsuki City, 17. v. 1988 (H. Suda); +, Mt. Mitsutoge, Kawaguchiko To., 22. v. 1990(H. Suda); +, Mitsutouge, 29. viii. 1993 (H. Takahashi); ㅇ, same locality, 4. vii. 1996 (H. Takahashi); q, mariyama road, Nirasaki City, 8. v. 1997 (H. Suda); đ̃, Hirano-Mt. Hirao, 19. viii. 2000 (H. Takahashi); Mitsutouge, 2. ix. 2000 (H. Takahashi); Nagano: + , Mt. Shirouma, Oyanohara, 15. iv. 1976(O. Tadauchi, ELKU); Kyoto: + , Hanase Pass, Sakyo, 17. v. 1997 (H. Suda).

Biology. The flight period is from mid April to early
November with most records in May in female, and from early August to early October in male.

Remarks. The female can be easily separated from the Japanese species by the slender hind femur. The male shares the character of the pilosus antenna with $S$. silvicola and $S$. murotai and can be recognized by the thin vestiture on face.

\section{Sphecodes murotai Tsuneki, 1983}

[Japanese name: Murota-yadori-kohanabachi] (Figs. 15-16)

Sphecodes murotai Tsuneki, 1983, Spec. Publ. Jap. Hymenopt. Assoc., (26): 49 [Holotype: Male. Type locality: Arashiyama, Asahigawa, Hokkaido, Japan].

Sphecodes kaiensis Tsuneki, 1983, Spec. Publ. Jap. Hymenopt. Assoc., (26): 56 [Holotype: Male. Type locality: Hirokawara, Yamanashi Pref., Honshu, Japan]. Syn. Nov.

Sphecodes akitanus Tsuneki, 1983, Spec. Publ. Jap. Hymenopt. Assoc., (26): 52 [Holotype: Male. Type locality: the Nyudoh Promontry, Akita Pref. Honshu, Japan]. Syn. Nov.

Sphecodes maetai Tsuneki, 1984, Spec. Publ. Jap. Hymenopt. Assoc., (30): 3 [Holotype: Male. Type locality: Kuriyagawa, Morioka City, Iwate Pref., Honshu, Japan]. Syn. Nov.

Sphecodes mutsuoides Tsuneki, 1984, Spec. Publ. Jap. Hymenopt. Assoc., (30): 1 [Holotype: Male. Type locality: Mt. Kyogatake, Fukui Pref., Honshu, Japan]. Syn. Nov.

\section{Redescription.}

Male.

Color: Body black except the following: mandible dark brown basally, yellowish brown medially, red apically; flagellar segment paler beneath. Terga wholly black, or T1 tinged with dark brown on apical margin. Femora black, tibiae slightly brown, tarsi yellowish brown.

Sculpture: Clypeus without median furrow; punctures dense, less a puncture diameter apart. Supraclypeal area punctate more densely than clypeus, interpunctural surface minutely rugose. Frons before frontal ocellus areolate-rugose. Vertex near preoccipital ridge and genal area rugose. Scutum densely punctate or punctate-reticulate on anterior one-third, and sparser posteriorly; punctures generally up to three puncture diameters apart. Scutellum areolate. Mesepisternum areolate moderately. T1 polished wholly with very scattered fine punctules, virtually impunctate; apical depressed margin not indicated. T2 polished with scattered punctules. T3-5 without punctules 
on exposed areas. T6 shagreen and superposed with indistinct, shallow punctures. T7 shagreen and superposed with indistinct shallow punctures except apicomedian smooth and impunctate area; apical margin not well produced, but gently curved and turned highly upward.

Vestiture: Vestiture on face white or slightly yellowish, moderately dense, densely plumose, short, not concealing integument, but obscuring that to some extent.

Structure: Body length 5.5-6.5 mm. Head about 0.83 times as long as wide. Vertex behind lateral ocelli developed upward slightly beyond lateral ocelli in frontal view. Genal area narrower than compound eye in lateral view, about 0.5 times as wide as compound eye. Exposed portion of pedicel about as long as FL1. Relative length of

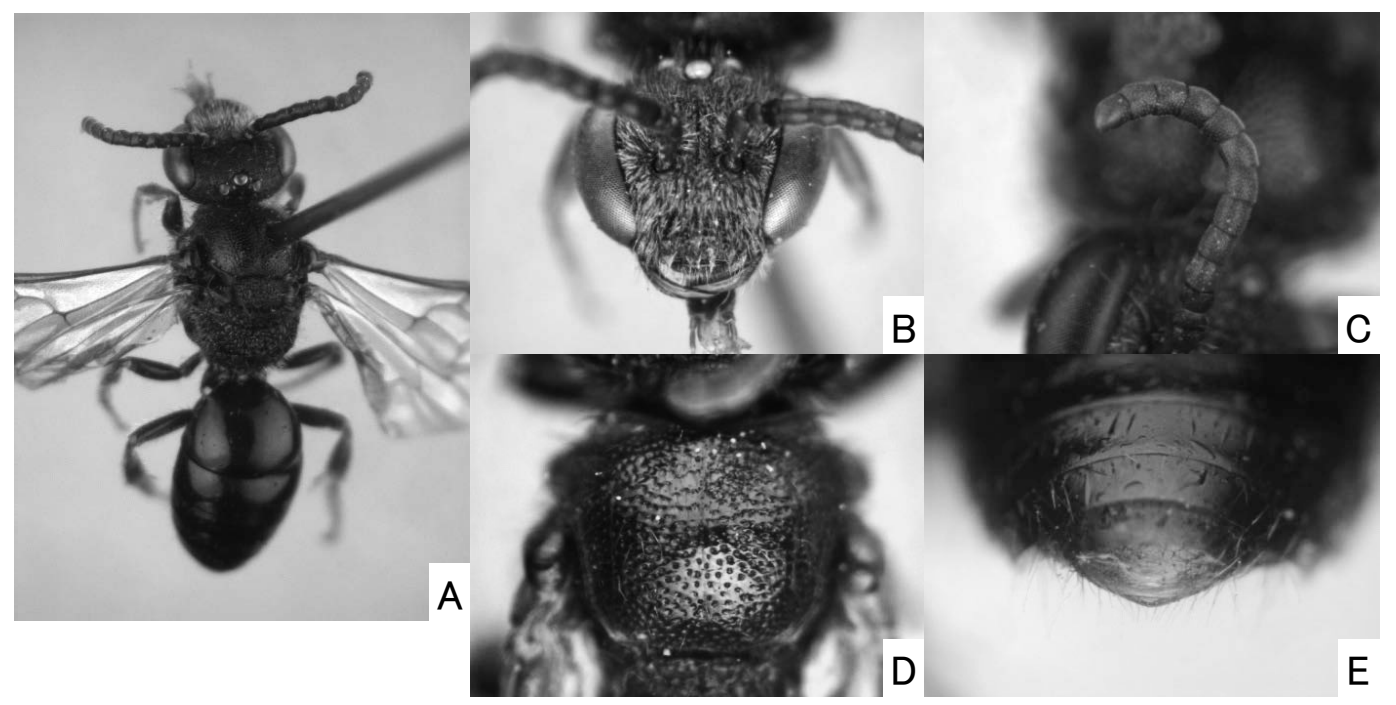

Fig. 15. Sphecodes murotai Tsuneki, male. A: habitus, dorsal view. B: head. C: antenna. D: scutellum. E: pygidial plate.
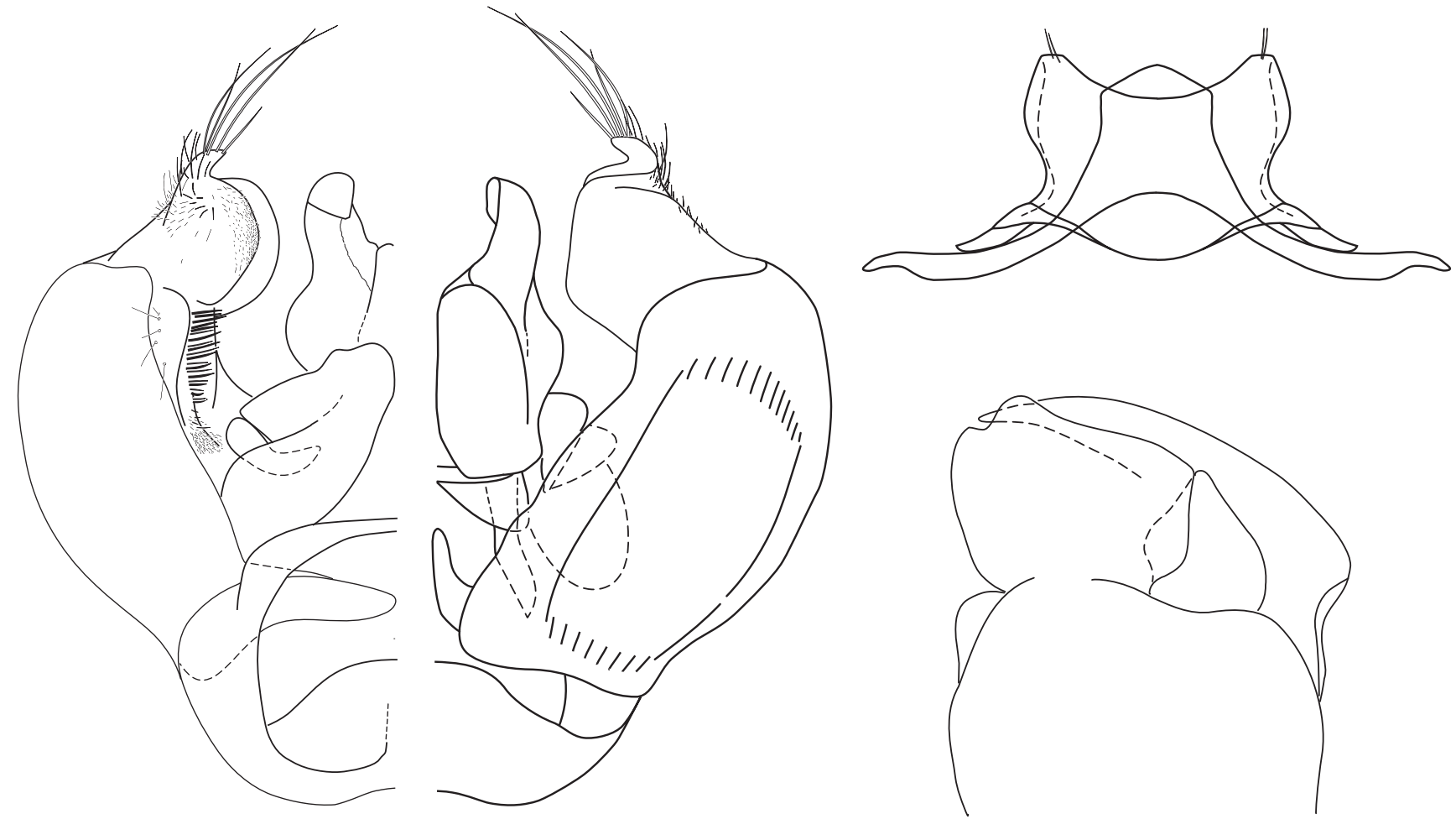

Fig. 16. Sphecodes murotai, male. A: genital capsule (left, ventral view; right, dorsal view). B: 7th and 8th metasomal sterna, ventral view. C: gonostylus, lateral view (vestiture omitted). 
FL1 $: 2: 3=1.0: 1.6: 1.6$. FL1 0.6 times as long as width, FL2 1. 2times, FL3 1.1 times, and remaining segments slightly longer than width. Flagellar segments simply cylindrical, not swollen medially, without velvet-like area. Collar gently curved between frontal and lateral sides. Pronotum with lateral ridge lowly raised. Scutellum flat. Hind femora slender, relative breadth to length of hind femur 0.3-0.32. Apical process of hind tibia hardly produced. Hook on hind wing 5-6 in number. Disc of S7 pentagonal. S8 with posterior margin deeply emarginated, posterolateral corner with a few setae; lateral margin strongly wavy; anterior margin roundly produced anteriorly. Gonocoxite striate with dorsal depression. Gonostylus with long vestiture near top and with moderately dense vestiture on other surface; inner basal surface with dense setae finer downwards; basoventral lobe distinct with a row of several setae.

Female. unknown.

Distribution. JAPAN [Honshu, Shikoku, Kyushu].

Specimens examined. Holotype [MNHAH], male with three labels as follows: "(JAPAN: HOKKAIDO)/ Arashiyama, Asahikawa/ 6. viii. 1977/T. Murota leg. [white rectangle with typed and handwritten letters]", "Sphecodes/ murotai/ Tsuneki $\delta /$ HOLOTYPE [red rectangle with handwritten letters]", and "B1-288282 [white rectangle with printed register-number of MNHAH and a bar-code]".

Other specimens: We have examined about 35 males. Some of them are listed as follows: JAPAN [Honshu] Aomori: đ̃, Takinomata (Takko), 23. ix. 1986 (M. Yamada, APM); ふै, Nizinoko (Kuroisi), 9. x. 1993 (M. Yamada, APM); ô, Akakurasawa (Mt. Iwaki, 13. ix. 1996 (M. Yamada, APM). Iwate: đ̃, Zyouhohzi, 18. viii. 1991 (M. Yamada, APM). Tochigi: đ̃, Yoichi Park, Ohtawara, 15. vi. 1999 (E. Katayama). Gumma: $3 \hat{\jmath}$, Haruna-Kogen, Gunma Gun, 1. ix. 1987(H. Suda). Saitama: đ̂, Green School, Ootaki ,10. vii. 1999 (T. Nambu); đે, Ootaki, 10. vii. 1999 (T. Nambu). Kanagawa: $\widehat{\jmath}$, Minoge-Yabitsutoge, Hadano-shi, 21. vi. 1997 (M. Kato, H. Nagase's coll.); đૈ, Mikunitoge, Yamakitamachi, Ashigarakamigun, 17. viii. 1998 (H. Nagase); 2ð, Myojinyama, Yamakita, 28. viii. 1999 (H. Nagase); ふ̂, Mikuni Pass, Yozuku, Kitayamamachi, Ashigarakami-gun, 24. viii. 2000 (I. Waki, H. Nagase's coll.). Fukui: §̂, Fukui, Suwara, Ohno, 29. viii. 1986 (Y. Haneda); đ̃, same locality, 5. ix. 1986 (Y. Haneda); đ̂, same locality, 17. viii. 1997 (Y. Haneda); đે, Ootaki, 10. vii. 1999 (T. Nambu). Yamanashi: ô, Yakeyama road, Makioka Town, 9. viii. 1978 (Y. \& H. Suda); đ̂, Yakiyama, Makioka, Higashiyamana, 9. viii. 1978 (Y. H. Suda); đ̃, Kouyoudai-Mikodai, 17. viii. 1981 (Y. T. \& H. Suda); đ̃, Mt. Mitsutoge, Kawaguchiko To., 8. viii. 1990 (H. Suda); Ĵ, Daibosatsu road, Enzan City, 17. vii. 1996 (H. Suda). Nagano: đ̃, Miyata High land, alt. 1600m, Miyata-mura, 1. ix. 2005 (K. Mitai). [Shikoku] Ehime: ふૈ, Mt. Ishizuchi, Omogo-mura, 12. ix. 1999 (M. Shiraishi, H. Takahashi's coll.); §ૈ, Mt. Kamegamori, 26. ix. 1999 (Y. Maeta, EBSU). [Kyushu] Kagoshima: 3ڤ̂,, Sata (Osumi), Hetsuka, 25. v. 1952 (Esaki and Hirashima, ELKU); ふૈ, Mt. Kirishima, 28. vi. 1959 (Y. Takemura, H. Nagase's coll.); ð̃, Tajiri, Sata-cho, 70m, 7. vi. 1987 (S. Ikudome).

Biology. Tsuneki (1984) described S. maetai as a new species, based on four females and four males excavated from the two nest of Lasioglossum baleicum (Cockerell, 1937). Before Tsuneki's description, Haneda (1984) examined the same materials and identified the females as S. koikensis and the males as $S$. mutsu, and presumed that they are conspecific. In the present study, we examined the holotype male and a paratype female of $S$. maetai, and conclude that the female is $S$. okuyetsu, and that the male is $S$. murotai. Considering the fact that they were excavated from the same nests of a host Lasioglossum, it is very likely that they are conspecific, as in the above-mentioned conclusions of Tsuneki and Haneda. However, we must conclude that they are two different species, judging from the formerly known combination of sexes of S. okuyetsu whose male is different from that of $S$. maetai.

Remarks. Among species without velvet-like area on antenna, this species is similar to $S$. silvicola, but can be easily separated from the latter by the areolate scutellum.

\section{Sphecodes nagasei \\ Mitai et Tadauchi, sp. nov.}

[Japanese name: Nagase-yadori-kohanabachi]

(Figs. 17-18)

\section{Description.}

Female.

Color: Head and mesosoma black except the following: clypeus tinged with red; labrum yellowish brown; mandible yellowish brown basally, apex red. T1 red, and T2 dark red. Legs blackish brown.

Sculpture: Clypeus without median furrow; punctures moderately dense on upper area, where interpunctural surface is as wide as a puncture diameter, much sparser apically; apical margin shallowly transversely furrowed. Supraclypeal area punctate more densely than clypeus. Frons punctate-reticulate narrowly medially, much sparser laterally and toward vertex. Vertex and genal area polished with scattered small punctures. Scutum scattered with small punctures, much smaller laterally and posteriorly. Scutellum punctured as scutum. Propodeal triangle 
enclosed by semicircular carina, which surrounds smaller semicircular carina; these two carinae connected by four to six ridges; longitudinal, straight ridge present medially. Mesepisternum rugose anteriorly except posterior area; hypoepimeral area polished with sparse punctules. T1-4 shiny with scattered fine punctules basally; punctures denser gradually on succeeding tergum; apical depressed areas of terga indistinctly indicated and impunctate. Pygidial plate not observable.

Vestiture: Finely plumose, appressed, short, slightly yellowish hairs present on supraclypeal and surrounding area. The similar but denser vestiture presents on mesosoma except anterior face of pronotal lateral lobe, scutum, hypoepimeral area, scutellum, and propodeal triangle.
Apical polish areas of T2-4 with long, fine, sparse, simple hairs which are about as long as width of apical polish area. Hind femur beneath with long, weakly sinuate hairs, which are not tomentose, but relatively denser than those of other Japanese species.

Structure: Body length $6.5 \mathrm{~mm}$. Head 0.80 times as long as wide. Labrum semicircular, short, 0.45 times as long as wide; apex widely obtuse. Interantennal elevation low; median sharp carina ends as sharp edge. Vertex behind lateral ocelli not developed upward beyond lateral ocelli in frontal view. Genal area much narrower than compound eye in lateral view, about 0.4 times as wide as compound eye. Exposed portion of pedicel roughly 1.5 times as long as FL1. Relatively length of FL1 $: 2: 3=1.0$

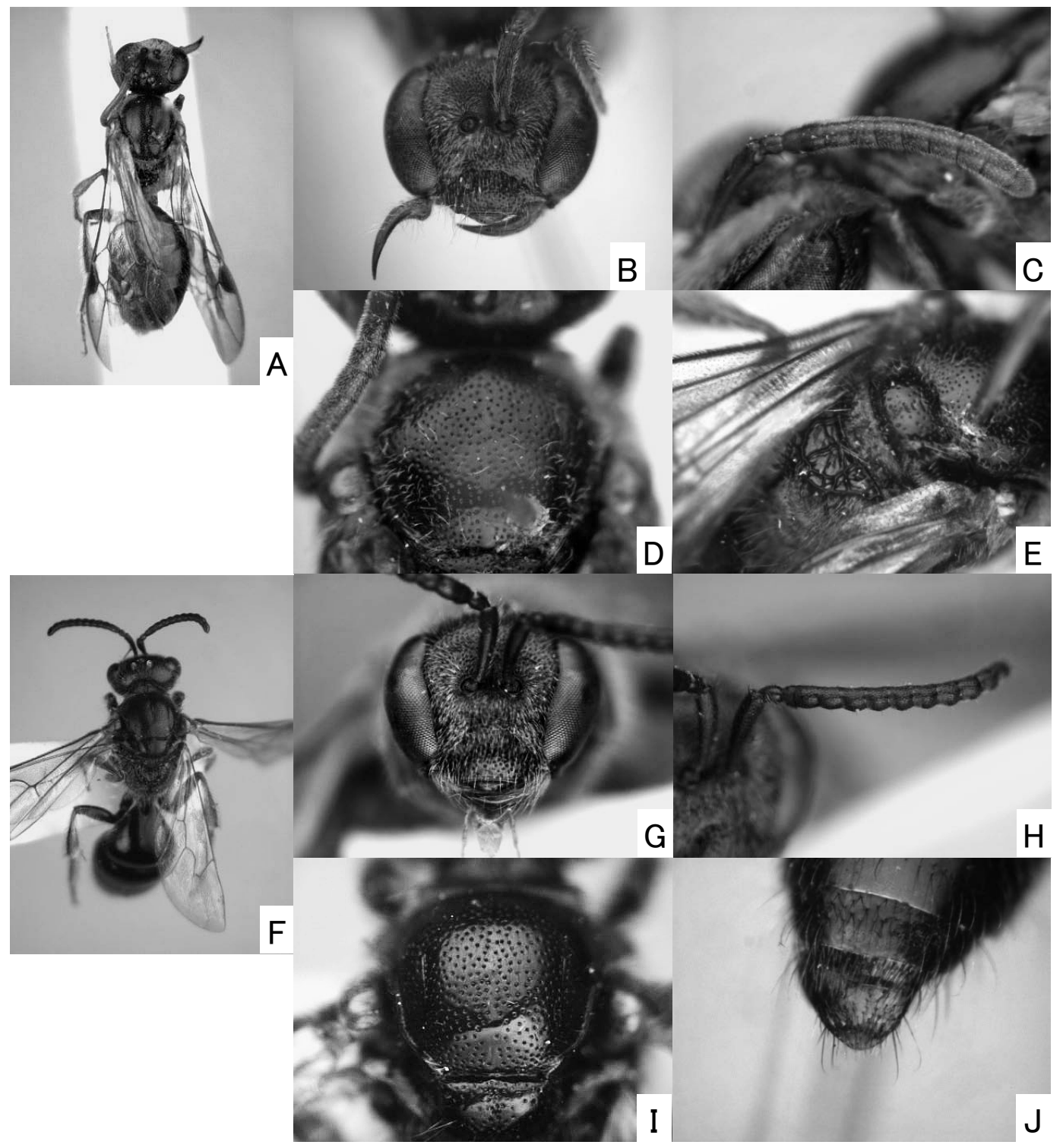

Fig. 17. Sphecodes nagasei Mitai et Tadauchi, sp. nov. Female: A-H. Male: I-N. A, I: habitus, dorsal view. B, J: head. C, K: antenna. D, L: clypeus. E: labrum. F, M: scutellum. G: hind femur. H, N: pygidial plate. 

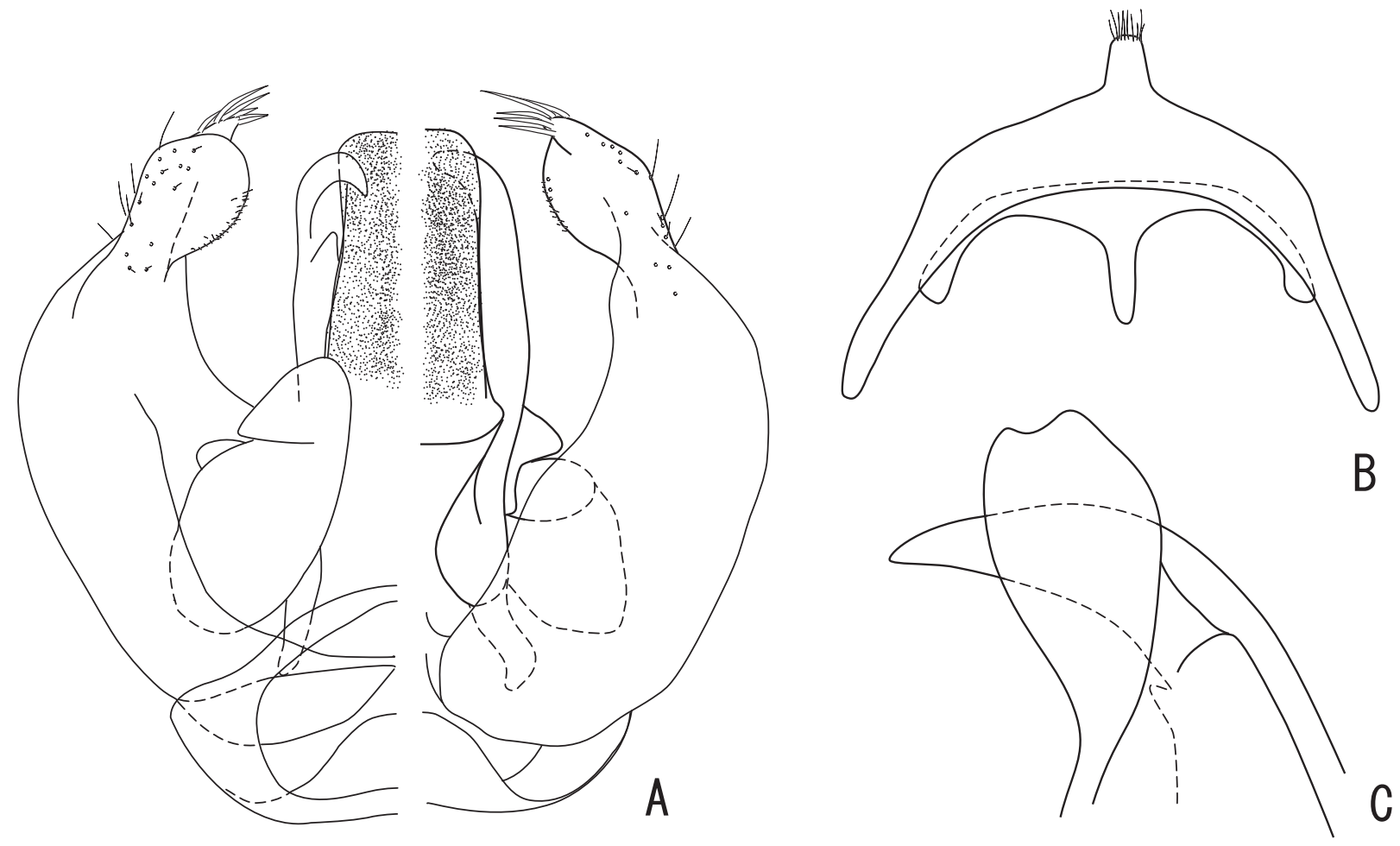

Fig. 18. Sphecodes nagasei sp. nov., male. A: genital capsule (left, ventral view; right, dorsal view). B: 7th and 8th metasomal sterna, ventral view. C: gonostylus, lateral view (vestiture omitted).

: $1.0: 1.1$, and F1 and FL2 0.8 times as long as width, FL3 0.9 times, and remaining segment about as long as width. FL1-2, and narrowly basal beneath of FL3 densely shagreen, matt. Undersides of FL4 and the following segments shiny. Mandible without an inner tooth. Collar gently curved between frontal and lateral sides. Pronotum with lateral ridge recognized as indistinct convex. Scutellum gently roundly convex. Hind femora slender, relative breadth to length of hind femur about 0.28 . Apical process of hind tibia hardly produced. Hook on hind wing 5 in number.

\section{Male.}

Color: Body black except the following: mandible yellowish medially, red apically; terga dark brown. Legs dark brown; tarsi paler apically.

Sculpture: Clypeus and Supraclypeal area similar to those of female except apical margin of clypeus without furrow. Frons, vertex and general area generally as female, but somewhat denser. T1-5 highly polished with very scattered, fine, setigerous punctules on exposed areas. Apical depressed margin not indicated on T1. T7 polished with sparse setigerous punctules; apical margin well produced with round at apex, not turned upward.

Vestiture: Vestiture similar to that of female, but plumose hairs on face and short hairs on mesosoma distinctly sparser. Hind femur with sparse hairs as those of other Japanese species.

Structure: Body length $5.5 \mathrm{~mm}$. Head about 0.83 times as long as wide. Exposed portion of pedicel as long as FL1. Relative length of FL1 $: 2: 3=1.0: 1.2: 1.4$. FL1 0.8 times as long as width, FL2 0.9 times, FL3 1.0 times, and remaining segments about as long as or slightly shorter than width. Each segment after FL2 swollen medially. Undersides of FL4 and the following segments deeply convex, with hairs moderately dense basally, appearing loose velvet-like areas. S7 U-shaped with posterior median process slender. S8 small with posterior long median process. Gonocoxite smooth and partially very weakly striate, without dorsal depression. Gonostylus with long setae on the lobe and with much finer, very sparse, short setae on lateral surface; inner basal surface without setae; basoventral lobe not recognized.

Distribution. JAPAN [Honshu, Kyushu].

Specimens examined. Holotype (Type No. 3324. ELKU), Ô, Shimoyama, Izumi, Fukui, Pref. Honshu, 5. ix. 1990 (Y. Haneda). Paratypes: [Honshu] Kanagawa: $\curvearrowright$, Hitorizawa, Isogoku, Yokohama, 4. v. 1997 (K. Kubo, H Nagase's coll.). Tottori: गे, Hino-cho, Michi-mihara[?], 17. v. 1999 (collected by Wesco Co. Ltd., Y. Haneda's coll.). [Kyushu] Nagasaki: ㅇ, Mt. Uzen, 8. viii. 1953 (H. 
Nagase)

Biology. Three males are from early to mid May, and early September. The only female is from early August.

Remarks. This species is very unique among the Japanese species, having the dense yellowish vestiture on propodeum, and the characteristic carinae and ridges in the propodeal triangular.

\section{Sphecodes nambui Tsuneki, 1983}

[Japanese name: Nambu-yadori-kohanabachi]

(Figs. 19-20)

Sphecodes nambui Tsuneki, 1983, Spec. Publ. Jap. Hymenopt. Assoc., (26): 13 [Holotype: Male. Type locality: Kodama, Saitama Pref., Honshu, Japan].

\section{Redescription.}

Male.

Color: Body black except the following: mandible dark red apically; T1 apically, T2 basally or wholly red. Legs black except fore tibiae beneath yellowish.

Sculpture: Clypeus densely punctate-reticulate without median furrow. Supraclypeal area and vertex densely areolate with partitions of convexity highly raised. Frons before lateral ocelli deeply and coarsely areolate-rugose. Genal area rugose; outer orbit of compound eye furrowed. Scutum punctate-reticulate. Scutellum areolate. Mesepisternum areolate coarsely. T1-2 polished, T3-6 faintly coriarious. T1 with apical half scattered small distinct punctures intermixed with much smaller punctules nearly up to margin. $\mathrm{T} 2$ and $\mathrm{T} 3$ punctate as $\mathrm{T} 1$, apical depressed area impunctate. T4-6 only with setigerous punctules. Apical portion polished and widely produced with apical margin obtuse-angled.

Vestiture: Vestiture on lower face golden in color, rather dense, densely plumose and appressed, not concealing integument, but obscuring that to some extent.

Structure: Body length 7.5-9 mm. Head about 0.80.83 times as long as wide. Interantennal elevation low with median carina abruptly ends apically. Vertex behind lateral ocelli well developed upward much beyond lateral ocelli in frontal view. Genal area much narrower than compound eye in lateral view, about 0.5 times as wide as compound eye. Exposed portion of pedicel as long as FL1. Relative length of FL1 $: 2: 3=1.0: 2.8: 2.8$. FL1 0.5 times as long as width, FL2 1. 6 times, FL3 1.5-1.6 times, and remaining segments distinctly longer than width. Each segment after FL2 swollen medially. Undersides of FL2 and the following segments with velvet-like area. Velvet-like area on FL2 confined peripherally; those the on more following segments gradually much wider; hairless area surrounded by velvet-like area, becoming one or a pair of small spot on last several segment, but on last segment hairless area wide, occupying apical half of segment. Collar sharply angulate between frontal and lateral sides. Pronotum with lateral ridge highly raised and produced anteriorly. Scutellum flat. Hind femora slender, relative breadth to length of hind femur 0.3 . Apical process of hind tibia shortly rounded. Hook on hind wing 7-8 in number. S7 oblong pentagonal. S8 with posterior margin weakly produced; lateral margin deeply wavy; anterior margin widely roundly produced anteriorly. Gonostylus with a loose row of long setae on top; basolateral sides of gonostylus with long setae; inner

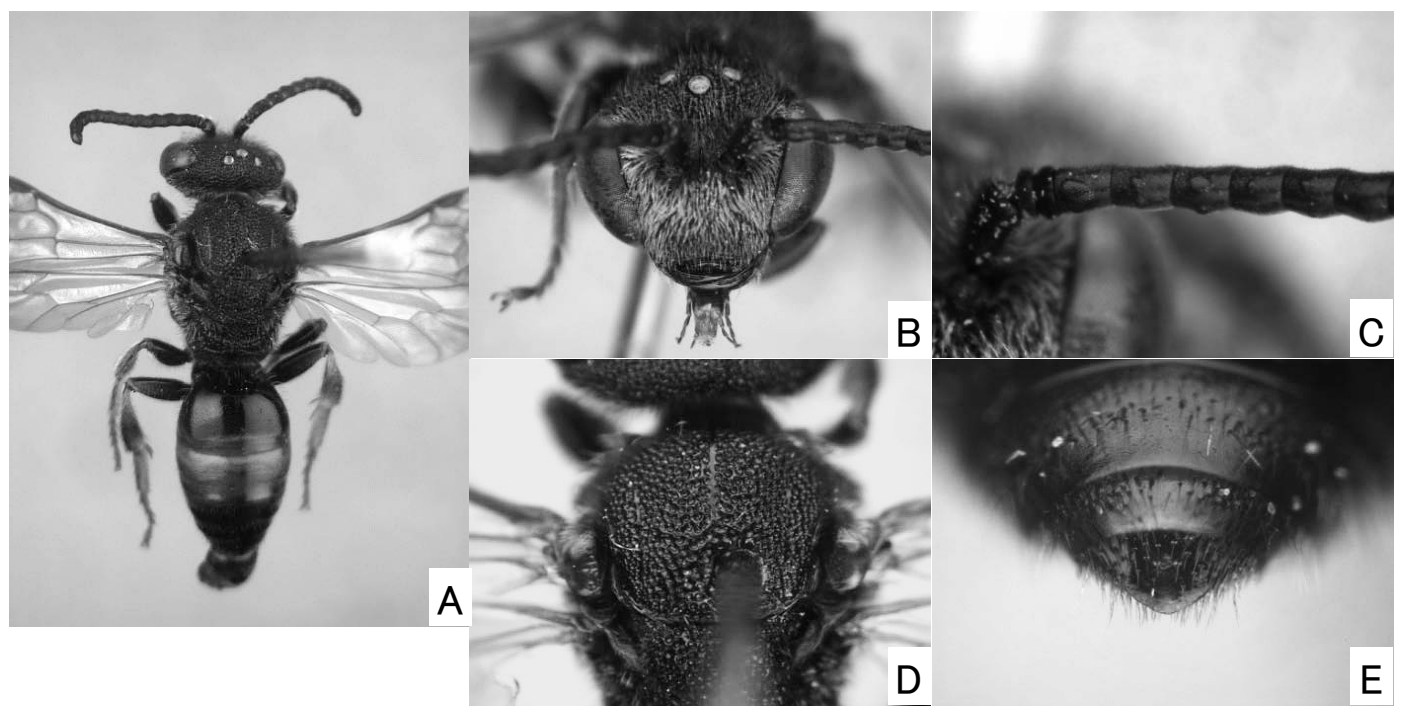

Fig. 19. Sphecodes nambui Tsuneki, male. A: habitus, dorsal view. B: head. C: antenna. D: scutellum. E: pygidial plate. 

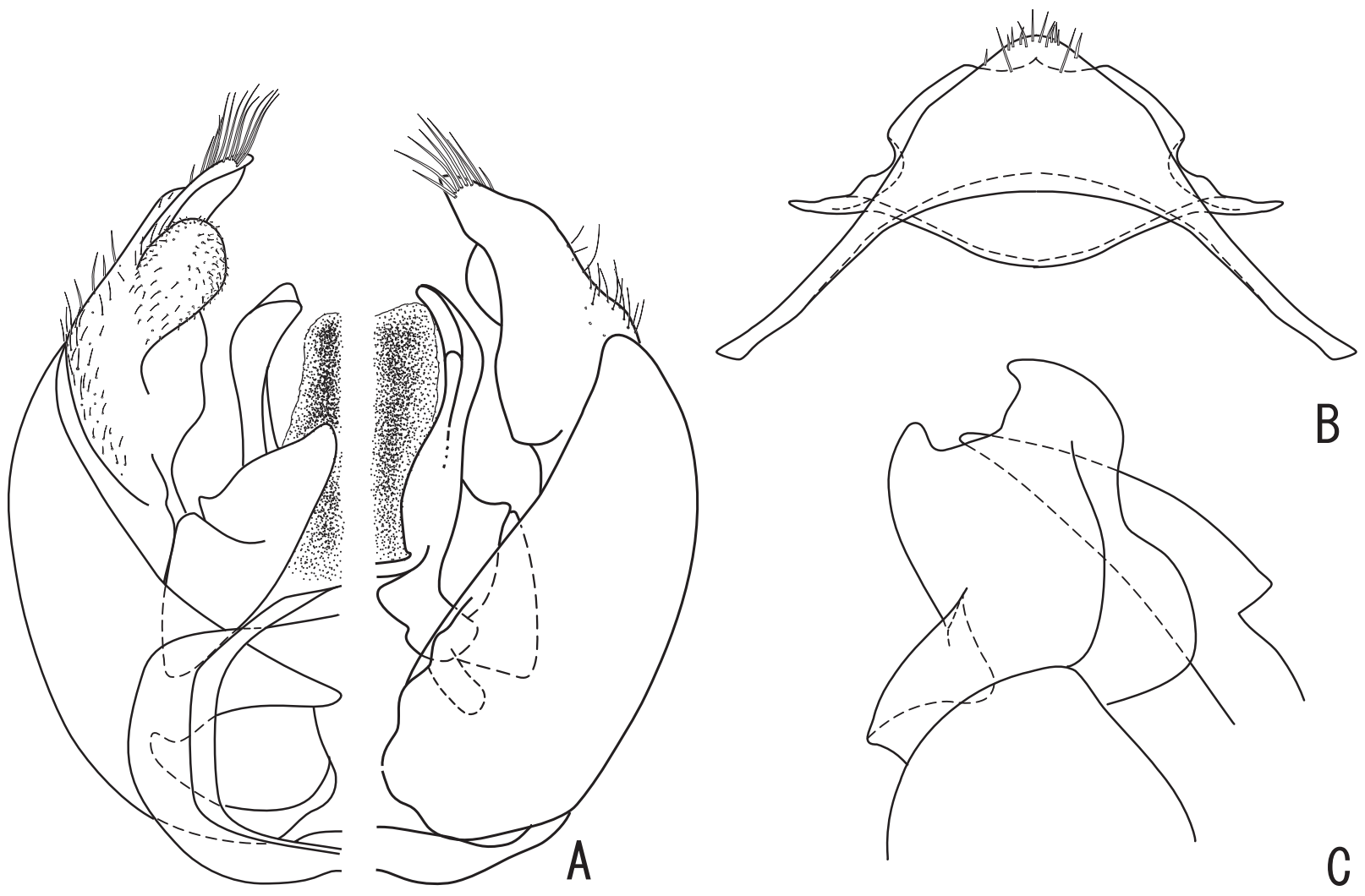

Fig. 20. Sphecodes nambui Tsuneki, male. A: genital capsule (left, ventral view; right, dorsal view). B: 7th and 8th metasomal sterna, ventral view. C: gonostylus, lateral view (vestiture omitted).

basal surface without setae; basoventral lobe rounded ridge-shaped, then being sharply carinate obliquely upwards with loose row of setae which are longer upwards.

Female. unknown.

Distribution. JAPAN [Honshu, Shikoku].

Specimens examined. Holotype [MNHAH], male with three labels as follows: "Kodama, Saitama/ Honshu, 22-IX/ T. NAMBU 1972 [white rectangle with typed and handwritten letters]", "Sphecodes/ nambui/ Tsuneki $\hat{\jmath} /$ HOLOTYPE [red rectangle with handwritten letters]", and "B1-288285 [white rectangle with printed registernumber of MNHAH and a bar-code]".

Other specimens: We have examined about 20 males. Some of them are listed as follows: JAPAN [Honshu] Saitama: Ĵ, Juniten-ike Pond, Kodama, 18. ix. 1972 (T. Nambu); ô, Idegahara, Ryokami, 25. vii. 1972 (K. Hara, T. Nambu's coll.); đ̃, Kinsyozan, Ogawa, 24. viii. 1995 (T. Nambu); 2ð, Kanatake-zawa, kamifurutera, Ogawamachi, 25. x. 1997 (collector unknown, NSMT). Chiba:

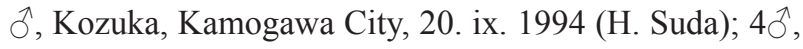
Kobota, Kyonan, Awa, 20. ix. 1997 (H. Suda). Kanagawa: J., Okusuyama, Yokosuka, 25. ix. 2000 (H. Nagase). Fukui: ふૈ, Tani, Katsuyama, 14. x. 1995 (C. Nozaka, Y.
Haneda's coll.); Oૈ, Akadani, Miyamacho, 7. x. 1997 (H. Kurokawa); ふૈ, Ozigadani, 29. ix. 2000 (H. Kurokawa); ふૈ, Akatani, Miyama-cho, 9. x. 2001 (C. Nozaka); Hyogo: ô, Fujiokaoku, Sasayama (Tamba), 1. x. 1954 (S. Taniguti, ELKU); đ̃, Higashihamana, Sasayama, 21. ix. 1954 (S. Taniguti, ELKU); ふૈ, Fujiokaoku, Sasayama (Tamba), 1. x. 1954 (S. Taniguti, ELKU). [Shikoku] Kochi: ô, Kurotaki, 8. x. 1975 (S. Ikudome).

Biology. The flight period is from late July to late October with most records from September and October.

Remarks. In his key, Tsuneki (1983) separated this species from $S$. japonicus (=S. scabricollis) by the relative length of the flagellar segments. However, this difference is obscured by a range of individual variation. The striking character separating this species from S. scabricollis is the shape of velvet-like area on antenna. This character state is also helpful for separating this species from S. ikudomei n. sp. 


\section{Sphecodes nippon Meyer, 1922}

[Japanese name: Nippon-yadori-kohanabachi]

(Figs. 21-22)

Sphecodes nippon Meyer, 1922, Arch. Naturg., 88A: 171 [Holotype: Male. Type locality: Yokohama, Honshu, Japan]

Sphecodes aino Tsuneki, 1983, Spec. Publ. Jap. Hymenopt. Assoc., (26): 26 [Holotype: Female. Type locality: Dyozankei, Hokkaido, Japan]. Syn. Nov.

Sphecodes awaensis Tsuneki, 1983, Spec. Publ. Jap. Hymenopt. Assoc., (26): 27 [Holotype: Female. Type locality: Mt. Tsurugi, Tokushima Pref., Shikoku, Japan]. Syn. Nov.

\section{Redescription.}

Female.

Color: Head and mesosoma black except labrum and apical portion of mandible tinged with red. T1-3 red except basal narrow portion of $\mathrm{T} 1$ darker. Leg black except tarsi brown apically. Wings uniformly infuscate.

Sculpture: Clypeus with median furrow on apical half; puncture coarse and moderately dense, at most 1.5 times puncture diameter apart, but smaller and continuous on apical margin of clypeus. Supraclypeal are smaller and denser than clypeus. Frons punctate-reticulate. Vertex punctate-reticulate, slightly sparser behind lateral ocelli, where punctures are separated generally by a puncture diameter. Vertex around preoccipital ridge punctate subobsolately, and genal area similarly punctate, but partially costate without puncture. Scutum irregularly sparsely punctate with punctures generally two to three, or more in places, puncture diameters apart; interpunctural area scattered with punctules. Scutellum punctate as scutum, but usually more densely posteriorly. Mesepisternum areolate moderately; hypoepimeral area generally costate. T1-6 polished. T1 with dense punctures on apical half; punctures generally one to three puncture diameters apart, intermixed with much small punctules, wider in some places. T2 punctate as T1; apical depressed area with sparser, distinct punctures. Terga after $\mathrm{T} 2$ gradually more sparsely punctate by apical depressed areas impunctate. Pygidial plate not wide, 0.7 times as wide as width of FL3; surface shagreen basally, usually shiny apically, turned not highly upward peripherally.

Vestiture: Vestiture on face short; that on clypeus, supraclypeal area, frons and vertex rather sparse, simple or slightly plumose; that on middle to lower paraocular area densely plumose, but not so dense to obscure integument.

Structure: Body length 8.5-10.5 mm. Head about 0.70 times as long as wide. Labrum about 0.7-0.8 times as long as wide without distinct medial furrow; apex usually shallowly broadly emarginate, varying from deeply emarginate to shallowly so, or nearly straight. Interantennal elevation roundly moderately raised. Vertex behind lateral ocelli well developed upward much beyond lateral ocelli in frontal view; Area from top of head to upper margin of lateral ocellus about twice as wide as lateral ocellar diameter. Genal area much narrower than compound eye in lateral view, about 0.5 times as wide as compound eye. Exposed portion of pedicel roughly as long as FL1. Relatively length of FL1 : $2: 3=1.0: 0.9: 1.4$, and F1 0.7 times as long as width, FL2 0.5 times, FL3 0.9 times, and remaining segment as long as width. FL1-2 densely shagreen, matt. Undersides of FL3 and the following segments slightly shiny. Collar sharply angulate between frontal and lateral sides. Pronotum with lateral ridge highly raised and produced anteriorly. Scutellum flat. Hind femora robust, relative breadth to length of hind femur 0.42-0.44. Apical process of hind tibia large, usually oblong, but shape of apex variable from obliquely truncate to expanded. Hook on hind wing usually 10 in number.

Male.

Color: Body black except the following: mandible dark red apically; T1 apically, T2 wholly, T3 basally or wholly red. Tarsi paler apically. Wings uniformly infuscate.

Sculpture: Clypeus deeply punctate-reticulate without median furrow. Supraclypeal area punctate more densely than clypeus. Frons, vertex and genal area slightly sculptured coarser and punctures more distinct than those of female. Vertex punctate-reticulate more densely than that of female; punctures less than one puncture diameter apart. Scutum punctate-reticulate peripherally, more irregularly sparsely medially; punctures in medial part five to six, or more sometimes, puncture diameters apart. Scutellum punctate as scutum. T7 with setigerous punctures; apical portion polished and widely produced with apical margin truncate or rounded.

Vestiture: Vestiture on face golden in color, very dense [slightly sparser on clypeus], densely plumose and largely appressed, not concealing integument, but obscuring that to some extent.

Structure: Body length 6.5-10 mm. Head 0.80-0.83 times as long as wide. Genal area much narrower than compound eye in lateral view, about 0.3 times as wide as compound eye. Exposed portion of pedicel shorter than FL1. Relative length of FL1 $: 2: 3=1.0: 2.6-2.8: 2.6-2.8$. FL1 0.5 times as long as width, FL2 1.8-2.0 times, FL3 1.6-1.8 times, and remaining segments much longer than 
width. Each segment after FL2 weakly swollen medially. Undersides of FL3 and the following segments with velvet-like areas. Velvet-like area on FL3, narrow, bandshaped basally, reaching at most basal one-fifth of segment; those on FL4-9 gradually wider on more apical segment, becoming widest on FL6-8, developed beyond basal one-third of segment, and those on the following segments slightly thinner. Hind femora slender to moderate, relative breadth to length of hind femur about
0.32-0.34. Apical process of hind tibia shortly rounded. Disc of S7 quadrangular. S8 with posterior margin truncate or produced posterolaterally; posterolateral corner with a few setae; lateral margin moderately wavy; anterior margin widely produced anteriorly. Gonocoxite weakly striate without dorsal depression. Gonostylus long with apical portion expanded; vestiture on apical expanded portion long and sinuate; dorsal lobe also with long vestiture; inner basal surface with dense short setae;

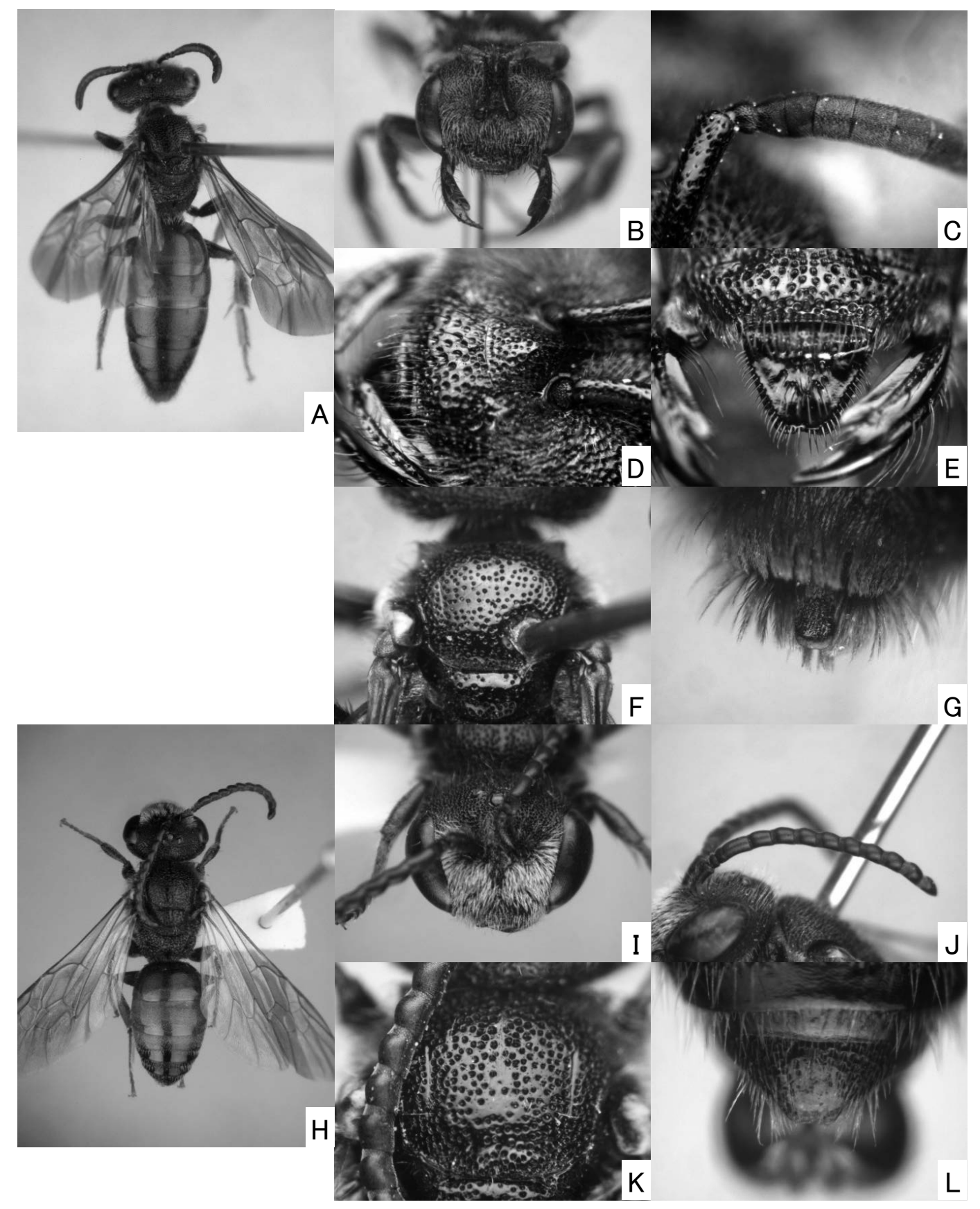

Fig. 21. Sphecodes nippon Meyer. Female: A-H. Male: I-N. A, I: habitus, dorsal view. B, J: head. C, K: antenna. D, L: clypeus. E: labrum. F, M: scutellum. G: hind femur. H, N: pygidial plate. 


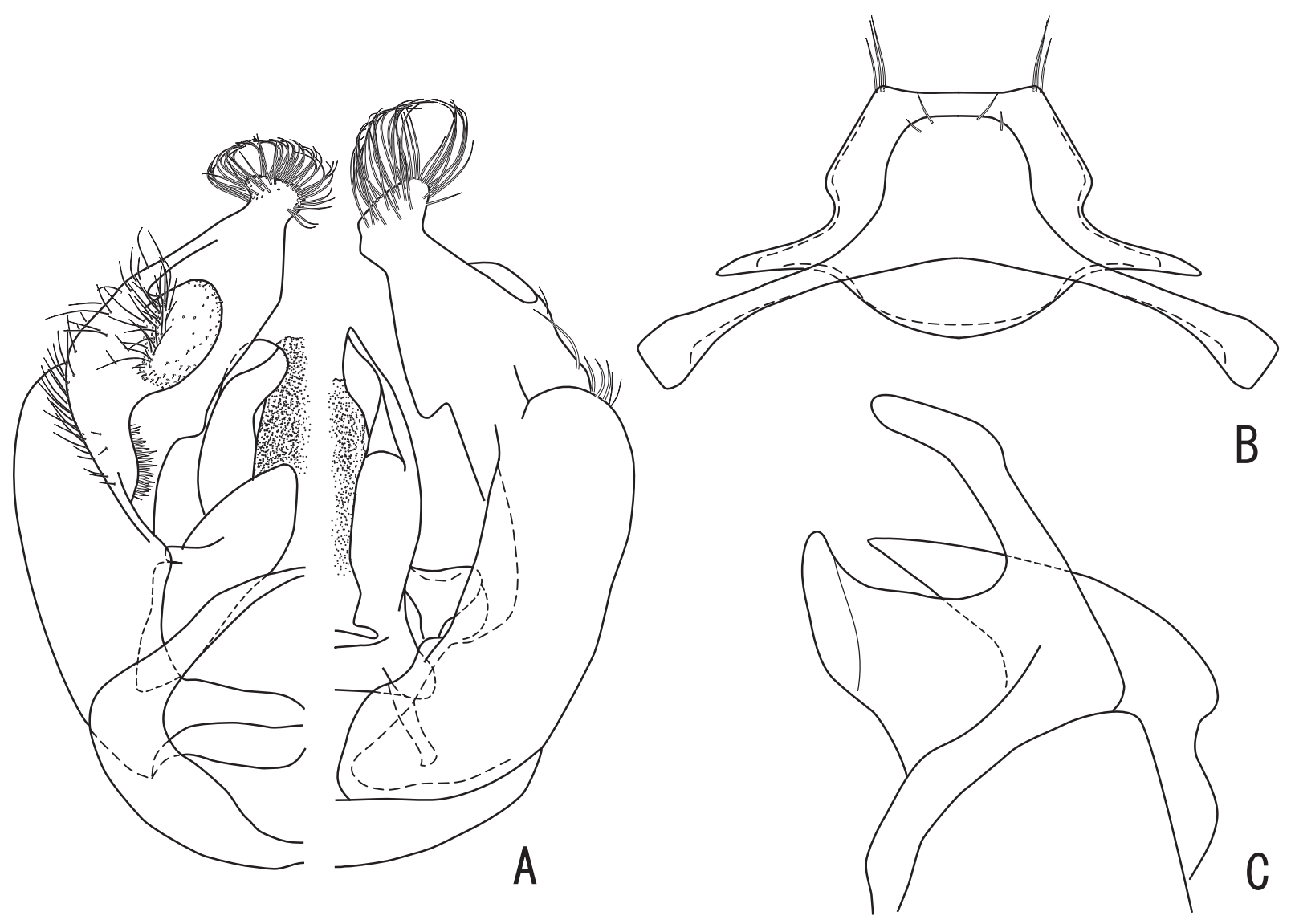

Fig. 22. Sphecodes nippon Meyer, male. A: genital capsule (left, ventral view; right, dorsal view). B: 7th and 8th metasomal sterna, ventral view. C: gonostylus, lateral view (vestiture omitted).

basoventral lobe sharply carinate, extending obliquely upwards to base of dorsal lobe, with a low of long setae on top.

Distribution. JAPAN [Hokkaido, Honshu, Shikoku, Kyushu].

Specimens examined. We have examined about 80 females and 40 males. Some of them are listed as follows: JAPAN [Hokkaido] 2ðð, Sapporo, 20. viii. 1927 (K. Sato, ELKU); + , Ikomanbetsu, Mt. Daisetsu, 23-25. vii. 1955 (Y. Hirashima, ELKU); + , Hakodateyama, 9. vii. 1958 (M. Munakata, ELKU); , S Sapporo, 9. ix. 1958 (S. Ueda, ELKU); ô, Ounuma Park, 1. x. 1959 (K. Munakata, ELKU); ㅇ, Jozankei, nr Sapporo, 9. vi. 1961 (H. Nagase); †, Atsunai, 10. viii. 1969 (M. Wakayama); ふૈ, Otarunai, 8. viii. 1973 (H. Fukuda, ELKU); §̂, same locality, 6. ix. 1973 (H. Fukuda, ELKU); đ̃, same locality, 22. ix. 1973 (H. Fukuda, ELKU); + , Usubetsu, 6. vi. 1973 (H. Fukuda, ELKU); §̂, Mt. Upepesanke, 600m alt., Tokachi, 16. ix. 1976 (M. Usui, K. Nakamura’s coll.); +, Nukabira, 20. vii. 1976 (H. Fukuda, ELKU); ふૈ, Nukabira, Kamishihoro-cho, 4. ix. 1977 (S. Ikudome); †, Shotoshibetsu,
Ribubetsu, 27. v. 1984 (O. Tadauchi, ELKU); ㅇ, Mt. Teinekanayama, Teine, Sapporo, 29. vi. 1999 (H. Suda). [Honshu] Aomori: $q$, R-Oirase, Nishi gun, 17. vi. 1973 (K. Shimoyama, APM); ふૈ, Mt. Iwaki, 29. vii. 1982 (M. Yamada, APM); 1 워, Ainai (Shiura); 6. viii. 1994 (M. Yamada, APM). Iwate: đ̃, Koiwa, 1. ix. 1922 (K. Sato, ELKU); + , Kuriyagawa, Morioka, 23. vi. 1964 (Y. Maeta, ELKU); ㅇ, Takizawa, Exp. Forests, 8. vii. 1976 (Y. Maeta and T. Matsumura, EBSU); Ô, Sennin Pass, 31. viii. 1980 (Y. Maeta, EBSU); 12ㅅ, Kanegasaki, 2. viii. 1987 (Sk. Yamane, S. Ikudome's coll.). Miyagi: +, Miyagi, Mt. Aobayama, 27. v. 1977 (K. Goukon); + , same locality, 21. vii. 1979 (K. Goukon). Yamagata: 9 , Yonezawa, 8. vi. 1944 (Y. K., ELKU). Tochigi: \&, Mine, Utsunomiya, 29. viii. 1979 (K. Nakamura). Saitama: q, Backyard of High School, Ogose, 22. vi. 1977 (T. Nambu); ठ̊, Toda Kooen, 30. ix. 1986 (K. Hara, MNHAH); 2ð, Mountain pass $\sim$ top of Mt. Kasayama, Kasayama, Ogawa, 4. vii. 1997 (T. Nambu). Chiba: đ̊, Kohoku, Abiko City, 12. viii. 1971 (H. Suda); ô, Yamanashi, Yotsukaido City, 4. ix. 1996 (H. Suda). Tokyo: 2ð̄, Shiroyama, Takao, Hachioji City, 16. 
vii. 1965 (H. Suda). Kanagawa: \&, Mikumitoge, 1100m, Yamakita, 24. viii. 2000 (H. Nagase). Niigata: ô, Kawakura, Sado Is., 14. vii. 1933 (K. Baba, ELKU); 우, Mt. Monnai, N-Echigo, 3. viii. 1965 (K. Baba, ELKU); 우, Kanamaru, N-Echigo, 4. vi. 1977 (K. Baba, ELKU); ㅇ, same locality, 20. v. 1980 (K. Baba, ELKU). Ishikawa: đ̃, Monzen-machi, 17. vii. 1979 (I. Togashi, ELKU). Fukui: †, Mt. Hino, 18. viii. 1973 (T. Tano); , Tsuchiuchi, Ohno, 25. v. 1976 (Y. Haneda); q, Rokuroshi, Ohno, 11. viii. 1976 (Y. Haneda); , same locality, 8. v. 1986 (Y. Haneda); ふૈ, Mt. Hozukiyama, Rokuroshi, Ohno, 29. vii. 1995 (Y. Haneda). Yamanashi: $q$, Mt. Amarisan, Nirasaki City, 13. ix. 1972 (H. Suda); ô, Mt. Minobusan, Minamikoma Dist., 11. viii. 1977 (Y. T. \& H. Suda). Nagano: q, Iizuna-kogen, 8. v. 1961 (T. Kitamura, EBSU); , Minamiminowa, Ina, 11. vi. 1961 (Y. Maeta, EBSU); 2ð, Yokoyama, Ina, 12. ix. 1961 (Y. Maeta, EBSU); q, Habiro, Ina, 7. ix. 1962 (Y. Maeta, EBSU); , Minamiminowa, Ina, 28. vii. 1962 (Y. Maeta, EBSU); ㅇ, Miyada-Kougen, Miyada Village, 4. viii. 1980 (Y. T. \& H. Suda); , Mt. Nyugasa, Ina, 17. vii. 1962 (Y. Maeta, EBSU); +, Mt. Yatsugatake, 20. vi. 1962 (Y. Maeta, EBSU). Gifu: + , Shiratori, Korigami town, 14. v. 2004 (T. Sugimoto, K. Mitai's coll.). Shimane: + , Mt. Sanbe, 31. v. 1992 (Y. Maeta, EBSU). Hiroshima: đ̃, Degoyama (Aki), 30. vii. 1953 (S. Taniguti, ELKU). [Kyushu] Fukuoka: 5 , Inugatake (Buzen), 14. vii. 1938 (Hori, Kawahara \& Yasumatsu, ELKU); +, Mt. Sangun, Fukuoka, 13. vii. 1959 (Y. Maeta, ELKU).

Biology. The flight period is from early May to late September in female, and from early July to early October in male. Maeta et al. (1996) reported Lasioglossum sakagamii Ebmer, 1978 is a host, based an identification of Sphecodes adults reared from brood cells of $L$. sakagamii, although we were not able to examined the specimens.

Remarks. Blüthgen (1923) synonymized S. nippon with S. gibbus, and Warncke (1994) followed Blüthgen's view. Tsuneki (1983) gave no comment about the status of S. nippon in his redescription. Our examination revealed that $S$. nippon is distinctly different from $S$. gibbus in the following characters: the pygidial plate narrower, the maximum width is 0.7 times as wide as width of FL3; the apical portion of gonostylus is much widely expanded.

\section{Sphecodes nipponicus Yasumatsu et Hirashima, 1951}

[Japanese name: Yamato-yadori-kohanabachi] (Figs. 23-24, Table 3)

Sphecodes nipponicus Yasumatsu et Hirashima, 1951, Ins.
Mats. , 7: 122-124 [Holotype: Male. Type locality: Ishidozawa, Provinz Shinano, Honshu, Japan]; Tsuneki, 1983, Spec. Publ. Jap. Hymenopt. Assoc. (26): 20-21 [redescription].

Sphecodes iwatensis Tsuneki, 1983, Spec. Publ. Jap. Hymenopt. Assoc., (26): 25 [Holotype: Female. Type locality: Takinoue, Iwate Pref., Honshu, Japan]. Syn. Nov.

Sphecodes kisukei Tsuneki, 1983, Spec. Publ. Jap. Hymenopt. Assoc., (26): 24 [Holotype: Female. Type locality: Koike, Fukui Pref., Honshu, Japan]. Syn. Nov.

Sphecodes itidyo Tsuneki, 1983, Spec. Publ. Jap. Hymenopt. Assoc., (26): 23 [Holotype: Female. Type locality: Taniyama, Fukui Pref., Honshu, Japan]. Syn. Nov.

Sphecodes rikuchu Tsuneki, 1983, Spec. Publ. Jap. Hymenopt. Assoc., (26): 25 [Holotype: Female. Type locality: Takinoue, foot of Mt. Hachimantai, Iwate Pref., Honshu, Japan]. Syn. Nov.

\section{Redescription.}

\section{Female.}

Color: Head and mesosoma black except apex of mandible slightly tinged with red. T1-2 dark red. S1-2 darker red than T1-2. Leg nearly wholly black or somewhat paler.

Sculpture: Clypeus without median furrow; punctures large, irregularly spaced, at most a puncture diameter apart; apical margin of clypeus curved downward, and punctate continuous. Supraclypeal area punctate slightly more densely clypeus. Frons punctate-reticulate, or areolate until vertex. Vertex around preoccipital carina and genal area coarsely rugose, partially coarsely areolate; outer orbit of compound eye furrowed. Scutum with large, deep, irregularly spaced punctures, which are separated generally by up to two puncture diameters apart, or much denser in places to appear punctate-reticulate. Scutellum punctate as scutum, tending to more densely posteriorly. Mesepisternum areolate moderately. T1-2 polished, T3-6 faintly coriarious. T1 with apical half scattered, small distinct punctures intermixed with much smaller punctules; narrow apical rim impunctate. T2-4 punctate as T1, apical depressed areas impunctate. T5 punctate much densely. Pygidial plate rounded or slightly truncate at apex, wide as width of FL3; surface shagreen, matt, usually flat, sometimes weakly turned upward peripherally.

Vestiture: Vestiture on body generally brown to dark brown; that on face sparse, composed of relatively hard, simple hairs.

Structure: Body length 8.5-11 mm. Head about 
0.75-0.8 times as long as wide. Labrum about 0.6-0.7 times as long as wide with roughly triangular convexity immediate below basal elevation; apex usually widely triangularly emarginate, degree of emargination variable, sometimes apical margin truncate. interantennal elevation roundly highly raised; median carina gradually fading out apically. Vertex behind lateral ocelli well developed upward beyond lateral ocelli in frontal view. Genal area much narrower than compound eye in lateral view, about
0.5 times as wide as compound eye. Exposed portion of pedicel slightly longer than FL1. Relatively length of FL1 $: 2: 3=1.0: 1.3: 2.0$, and F1 0.6 times as long as width, FL2 0.7 times, FL3 equal to width, and remaining segment about equal to width. FL1 and FL2 basally densely shagreen, matt. Undersides of FL2 apically and the following segments slightly shiny. Collar sharply angulate between frontal and lateral sides. Pronotum with lateral ridge highly raised and produced anteriorly beyond

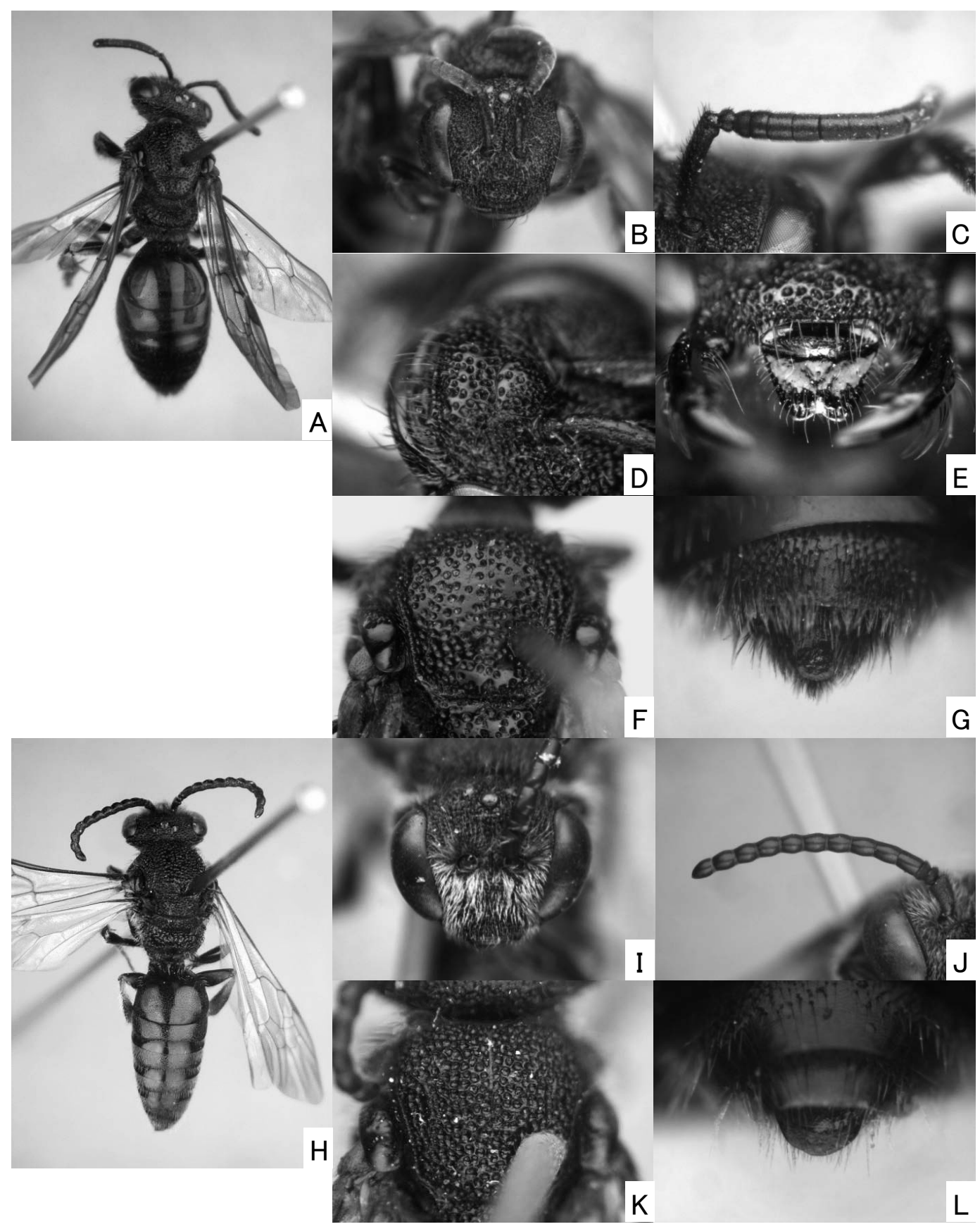

Fig. 23. Sphecodes nipponicus Yasumatsu et Hirashima. Female: A-G. Male: H-L. A, H: habitus, dorsal view. B, I: head. C, I: antenna. D: clypeus. E: labrum. F, K: scutellum. G, L: pygidial plate. 

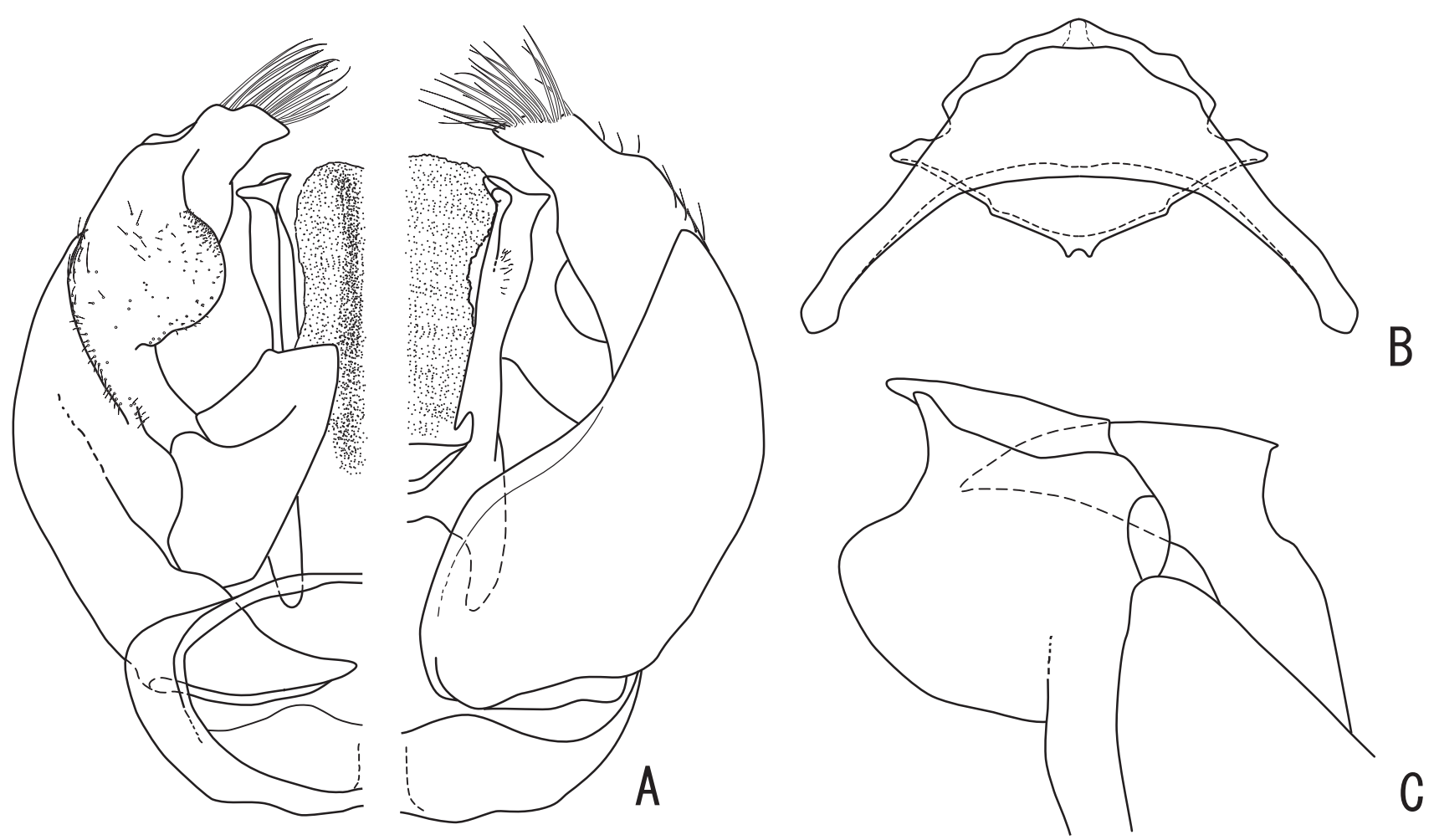

Fig. 24. Sphecodes nipponicus Yasumatsu et Hirashima, male. A: genital capsule (left, ventral view; right, dorsal view). B: 7th and 8th metasomal sterna, ventral view. C: gonostylus, lateral view (vestiture omitted).

anterolateral margin of pronotum. Scutellum flat. Hind femora moderate in breadth, relative breadth to length of hind femur about 0.35. Apical process of hind tibia oblong. Hook on hind wing 10-11 in number.

\section{Male.}

Color: Body black except the following: mandible apically dark red; antennae dark brown to black; T2 tinged with dark red narrowly basally. Fore tibiae yellowish beneath.

Sculpture: Clypeus deeply punctate-reticulate with faintly median furrow; apical margin punctate so continuously to appear transversely furrowed. Scutum, scutellum, and mesepisternum punctate much more densely than those of female, partially irregularly and coarsely rugose. T1-2 polished, T3-6 faintly coriarious. T1 with moderately punctures without intermixed punctules; punctures generally two to three puncture diameters apart, but wider in some places. T2 punctate as T1 with apical depressed impunctate area. T3 with much smaller punctures and apical impunctate area. T4-6 only with fine setigerous punctules. T7 widely produced posteriorly with apical margin obtuse-angled.

Vestiture: Vestiture on face golden in color, rather dense [much sparser on clypeus], densely plumose and largely appressed, not concealing integument, but obscuring that to some extent.

Structure: Body length 6.5-9 mm. Head about 0.800.83 times as long as wide. Genal area much narrower than compound eye in lateral view, about 0.4 times as wide as compound eye. Exposed portion of pedicel as long as FL1. Relative length of FL1 : $2: 3=1.0: 2.7-3.0$ : 2.8-3.0. FL1 0.4-0.5 times as long as width, FL2 1.5-1.7 times, FL3 1.4-1.6 times, and remaining segments longer than width. Each segment after FL2 swollen medially. Undersides of FL3 and the following segments with velvet-like areas. Velvet-like areas on FL3 and FL4 inconspicuous, confined to basal narrow margin of segments; those on the following segments somewhat distinct, narrow, band-shaped, reaching basomedial one-fifth of each segments. Hind femora slender, relative breadth to length of hind femur about 0.30 . Apical process of hind tibia shortly rounded. Hook on hind wing 8 in number. Disc of S7 roughly oblong with posterior margin weakly produced. S8 with posterior margin weakly produced; lateral margin deeply wavy; anterior margin widely produced anteriorly, apex bifid. Gonocoxite weakly striate laterally, obliterated medially, without dorsal depression. Gonostylus with anterior half flat or shallowly concave, 
Table 3. Seasonal change in number of the captured individuals of S. nipponicus in Japan (E: early, M: mid, L: late).

\begin{tabular}{|c|c|c|c|c|c|c|c|c|c|c|c|c|c|c|c|c|c|c|c|c|c|c|c|c|c|}
\hline \multirow{2}{*}{ Main Island } & \multirow{2}{*}{ Prefecture } & \multicolumn{3}{|c|}{ April } & \multicolumn{3}{|c|}{ May } & \multicolumn{3}{|c|}{ June } & \multicolumn{3}{|c|}{ July } & \multicolumn{3}{|c|}{ August } & \multicolumn{3}{|c|}{ September } & \multicolumn{3}{|c|}{ October } & \multicolumn{3}{|c|}{ November } \\
\hline & & E & M & $\mathrm{L}$ & E & M & $\mathrm{L}$ & $\mathrm{E}$ & $\mathrm{M}$ & $\mathrm{L}$ & E & M & $\mathrm{L}$ & E & M & $\mathrm{L}$ & $\mathrm{E}$ & M & $\mathrm{L}$ & E & M & $\mathrm{L}$ & & M & $\mathrm{L}$ \\
\hline \multicolumn{26}{|l|}{ FEMALE } \\
\hline Hokkaido & & & & & & & & 1 & & 2 & 1 & 7 & 8 & 2 & 4 & & 2 & 1 & & 1 & & & & & \\
\hline $\begin{array}{l}\text { Honshu } \\
\text { [Tohoku] }\end{array}$ & $\begin{array}{l}\text { Aomori } \\
\text { Iwate } \\
\text { Miyagi } \\
\text { Fukushima }\end{array}$ & & & & & & & 1 & $\begin{array}{l}1 \\
1 \\
1\end{array}$ & $\begin{array}{c}3 \\
13\end{array}$ & $\begin{array}{l}6 \\
4 \\
9\end{array}$ & $\begin{array}{c}3 \\
1 \\
15\end{array}$ & $\begin{array}{l}4 \\
3 \\
6\end{array}$ & & & 4 & $\begin{array}{l}2 \\
1 \\
6\end{array}$ & $\begin{array}{l}4 \\
5 \\
6\end{array}$ & $\begin{array}{l}1 \\
7 \\
1\end{array}$ & $\begin{array}{l}5 \\
1\end{array}$ & & & & & \\
\hline [Kanto] & $\begin{array}{l}\text { Ibaraki } \\
\text { Tochigi } \\
\text { Gumma } \\
\text { Saitama } \\
\text { Chiba } \\
\text { Tokyo } \\
\text { Kanagawa }\end{array}$ & & 1 & & 1 & 5 & $\begin{array}{c}5 \\
1 \\
18 \\
6\end{array}$ & $\begin{array}{l}6 \\
9 \\
1\end{array}$ & $\begin{array}{c}1 \\
1 \\
7 \\
7 \\
11\end{array}$ & $\begin{array}{l}5 \\
2\end{array}$ & $\begin{array}{l}1 \\
2\end{array}$ & $\begin{array}{l}1 \\
1 \\
1\end{array}$ & $\begin{array}{l}2 \\
1\end{array}$ & $\begin{array}{l}6 \\
1\end{array}$ & $\begin{array}{l}1 \\
4 \\
2\end{array}$ & $\begin{array}{l}1 \\
1 \\
4\end{array}$ & $\begin{array}{l}1 \\
4 \\
3\end{array}$ & $\begin{array}{l}1 \\
4 \\
3\end{array}$ & $\begin{array}{l}1 \\
1 \\
3\end{array}$ & & & & & & \\
\hline [Chubu] & $\begin{array}{l}\text { Niigata } \\
\text { Fukui } \\
\text { Yamanashi } \\
\text { Nagano } \\
\text { Gifu } \\
\end{array}$ & & & & 1 & 1 & & 1 & $\begin{array}{l}1 \\
2 \\
2\end{array}$ & $\begin{array}{l}3 \\
1\end{array}$ & 1 & $\begin{array}{l}2 \\
1\end{array}$ & $\begin{array}{l}1 \\
2\end{array}$ & $\begin{array}{l}1 \\
2\end{array}$ & $\begin{array}{l}1 \\
1 \\
1 \\
\end{array}$ & $\begin{array}{l}1 \\
1\end{array}$ & $\begin{array}{l}2 \\
1\end{array}$ & & $\begin{array}{l}1 \\
1\end{array}$ & $\begin{array}{l}1 \\
1\end{array}$ & & & & & \\
\hline [Kinki] & $\begin{array}{l}\text { Kyoto } \\
\text { Hyogo }\end{array}$ & & & & & & & $\begin{array}{l}1 \\
1 \\
\end{array}$ & & & & 1 & & & & 1 & & & & & & & & & \\
\hline [Chugoku] & $\begin{array}{l}\text { Shimane } \\
\text { Hiroshima }\end{array}$ & 1 & & & & & & $\begin{array}{l}1 \\
1\end{array}$ & & & 1 & & 1 & & & 5 & & & & 1 & & & & & \\
\hline Shikoku & Ehime & & & & & & & & & & 1 & & & & & 1 & & & & & & & & & \\
\hline Kyushu & $\begin{array}{l}\text { Fukuoka } \\
\text { Kagoshima }\end{array}$ & & & & 1 & & & 1 & 1 & & & & 1 & 1 & & & 1 & & 1 & & & & 1 & & \\
\hline \multicolumn{26}{|l|}{ MALE } \\
\hline Hokkaido & & & & & & & & & & & 1 & & & & & 1 & & 1 & 2 & & & & & & \\
\hline $\begin{array}{l}\text { Honshu } \\
\text { [Tohoku] }\end{array}$ & $\begin{array}{l}\text { Aomori } \\
\text { Iwate } \\
\text { Miyagi }\end{array}$ & & & & & & & & & & 6 & & 2 & 1 & $\begin{array}{l}2 \\
1 \\
\end{array}$ & $\begin{array}{c}4 \\
12 \\
21 \\
\end{array}$ & $\begin{array}{c}2 \\
11 \\
28 \\
\end{array}$ & $\begin{array}{c}7 \\
15 \\
14 \\
\end{array}$ & $\begin{array}{c}3 \\
12 \\
9 \\
\end{array}$ & 8 & 1 & & & & \\
\hline [Kanto] & $\begin{array}{l}\text { Ibaraki } \\
\text { Tochigi } \\
\text { Saitama } \\
\text { Chiba } \\
\text { Kanagawa }\end{array}$ & & & & & & & & & & & $\begin{array}{l}1 \\
2\end{array}$ & $\begin{array}{l}7 \\
2\end{array}$ & $\begin{array}{c}13 \\
6\end{array}$ & $\begin{array}{l}1 \\
4 \\
3\end{array}$ & $\begin{array}{l}3 \\
6\end{array}$ & $\begin{array}{l}8 \\
9 \\
3\end{array}$ & $\begin{array}{c}20 \\
2\end{array}$ & $\begin{array}{l}6 \\
1 \\
1\end{array}$ & $\begin{array}{l}5 \\
1 \\
1 \\
1\end{array}$ & & 1 & 1 & & \\
\hline [Chubu] & $\begin{array}{l}\text { Fukui } \\
\text { Yamanashi } \\
\text { Nagano } \\
\text { Gifu }\end{array}$ & & & & & & & & & & & & 1 & & & $\begin{array}{l}4 \\
2\end{array}$ & $\begin{array}{l}9 \\
1\end{array}$ & $\begin{array}{c}1 \\
1 \\
11 \\
2 \\
\end{array}$ & $\begin{array}{l}5 \\
2\end{array}$ & & & & & & \\
\hline [Chugoku] & $\begin{array}{l}\text { Tottori } \\
\text { Shimane }\end{array}$ & & & & & & & & & & & & & & 1 & 10 & & 4 & 1 & & & & & & \\
\hline Kyushu & $\begin{array}{l}\text { Nagasaki } \\
\text { Kumamoto } \\
\text { Kagoshima }\end{array}$ & & & & & & & & & & & & & 1 & 2 & 1 & $\begin{array}{l}1 \\
1\end{array}$ & & $\begin{array}{l}1 \\
4 \\
5 \\
\end{array}$ & & & & & & \\
\hline Nansei Is. & Okinawa & & & & & & & & & & & 1 & & & & & & & & & & & & & \\
\hline Total: female & & 1 & 1 & 0 & 3 & 7 & 30 & 33 & 29 & 29 & 45 & 33 & 30 & 13 & 14 & 21 & 23 & $\begin{array}{l}24 \\
78\end{array}$ & $\begin{array}{l}17 \\
51\end{array}$ & 10 & 0 & 0 & 1 & 0 & 0 \\
\hline $\begin{array}{l}\text { Total: male } \\
\text { Total }\end{array}$ & & $\begin{array}{l}0 \\
1\end{array}$ & $\begin{array}{l}0 \\
1\end{array}$ & $\begin{array}{l}0 \\
0\end{array}$ & $\begin{array}{l}0 \\
3\end{array}$ & $\frac{0}{7}$ & $\begin{array}{c}0 \\
30\end{array}$ & $\frac{0}{33}$ & $\begin{array}{c}0 \\
29\end{array}$ & $\begin{array}{c}0 \\
29\end{array}$ & $\frac{7}{52}$ & $\begin{array}{c}4 \\
37\end{array}$ & $\frac{12}{42}$ & $\frac{21}{34}$ & $\frac{14}{28}$ & \begin{tabular}{l|}
64 \\
85
\end{tabular} & $\begin{array}{l}73 \\
96\end{array}$ & $\begin{array}{c}78 \\
102\end{array}$ & $\begin{array}{l}51 \\
68\end{array}$ & $\frac{15}{25}$ & $\begin{array}{l}1 \\
1\end{array}$ & $\frac{1}{1}$ & $\frac{1}{2}$ & $\begin{array}{l}0 \\
0\end{array}$ & $\frac{0}{0}$ \\
\hline
\end{tabular}

sharply carinate between dorsal and ventral surfaces; dorsal margin fringed with long setae; inner basal surface without setae; basoventral lobe rounded ridge-shaped, then being sharply carinate obliquely upwards with loose row of setae which are longer upwards.

Distribution. JAPAN [Hokkaido, Honshu, Shikoku, Kyushu, Okinawa-Honto].

Specimens examined. Holotype [ELKU], male with three labels as follows: "ISHIDOSAWA [only "SAWA" in Japanese]/IX-16. 1931 [cellophane with typed letters]", "Ishido-sawa/ Shinano/ IX-16. 1934/ S. Miyamoto [white rectangle with handwritten letters]", "Holotype/ Sphecodes/ nipponicus/ Yasum. et Hiras./ 1951 [red rectangle with handwritten letters]".

Other specimens: We have examined nearly 400 individuals in each sex. The localities and phenology are 
shown in Table 3.

Biology. The flight period is from early May to late September in female, from early July to early October in male.

Remarks. This is one of the commonest species in Japan, and is similar to $S$. scabricollis which is also common in Japan. Both sexes of S. nipponicus can be separated from the latter by the gradually ventrally ending median carina on face, and the much coarser punctures on the face, scutum, scutellum and terga. In addition, the wholly black abdomen will easily separate the male of this species from that of $S$. scabricollis.

\section{Sphecodes ohdeyamanus Tsuneki, 1984}

[Japanese name: Ohde-yadori-kohanabachi] (Fig. 25)

Sphecodes ohdeyamanus Tsuneki, 1983, Spec. Publ. Jap. Hymenopt. Assoc., (30): 9 [Holotype: Female. Type locality: Mt. Ohdeyama, Yamanakako, Yamanashi Pref., Honshu, Japan].
Redescription.

Female.

Color: Head and mesosoma black except the following: labrum blackish brown; mandibles brown with apical one-thirds reddish; flagellar segments blackish brown beneath, slightly paler apically. T1-2, and T3 basally red, often $\mathrm{T} 1$ darkened basally. In some specimens terga wholly darker. Sterna colored similar to terga. Legs blackish brown with tarsi much paler apically.

Sculpture: Clypeus with faint median furrow, punctures shallow and sparse, two or more puncture diameter apart medially; apical margin of clypeus punctate so continuously to appear transversely furrowed. Supraclypeal area slightly denser than clypeus. Frons moderately punctate; punctures generally a puncture diameter apart, sparser laterally and around ocelli, where punctures about two puncture diameters apart. Vertex near preoccipital ridge and genal area sparsely and finely costate. Scutum and scutellum scattered with small to moderate sized punctures. Mesepisternum areolate moderately. T1-4 shiny with scattered, fine punctules basally; punctules on T2 and T3 much denser than those on T1. Pygidial plate 1.3 times as wide as width of FL3; surface usually shiny, flat or slightly convex medially.

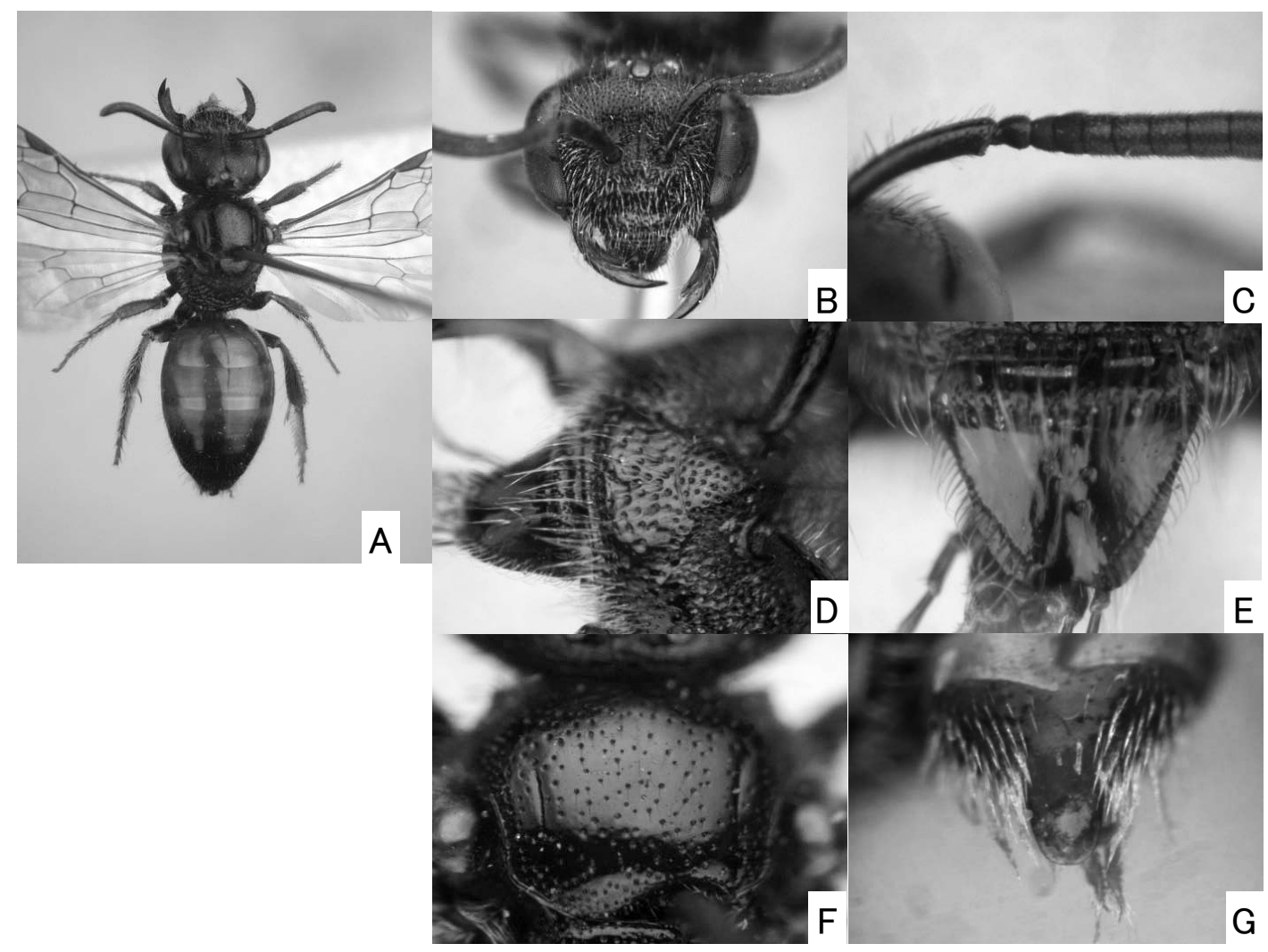

Fig. 25. Sphecodes ohdeyamanus Tsuneki, female. A: habitus, dorsal view. B: head. C: antenna. D: clypeus. E: labrum. F: scutellum. G: pygidial plate. 
Vestiture: Vestiture on face slightly yellowish, short, sparse, not densely plumose.

Structure: Body length 5.5-8 mm. Head about 0.75 times as long as wide. Labrum about 0.7 times as long as wide; apical margin varying from triangularly emarginate to truncate. Vertex behind lateral ocelli not developed upward beyond lateral ocelli in frontal view. Genal area much narrower than compound eye in lateral view, about 0.6 times as wide as compound eye. Exposed portion of pedicel about 1.5 times as long as FL1. Relatively length of FL1 $: 2: 3=1.0: 1.0: 1.2$, and F1 0.7 times as long as width, FL2 0.5 times, FL3 0.7 times, and remaining segment gradually longer, becoming nearly equal to width at second last segment. FL1 and FL2 densely shagreen, matt. Undersides of FL3 and the following segments slightly shiny. Collar distinctly angulate between frontal and lateral sides. Pronotum with lateral ridge lowly, sharply or roundly raised. Scutellum flat. Hind femora robust, relative breadth to length of hind femur about 0.4 . Apical process of hind tibia triangular, moderately long. Hook on hind wing 5 in number.

Male. Unknown.

Distribution. JAPAN [Hokkaido, Honshu].

Specimens examined. Holotype [MNHAH], female with four labels as follows: "Mt. Ohdeyama/ Yamanakako/ Yamanashi Pref./ v-23. 1980/H. Suda. [white rectangle with typed letters]", "6 [white rectangle with handwritten letter]", "Sphecodes/ ohdeyamanus/ Tsuneki o/ HOLOTYPE [red rectangle with handwritten letters]", and "B1-288286 [white rectangle with printed registernumber of MNHAH and a bar-code]".

Other specimens: We have examined about 70 females. Some of them are listed as follows: JAPAN [Hokkaido] q, University Campus, Sapporo, 21. v. 1959 (Sakagami); q, University Campus, Sapporo, 10. v. 1979 (Toda, FFPRI); + , University Campus, Sapporo, 18. vi. 1979 (Toda, FFPRI); ㅇ, same locality, 11. vi. 1959 (Sakagami); +, Hamakoshimizu, 19. vi. 1967, (collector unknown, ELKU); , Nokanan, 11. viii. 1967 (collector unknown, ELKU); ㅇ, same locality, 22. vi. 1967 (T. M., ELKU); ㅇ, Yukomanbetsu, 8. viii. 1967 (S. S., ELKU); ㅇ, Bannaguro, Ishikari, 5. viii. 1968 (T. Nambu); +, Higashikawa, Rumoi, 7. viii. 1968 (T. Nambu, ELKU); 9, Momijiyama, Ishikari, 5. viii. 1968 (T. Nambu); 2ᄋ, Soranuma, 2. x. 1968 (collector unknown, ELKU); + , Tansanshi, Jyozankei, 6. viii. 1968 (T. Nambu); 5ㅇ, Tenneru n. Kushiro, collecting date unknown (E. Ohtsuka, ELKU); , Tsukisappu, 7. v. 1968 (collector unknown, ELKU); 우, same locality, 16. v. 1968 (collector unknown, ELKU); 우, Asahiyama, Asahikawa, 13. v. 1969 (collector unknown, ELKU); + , same locality, 24. ix. 1969 (collector unknown,
ELKU); + , Atsunai, 13. v. 1969 (M. Wakayama); + , same locality, 18. v. 1969 (M. Wakayama); †, Inosawa, Asahikawa, 10. v. 1969 (collector unknown, ELKU); ㅇ, Nopporo, 9. viii. 1971 (H. Fukuda, ELKU), 29, Kamiotoineppu, 15. vi. 1972 (H. Fukuda, ELKU); 29, Moiwa, 23. v. 1972 (Kawano); +, Otarunai, 12. vii. 1973 (H. Fukuda, ELKU); 2q, Usubetsu, 25. v. 1973 (H. Fukuda, ELKU); , same locality, 6. vi. 1973 (H. Fukuda, ELKU); q, Urausu, 30. v. 1974 (H. Fukuda, ELKU); , Obihiro, Inada, 21. vi. 1975 (M. Usui); \&, same locality, 15. vii. 1975 (M. Usui); +, Obihiro, Tokachi, 2. v. 1976 (M. Usui); + , Shihoro, Tokachi, 3. vi. 1976 (M. Usui); 2q, Obihiro, Tokachi, 8. v. 1976 (M. Usui); 2q, same locality, 23. v. 1976 (M. Usui); , Tomakomai, Exp. For., 23. vi. 1978 (H. Fukuda, ELKU); +, Tokachimitsumata, Kamishihoro, 30. vi. 1984 (O. Tadauchi, ELKU). [Honshu] Yamanashi: $q$, Mt. Ohdeyama, Yamanakako Vill. 23. v. 1980 (H. Suda).

Biology. The flight period is from early May to early October. The nearly all specimens examined are from Hokkaido with only one specimen from Honshu. This species is rare, but the females were often collected together with those of the similar-looking species $S$. silvicola. At first, we suspected that $S$. ohdeyamanus might be a variant of $S$. silvicola, but our close examination revealed the below-mentioned, interspecific differences are stable, and they can be recognized as two good species.

Remarks. It is similar to S. silvicola in having the sparse punctate clypeus, scutum, and scutellum, but easily distinguishable from the latter: the labrum is longer, length/width ratio is 0.7 ; the hind femur is robuster, the maximum width/ length ratio is 0.4 .

\section{Sphecodes okuyetsu Tsuneki, 1983}

[Japanese name: Okuetsu-yadori-kohanabachi]

(Fig. 26-27, Table 4)

Sphecodes okuyetsu Tsuneki, 1983, Spec. Publ. Jap. Hymenopt. Assoc., (26): 42 [Holotype: Male. Type locality: Mt. Akausagi, Fukui Pref., Honshu, Japan].

Sphecodes duplipunctatus Tsuneki, 1983, Spec. Publ. Jap. Hymenopt. Assoc., (26): 39 [Holotype: Male. Type locality: Mt. Akausagi, Fukui Pref., Honshu, Japan]. Syn. Nov.

Sphecodes etizenensis Tsuneki, 1983, Spec. Publ. Jap. Hymenopt. Assoc., (26): 61 [Holotype: Female. Type locality: Sandyuhassha, Fukui City, Fukui Pref., Honshu, Japan], synonymized by Tsuneki, 1984: 3.

Sphecodes hasshanus Tsuneki, 1983, Spec. Publ. Jap. Hymenopt. Assoc., (26): 59 [Holotype: Female. Type locality: Sandyuhassha, Fukui City, Fukui Pref., 
Honshu, Japan]. Syn. Nov.

Sphecodes sapporoensis Tsuneki, 1983, Spec. Publ. Jap. Hymenopt. Assoc., (26):63 [Holotype: Female. Type locality: Maruyama Hills, Sapporo, Hokkaido, Japan]. Syn. Nov.

Sphecodes breviclypeatus Tsuneki, 1983, Spec. Publ. Jap. Hymenopt. Assoc., (30): 7 [Holotype: Female. Type locality: Mitomi Village, Nishizawa, Yamanashi Pref., Honshu, Japan]. Syn. Nov.
Sphecodes maetai (female): Tsuneki, 1983, Spec. Publ. Jap. Hymenopt. Assoc., (30): 3. [description of female].

Redescription.

Female.

Color: Head and mesosoma black except mandible paler medially with red apex. T1-2 and T3 basally red. S1 and $\mathrm{S} 2$ red. Femora and tibiae black, tarsi blackish brown.

Sculpture: Clypeus without median furrow, punctures

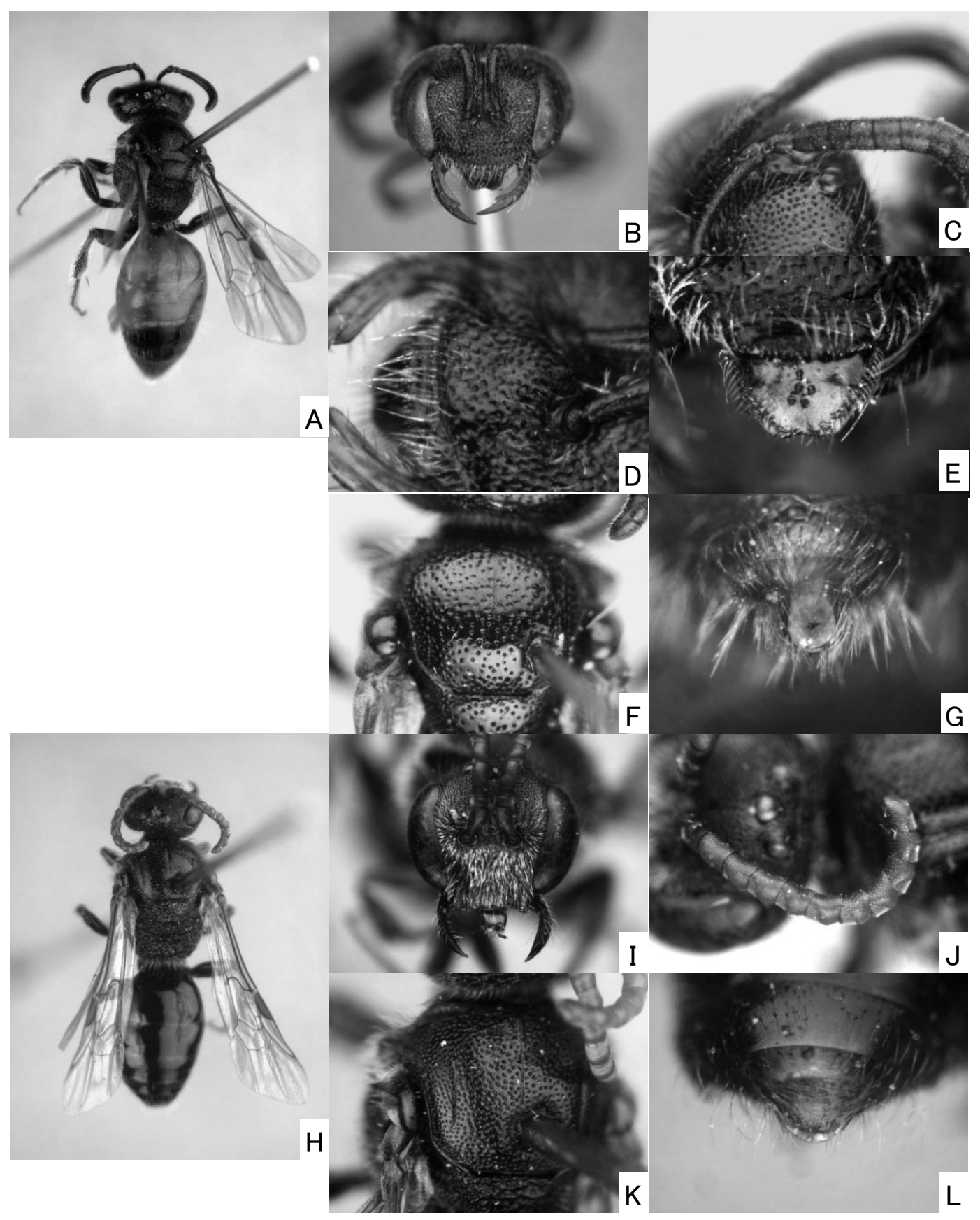

Fig. 26. Sphecodes okuyetsu Tsuneki. Female: A-G. Male: H-L. A, H: habitus, dorsal view. B, I: head. C, I: antenna. D: clypeus. E: labrum. F, K: scutellum. G, L: pygidial plate. 

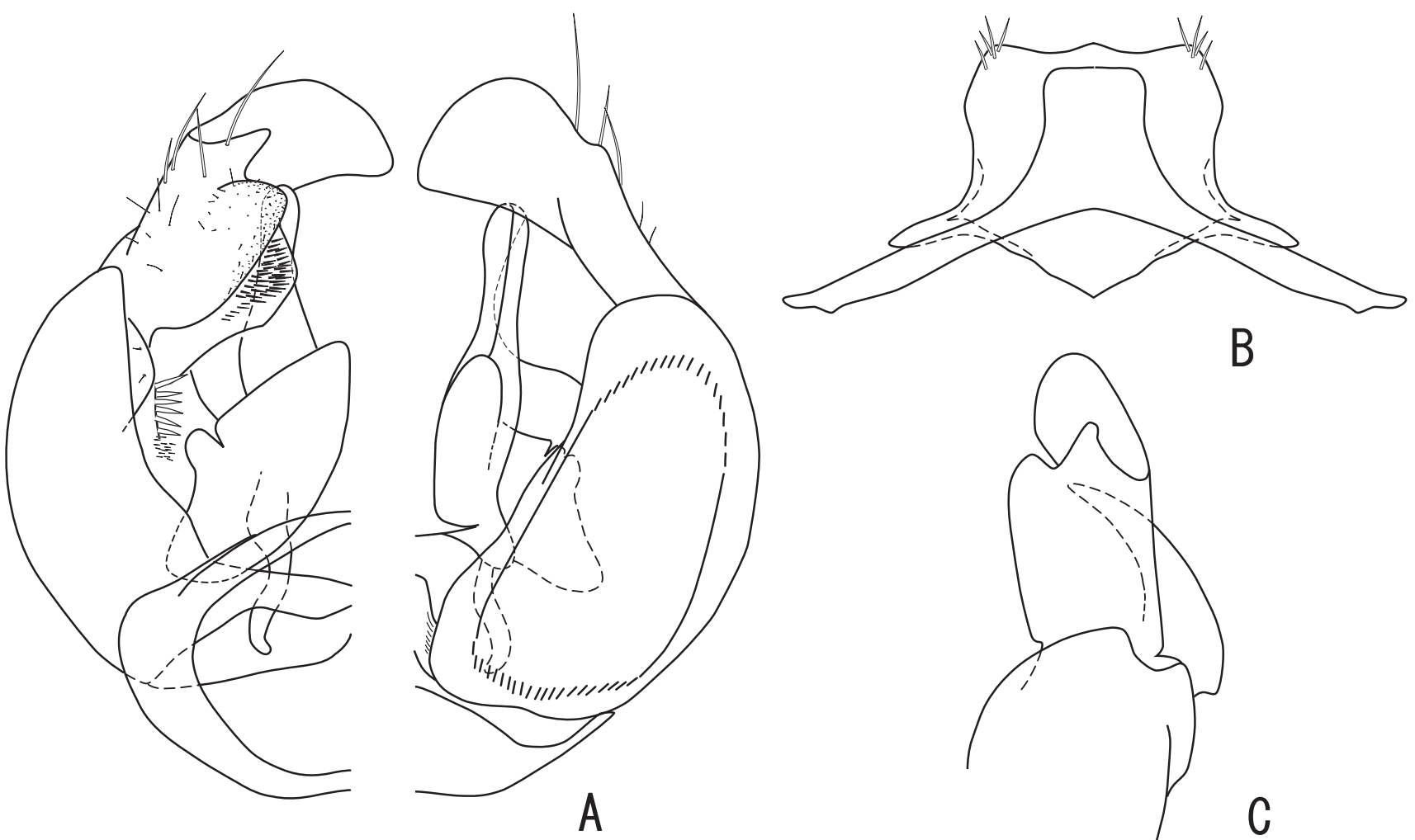

Fig. 27. Sphecodes okuyetsu Tsuneki, male. A: genital capsule (left, ventral view; right, dorsal view). B: 7th and 8th metasomal sterna, ventral view. C: gonostylus, lateral view (vestiture omitted).

dense, generally less a puncture diameter apart; apical margin of clypeus punctate so continuously to appear to be transversely furrowed. Supraclypeal area punctate as or slightly denser than clypeus. Frons moderately punctate, punctures at most two puncture diameters apart, sparser laterally and around ocelli. Vertex near preoccipital ridge and genal area sparsely and finely costate. Scutum and scutellum scattered with moderate sized punctures, much denser on posterior margin of scutellum. Mesepisternum areolate moderately. T1-4 shiny with scattered, fine punctules basally; punctures especially sparse, virtually impunctate on T1, slightly denser on T2-4. Pygidial plate 1.2 times as wide as width of FL3, surface usually shiny, flat or slightly convex medially.

Vestiture: Vestiture on face slightly yellowish, short, sparse, not densely plumose.

Structure: Body length 5-8 mm, usually 5-7 mm. Head about 0.75 times as long as wide. Labrum about 0.6-0.7 times as long as wide with wide median furrow; apex usually triangularly emarginate. Interantennal elevation moderately raised. Vertex behind lateral ocelli not developed upward beyond lateral ocelli in frontal view. Genal area narrower than compound eye in lateral view, about 0.6-0.7 times as wide as compound eye. Exposed portion of pedicel about 1.5 times as long as FL1. Relatively length of FL1 $: 2: 3=1.0: 1.2: 1.2$, and each 0.7 times as long as each width, and remaining segment shorter than width. FL1-3 densely shagreen, matt. Undersides of FL4 and the following segments slightly shiny. Collar gently curved between frontal and lateral sides. Pronotum with lateral ridge indistinct, at most lowly raised. Scutellum flat. Hind femora moderate in breadth, relative breadth to length of hind femur about 0.35 . Apical process of hind tibia rounded, variable from short to moderately long. Hook on hind wing 5 in number. Usually 1st recurrent vein interstitial with 1 st transverse cubital, or sometimes slightly basad of that.

Male.

Color: Body black except the following: mandible dark yellowish or red apically; terga and sterna usually black, in some specimens T1-3 tinged with dark red narrowly on apical margins. Femora black, tibiae slightly brown, tarsi yellowish brown.

Sculpture: Clypeus shallowly punctate-reticulate without median furrow. Supraclypeal area as clypeus. Frons shallowly areolate. Vertex bear preoccipital ridge and genal area costate. Scutum with shallow punctures; punctures subobsolete in places, denser on anterior 
Table 4. Seasonal change in number of the captured individuals of S. okuyetsu in Japan (E: early, M: mid, L: late).

\begin{tabular}{|c|c|c|c|c|c|c|c|c|c|c|c|c|c|c|c|c|c|c|c|c|c|c|c|c|c|}
\hline \multirow{2}{*}{ Main Island } & \multirow{2}{*}{ Prefecture } & \multicolumn{3}{|c|}{ March } & \multicolumn{3}{|c|}{ April } & \multicolumn{3}{|c|}{ May } & \multicolumn{3}{|c|}{ June } & \multicolumn{3}{|c|}{ July } & \multicolumn{3}{|c|}{ August } & \multicolumn{3}{|c|}{ September } & \multicolumn{3}{|c|}{ October } \\
\hline & & $\mathrm{E}$ & M & $\mathrm{L}$ & $\mathrm{E}$ & $M$ & $\mathrm{~L}$ & E & $\mathrm{M}$ & $\mathrm{L}$ & $E$ & $\mathrm{M}$ & $\mathrm{L}$ & $\mathrm{E}$ & $\mathrm{M}$ & $\mathrm{L}$ & $\mathrm{E}$ & $\mathrm{M}$ & $\mathrm{L}$ & $\mathrm{E}$ & $\mathrm{M}$ & $\mathrm{L}$ & $\mathrm{E}$ & $M$ & L \\
\hline \multicolumn{26}{|l|}{ FEMALE } \\
\hline Hokkaido & & & & & & & & 1 & 7 & 18 & 20 & 2 & 8 & 10 & 2 & 3 & 1 & 1 & & & & & & & \\
\hline $\begin{array}{l}\text { Honshu } \\
\text { [Tohoku] }\end{array}$ & $\begin{array}{l}\text { Aomori } \\
\text { Iwate } \\
\text { Miyagi } \\
\text { Fukushima }\end{array}$ & & & & & & & 1 & $\begin{array}{l}3 \\
1 \\
1\end{array}$ & $\begin{array}{l}8 \\
1\end{array}$ & $\begin{array}{l}1 \\
5\end{array}$ & $\begin{array}{l}6 \\
4\end{array}$ & $\begin{array}{l}1 \\
5\end{array}$ & $\begin{array}{l}1 \\
3\end{array}$ & $\begin{array}{l}1 \\
2\end{array}$ & 2 & & 1 & & & & & & 1 & \\
\hline [Kanto] & $\begin{array}{l}\text { Tochigi } \\
\text { Gumma } \\
\text { Saitama } \\
\text { Chiba } \\
\text { Tokyo } \\
\text { Kanagawa }\end{array}$ & & & & 2 & $\begin{array}{l}1 \\
4 \\
1 \\
6\end{array}$ & $\begin{array}{l}14 \\
13 \\
1 \\
2\end{array}$ & $\begin{array}{l}4 \\
4 \\
8\end{array}$ & $\begin{array}{l}4 \\
1 \\
4 \\
2 \\
1\end{array}$ & $\begin{array}{l} \\
9\end{array}$ & $\begin{array}{l}1 \\
4\end{array}$ & $\begin{array}{l}1 \\
1 \\
1\end{array}$ & 1 & 1 & & 1 & & & 1 & & 2 & & & & \\
\hline [Chubu] & $\begin{array}{l}\text { Niigata } \\
\text { Fukui } \\
\text { Yamanashi } \\
\text { Nagano }\end{array}$ & & & & & 1 & 3 & $\begin{array}{l}1 \\
6 \\
4\end{array}$ & $\begin{array}{c}14 \\
1 \\
1\end{array}$ & $\begin{array}{l}3 \\
1 \\
9 \\
1\end{array}$ & $\begin{array}{l}1 \\
1\end{array}$ & 1 & & & $\begin{array}{l}1 \\
2 \\
1\end{array}$ & & & & & & & & & & \\
\hline [Kinki] & $\begin{array}{l}\text { Kyoto } \\
\text { Osaka } \\
\text { Hyogo } \\
\text { Nara }\end{array}$ & & & & & 1 & 1 & & 2 & & & & & & & 1 & & & & & & & & & \\
\hline [Chugoku] & $\begin{array}{l}\text { Tottori } \\
\text { Shimane } \\
\text { Hiroshima } \\
\text { Yamaguchi }\end{array}$ & & & & & $\begin{array}{l}6 \\
2\end{array}$ & $\begin{array}{l}2 \\
1\end{array}$ & 1 & 1 & & & & & & & & & & & & & & & & \\
\hline Shikoku & $\begin{array}{l}\text { Tokushima } \\
\text { Ehime } \\
\text { Kochi }\end{array}$ & & & & & $\begin{array}{l}4 \\
5 \\
1\end{array}$ & & 1 & 1 & & & & & & & 1 & & & & & & & & & \\
\hline Kyushu & $\begin{array}{l}\text { Fukuoka } \\
\text { Saga } \\
\text { Kumamoto } \\
\text { Oita } \\
\text { Miyazaki } \\
\text { Kagoshima }\end{array}$ & 1 & & 30 & $\begin{array}{l}17 \\
1 \\
1\end{array}$ & $\begin{array}{l}4 \\
\\
1 \\
1 \\
1\end{array}$ & $\begin{array}{l}1 \\
3 \\
1\end{array}$ & 1 & 1 & 1 & & & & & 1 & & & & & & & & & & \\
\hline \multicolumn{26}{|l|}{ MALE } \\
\hline Hokkaido & & & & & & & & & & & & & & & & & & & & 6 & 1 & 4 & & & \\
\hline $\begin{array}{l}\text { Honshu } \\
\quad[\text { Kanto] }\end{array}$ & $\begin{array}{l}\text { Tochigi } \\
\text { Kanagawa }\end{array}$ & & & & & & & & & & & & & & & 1 & & & & & 1 & & & & \\
\hline [Chubu] & $\begin{array}{l}\text { Fukui } \\
\text { Gifu }\end{array}$ & & & & & & & & & & & & & & & & & & 1 & 1 & 2 & & 1 & & \\
\hline Shikoku & Ehime & & & & & & & & & & & & & & 2 & & & & & & & & & & \\
\hline Kyushu & Kagoshima & & & & & & & & & 1 & & & & & & & & & & & & & & & \\
\hline Total: female & & 1 & 0 & 30 & 21 & 39 & 42 & 36 & 44 & 53 & 33 & 16 & 15 & 17 & 10 & 9 & 1 & 2 & 1 & 0 & 2 & 0 & 0 & 1 & 0 \\
\hline Total: male & & 0 & 0 & 0 & 0 & 0 & 0 & 0 & 0 & 1 & 0 & 0 & 0 & 0 & 2 & 1 & 0 & 0 & 1 & 7 & 4 & 4 & 1 & 0 & 0 \\
\hline Total & & 1 & 0 & 30 & 21 & 39 & 42 & 36 & 44 & 54 & 33 & 16 & 15 & 17 & 12 & 10 & 1 & 2 & 2 & 7 & 6 & 4 & 1 & 1 & 0 \\
\hline
\end{tabular}

one-third or one-fourth of scutum, but posteriorly sparser, punctures generally up to two puncture diameters apart. Scutellum with punctures much larger than those on scutum, sparse medially, denser on peripheral area, which appear areolate. Mesepisternum areolate moderately. T1 polished wholly with very scattered, fine punctules, virtually impunctate; apical depressed margin not indicated. T2 polished with scattered punctules on T2. T3-6 without punctules on exposed areas. T7 densely shagreen, sparser apically with apical margin not strongly turned upward and well produced.
Vestiture: Vestiture on lower face white, moderately dense, densely plumose and appressed, but short so that integument beneath visible to some extent.

Structure: Body length 5.5-7 mm. Head about 0.830.85 times as long as wide. Genal area narrower than compound eye in lateral view, about 0.5 times as wide as compound eye. Exposed portion of pedicel as long as FL1. Relative length of FL1 : $2: 3=1.0: 2.0: 1.4-1.5$. FL1 0.7 times as long as width, FL2 1.4-1.5 times, FL3 1.0 times, and remaining segments as long as or slightly longer than width. Each segments after FL2 swollen 
medially. Undersides of FL3 and the following segments with velvet-like areas. Velvet-like area on FL3 confined to basal narrow margin of segments; those on the more following segments much wider, developed upwards beyond middle on several apical segments. Hind femora moderate in breadth, relative breadth to length of hind femur about 0.35 . Apical process of hind tibia hardly produced. S7 quadrangular. S8 with posterior margin shallowly or deeply emarginate with small production posterolaterally and medially; posterolateral corner with a few setae; lateral margin moderately or deeply wavy; anterior margin widely produced anteriorly. Gonocoxite striate with wide dorsal depression. Gonostylus with sparse long setae apically; apical portion very long, transparent; basodorsal portion expanded with thick seta on inside; inner basal surface with sparse short setae; dorsal lobe short, strongly curled inwards; basoventral lobe small but distinct, with a few, short setae.

Distribution. JAPAN [Hokkaido, Honshu, Shikoku, Kyushu].

Specimens examined. Holotype [MNHAH], male with three labels as follows: "(JAPAN: FUKUI PR.)/ Mt. Akausagi/ 3. ix. 1978/T. Murota leg. [white rectangle with typed and handwritten letters]", "Sphecodes/ okuyetsu/ Tsuneki $\delta /$ HOLOTYPE [red rectangle with handwritten letters]", "sp7 [small white rectangle with typed letters]", and "B1-288288 [white rectangle with printed registernumber of MNHAH and a bar-code]".

Other specimens: We have examined nearly 400 females and about 20 males. The localities and phenology are shown in Table 4.

Biology. The flight period is from early March to mid October in female with most records from late March to July, and from late May to early October in male with most records in September. Sakagami et al (1985) reported Lasioglossum allodalum as the host of S. okuyetsu.

Remarks. This is a common species, and represented by relatively many records on literature from many localities in Japan. Although, as explained in the section of $S$. coptis, females will be separable from similar species $S$. coptis and $S$. koikensis with some difficulty, the identity in the previous records should be verified.

\section{Sphecodes scabricollis Wesmael, 1885}

[Japanese name: Mizuho-yadori-kohanabachi]

(Fig. 28-29, Table 5)

Sphecodes scabricollis Wesmael, 1865, Ann. Soc. ent. France, (4)5: 429 [Holotype: Male, Belgie].

Sphecodes japonicus Cockerell, 1911, Proc. U.S. Nat. Mus., 39: 638. Syn. Nov.
Sphecodes asakura Tsuneki, 1983, Spec. Publ. Jap. Hymenopt. Assoc., (26): 16 [Holotype: Male. Type locality: Ohno City, Fukui Pref., Japan], synonymized by Tsuneki, 1984: 68.

Sphecodes hatogayuus Tsuneki, 1983, Spec. Publ. Jap. Hymenopt. Assoc., (26): 18 [Holotype: Male. Type locality: Hatogayu, Fukui Pref., Japan], synonymized by Tsuneki, 1983: 69 .

Sphecodes utinamius Tsuneki, 1983, Spec. Publ. Jap. Hymenopt. Assoc., (26): 12 [Holotype: Male. Type locality: Hatogayu, Fukui Pref., Japan]. Syn. Nov.

Sphecodes taicho Tsuneki, 1983, Spec. Publ. Jap. Hymenopt. Assoc., (26): 70 [Holotype: Male. Type locality: Sandyuhassha, Fukui City, Fukui Pref., Japan]. Syn. Nov.

Sphecodes daisi Tsuneki, 1983, Spec. Publ. Jap. Hymenopt. Assoc., (26): 70 [Holotype: Female. Type locality: Sandyuhassha, Fukui City, Fukui Pref., Japan]. Syn. Nov.

\section{Redescription.}

\section{Female.}

Color: Head and mesosoma black except the following: labrum blackish brown, slightly reddened apically, or wholly black; mandible black basally, red apically. T1-2, and $\mathrm{T} 3$ basally red; the extend of red area on Ts variable, sometimes only T1-2 red, or T1-3 wholly red. Legs black, or slightly paler.

Sculpture: Clypeus with faintly furrow medially; punctures coarse and moderately dense, at most a puncture diameter apart; interpunctural surface faintly rugose peripherally. Supraclypeal area punctate generally slightly denser than clypeus, especially at middle of clypeus. Frons and vertex areolate. Vertex near preoccipital ridge and genal area rugose, partially areolate; outer orbit of compound eye furrowed. Scutum with large, irregularly spaced punctures, which are separated by up to four puncture diameters apart; sometimes interpunctural area feebly rugose. Scutellum punctate as scutum, but more densely posteriorly. Mesepisternum areolate moderately, or rugose partially. T1 polished with scattered, fine punctules nearly up to margin, though rather sparse; apical depressed margin not indicated. T2-4 smooth or feebly coriarious with apical polished margins. T2 punctate as T1. T3 and T4 impunctate on exposed areas with hairs not accompanied by punctules. Pygidial plate as wide as width of FL3, apex round or slightly truncate.

Vestiture: Vestiture on face slightly yellowish, short; that on clypeus, supraclypeal area, frons and vertex rather sparse, simple or slightly plumose; that on middle to lower paraocular area more or less denser plumose, but not so 
dense to obscure integument.

Structure: Body length 7.5-10 mm. Head about 0.70.75 times as long as wide.

Labrum about 0.8 times as long as wide; apex emarginate; basal elevation notched medially. Interantennal elevation roundly highly raised; median carina abruptly ends apically. Vertex behind lateral ocelli well developed upward much beyond lateral ocelli in frontal view. Genal area much narrower than compound eye in lateral view, about 0.5 times as wide as compound eye. Exposed portion of pedicel slightly longer than FL1. Relatively length of FL1 : $2: 3=1.0: 1.0: 1.5$, and F1 0.6 times as long as width, FL2 0.6-0.7 times, FL3 0.9-1.0 times, and remaining segment about equal to width. FL1 and usually FL2, or at least basal underside of FL2 densely shagreen, matt. Undersides of FL3 and the following segments slightly shiny. Collar sharply angulate between frontal and lateral sides. Pronotum with lateral ridge highly raised

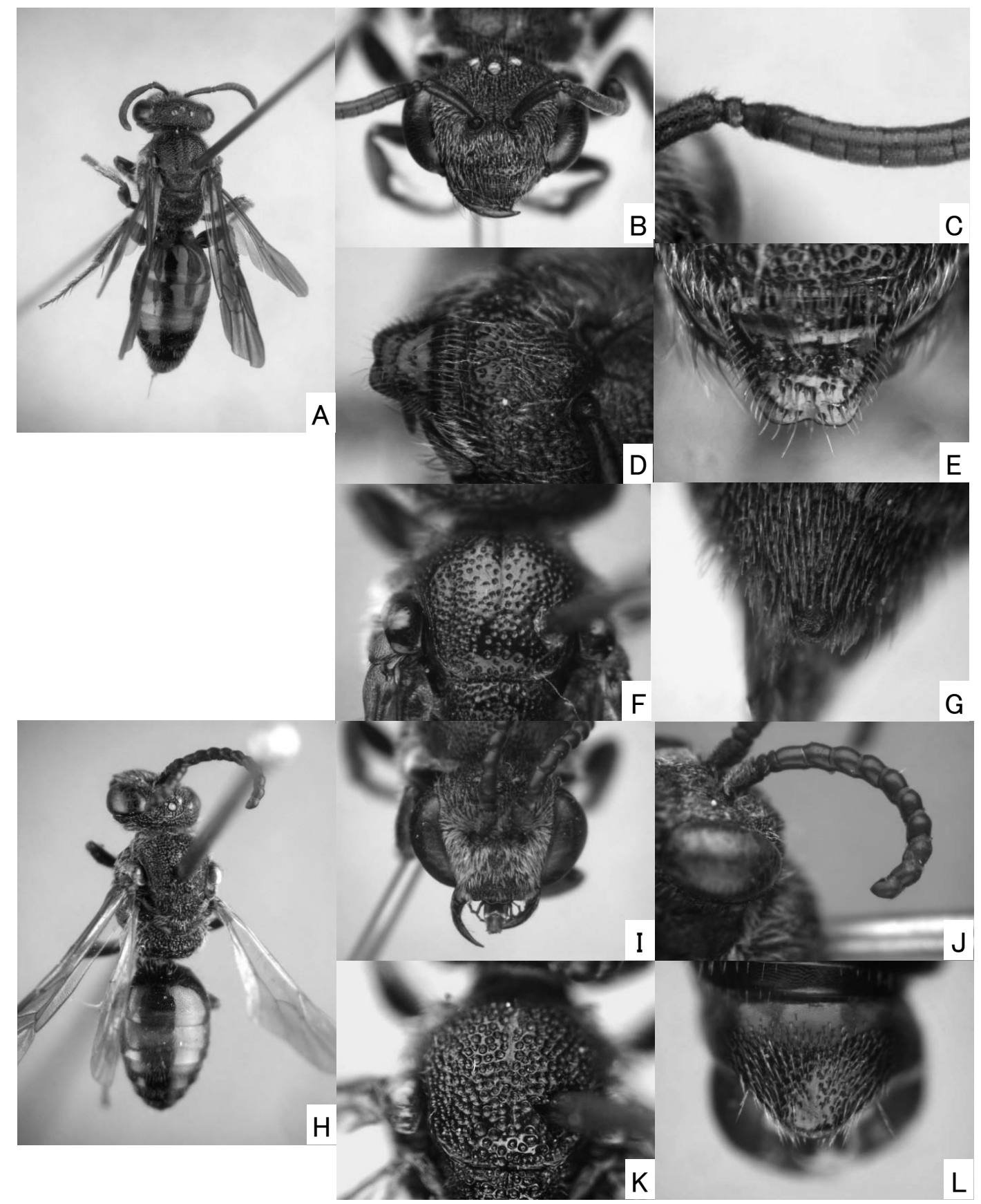

Fig. 28. Sphecodes scabricollis Wesmael. Female: A-G. Male: H-L. A, H: habitus, dorsal view. B, I: head. C, I: antenna. D: clypeus. E: labrum. F, K: scutellum. G, L: pygidial plate. 

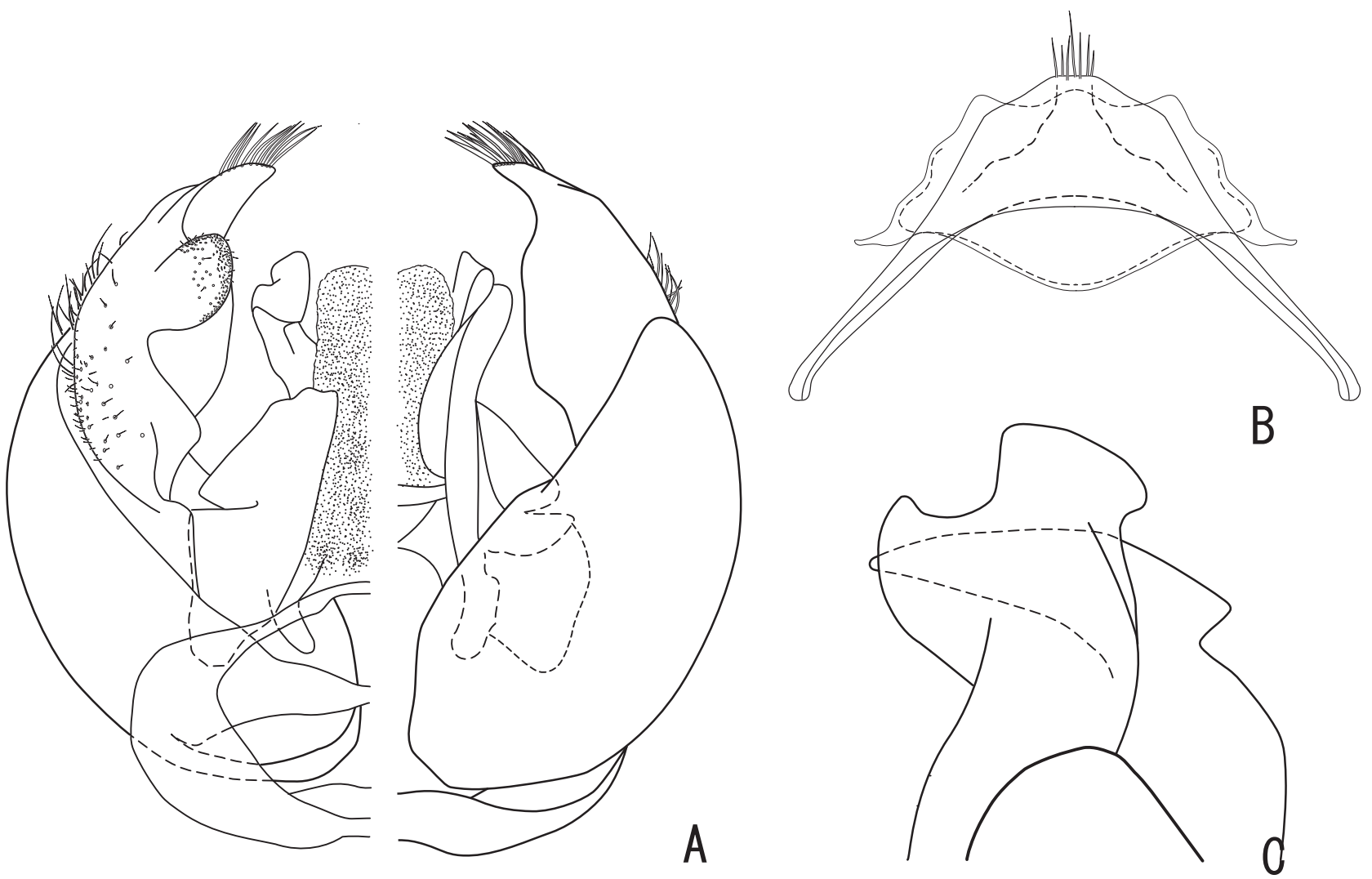

Fig. 29. Sphecodes scabricollis Wesmael, male. A: genital capsule (left, ventral view; right, dorsal view). B: 7th and 8th metasomal sterna, ventral view. C: gonostylus, lateral view (vestiture omitted).

and produced anteriorly beyond anterolateral margin of pronotum. Scutellum flat. Hind femora moderate in breadth, relative breadth to length of hind femur about 0.35 . Apical process of hind tibia narrowly oblong. Hook on hind wing variable, usually 8-9 in number, 12 at maximum.

\section{Male.}

Color: Body black except the following: mandible dark yellowish or red apically; Ts colored as in female, but at least T1 basally black, sometimes T1 nearly wholly black. Legs black except fore tibiae beneath yellowish.

Sculpture: Clypeus punctate-reticulate with faintly median furrow. Supraclypeal area as clypeus. Scutum punctate-reticulate. Scutellum punctate-reticulate, partially irregularly and coarsely rugose. Mesepisternum areolate coarsely. T1-2 polished, T3-6 faintly coriarious. T1 with apical half scattered, small distinct punctures intermixed with much smaller punctules nearly up to margin. T2 and T3 with punctate as T1, apical depressed area impunctate. T4-6 only with setigerous punctules. Apical portion polished and widely produced with apical margin widely obtuse-angled.

Vestiture: Vestiture on face silvery white in color, dense [slightly sparser on clypeus], densely plumose and largely appressed, not concealing integument, but obscuring that to some extent.

Structure: Body length 6-10.5 mm, usually 7.5-10 $\mathrm{mm}$. Head about 0.80 times as long as wide. Interantennal elevation low with median carina abruptly ends apically. Exposed portion of pedicel roughly as long as FL1. Relative length of FL1 : $2: 3=1.0: 3.8-4.0: 3.4-3.5$. FL1 0.4 times as long as width, FL2 and FL3 1. 6 times, and remaining segments distinctly longer than width. Each segment after FL2 swollen medially. Undersides of FL3 and the following segments with velvet-like areas. Velvetlike area on FL3 very narrow, band-shaped basally; those wider on the more following segments, becoming basal one-fourth of width of second last segment. Hind femora moderate in breadth, relative breadth to length of hind femur about $0.30-0.33$. Apical process of hind tibia shortly rounded. Hook on hind wing 7-8 in number. S7 roughly pentagonal; apex with several setae medially. S8 with posterior margin shallowly tridentate; lateral margin shallowly wavy; anterior margin widely produced anteriorly. Gonocoxite very weakly striate without dorsal depression. Gonostylus with a loose row of long setae on top; 


\section{K. MITAI \& O. TADAUCHI}

Table 5. Seasonal change in number of the captured individuals of S. scabricollis in Japan (E: early, M: mid, L: late).

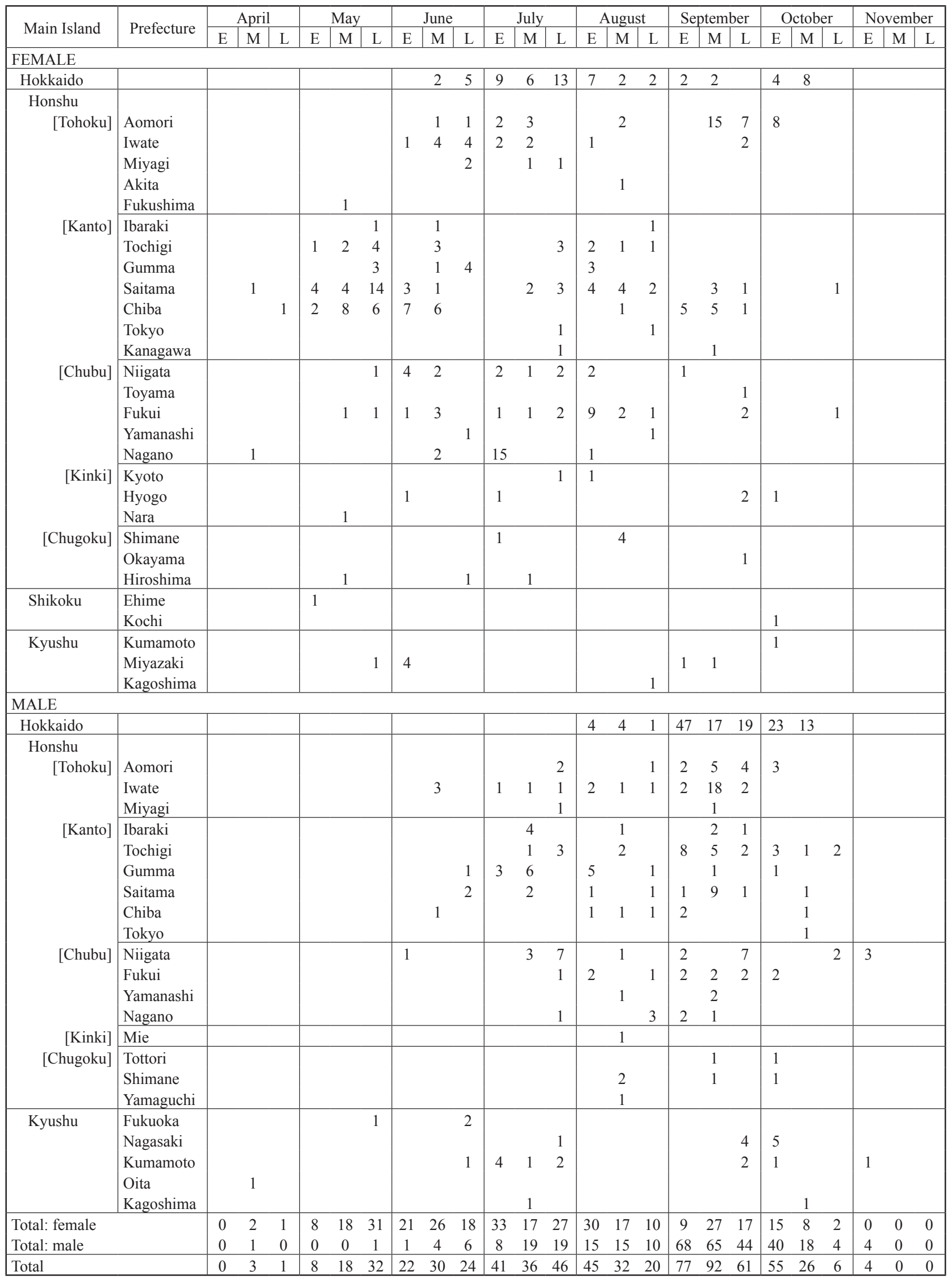


basolateral sides of gonostylus with long setae; inner basal surface without setae; basoventral lobe rounded ridge-shaped, then being sharply carinate obliquely upwards with loose row of setae which are longer upwards.

Distribution. Palearctic Region; JAPAN [Hokkaido, Honshu, Shikoku, Kyushu].

Specimens examined. We have examined nearly 350 individuals in each sex. The localities and phenology are shown in Table 5.

Biology. The flight period is from mid April to late October in female, and from mid April to early November in male with many records in September.

Remarks. Tsuneki (1983) discriminate $S$. hatogayuus [It was synonymized with $S$. japonicus by Tsuneki in the corrigenda of the same paper] from S. scabricollis, based on the punctuation and the color of wing. However, the differences must be within the range of variation of the species. This species is similar to S. nipponicus, but can be separated from it by the abruptly ventrally ending median carina on face, and less coarser punctures on the face, scutum, scutellum and terga. In males, the partially red abdomen will easily separate scabricollis from S. nipponicus which has the wholly black abdomen.

\section{Sphecodes silvicola Tsuneki, 1983}

[Japanese name: Morino-yadori-kohanabachi]

(Fig. 30-31, Table 6)

Sphecodes silvicola Tsuneki, 1983, Spec. Publ. Jap. Hymenopt. Assoc., (26): 60 [Holotype: Female. Type locality: Mt. Iide, Yamagata Pref., Honshu, Japan].

Sphecodes kitamius Tsuneki, 1983, Spec. Publ. Jap. Hymenopt. Assoc., (26): 55 [Holotype: Male. Type locality: Kitami Pass, Hokkaido, Japan]. Syn. Nov.

Sphecodes shirozui Tsuneki, 1983, Spec. Publ. Jap. Hymenopt. Assoc., (26): 42 [Holotype: Male. Type locality: Mt. Shiratori, Gokasho, Kumamoto, Kyushu, Japan]. Syn. Nov.

\section{Redescription.}

\section{Female.}

Color: Head and mesosoma black except the following: labrum black to blackish brown, sometimes strongly reddened; mandible black basally, red apically; flagellar segments brown to dark brown beneath. T1-2 and sometimes T3 basally red. Femora and tibiae black, tarsi somewhat paler.

Sculpture: Clypeus without median furrow; punctures shallow and sparse, three or more puncture diameters apart; sometimes interpunctural surface minutely rugose peripherally; apical margin of clypeus narrowly transversely furrowed. Supraclypeal area as clypeus. Frons punctate-reticulate narrowly medially, sparser laterally and toward vertex, where punctures are spaced by two to more puncture diameters apart. Vertex near preoccipital ridge and genal area costate. Scutum and scutellum scattered with small punctures, which are usually much denser on posterior margin of scutellum, but sometimes sparse as scutum, or coarsely rugose. Mesepisternum areolate shallowly; hypoepimeral area generally costate. T1-4 shiny with scattered, fine punctules basally; puncture especially sparse, virtually impunctate on T1, slightly denser on T2-4. Pygidial plate as wide as width of FL3; surface generally flat, shagreen but apically shiny.

Vestiture: Vestiture on face slightly yellowish, short, sparse, not densely plumose.

Structure: Body length 5.5-6.5 mm. Head about 0.750.80 times as long as wide. Labrum short, semicircular, 0.5 times as long as wide; apex feebly but always emarginate. Vertex behind lateral ocelli not developed upward beyond lateral ocelli in frontal view. Genal area much narrower than compound eye in lateral view, about 0.5 times as wide as compound eye. Exposed portion of pedicel slightly longer than FL1. Relatively length of FL1 $: 2: 3$ $=1.0: 1.2-1.3: 1.4-1.5$, and F1 and FL2 0.6 times as long as width, FL3 0.7 times, and remaining segment slightly shorter than width. FL1 and FL2 densely shagreen, matt. Undersides of FL3 and the following segments slightly shiny. Collar gently curved between frontal and lateral sides. Pronotum with lateral ridge indistinct, at most lowly raised. Scutellum flat. Hind femora moderate in breadth, relative breadth to length of hind femur about 0.35 . Apical process of hind tibia triangular, moderately long. Hook on hind wing 5 in number.

Male.

Color: Body black except the following: mandible dark yellow or red apically; flagellar segments slightly paler beneath: T1-3 tinged with dark red narrowly on apical margins. Femora black, tibiae slightly brown, tarsi yellowish brown.

Sculpture: Clypeus relatively highly and roundly convex, punctate-reticulate without median furrow. Supraclypeal area as clypeus. Frons punctate-reticulate, denser than that of female, until lateral ocelli; interpunctural surface minutely rugose. Vertex near preoccipital ridge and genal area costate, the costae more irregular than those of female. Scutum and scutellum moderately densely punctate; generally punctures separated by up to two puncture diameters apart, or more in places. Scutellum punctate as scutum; sometimes faintly raised, longitudinal line present medially. Mesepisternum areolate much more deeply and densely than that of female. T1 polished 
wholly with very scattered fine punctules, virtually impunctate; apical depressed margin not indicated. T2 polished with scattered punctules. T3-5 impunctate on exposed areas. $\mathrm{T} 7$ densely shagreen often all over on exposed area; apical margin moderately produced, usually somewhat truncate, and turned weakly upward.

Vestiture: Vestiture on lower face golden, dense, densely plumose and appressed, not concealing integument, but obscuring that to some extent.
Structure: Body length 5.5-6 mm. Head about 0.85 times as long as wide.

Genal area much narrower than compound eye in lateral view, about 0.4 times as wide as compound eye. Exposed portion of pedicel roughly as long as FL1. Relative length of FL1 : $2: 3=1.0: 1.6: 1.4-1.6$. FL1 0.6-0.7 times as long as width, FL2 1.0-1.1, FL3 1.0 times, and remaining segments distinctly as long as width or slightly longer. Each segment not swollen medially,

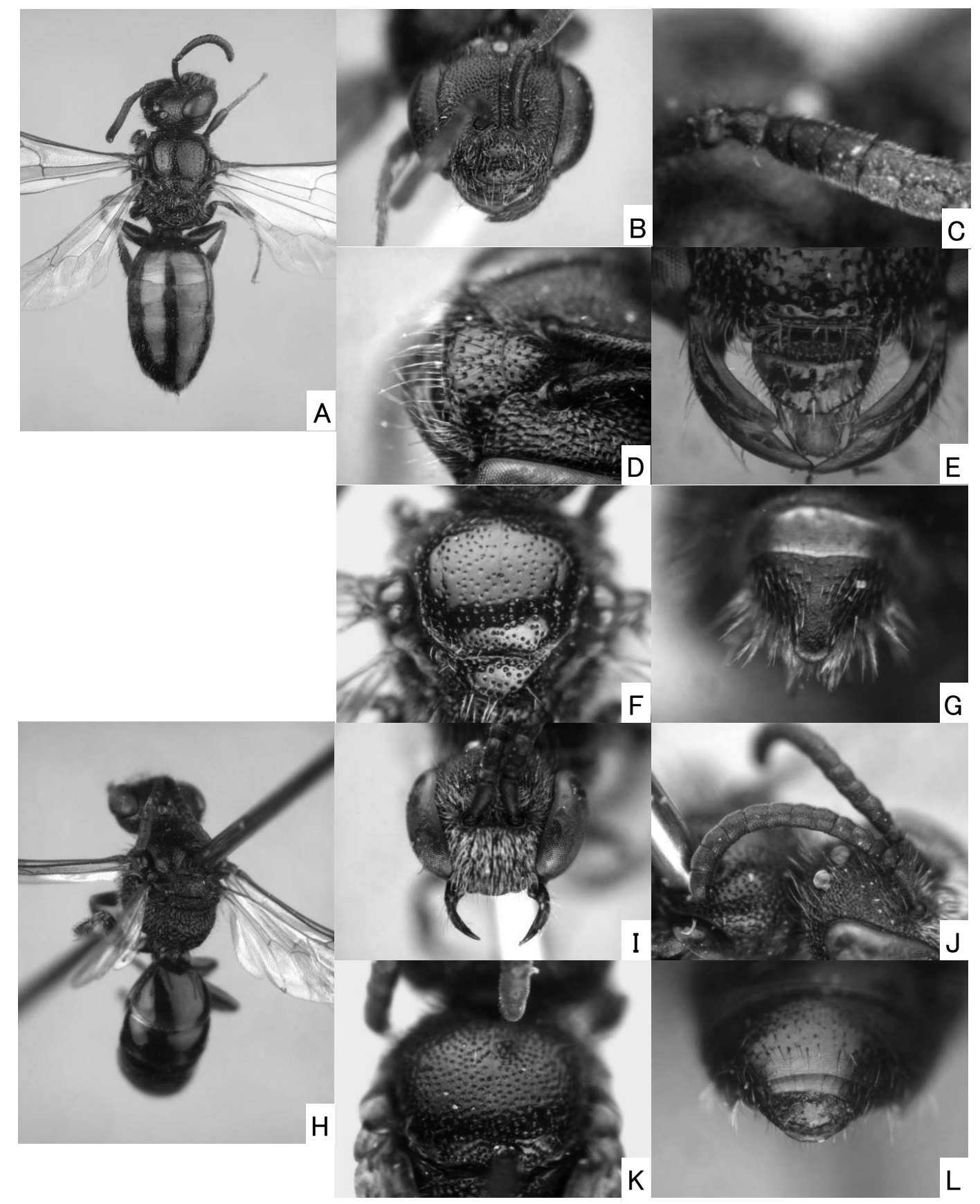

Fig. 30. Sphecodes silvicola Tsuneki Female: A-G. Male: H-L. A, H: habitus, dorsal view. B, I: head. C, I: antenna. D: clypeus. E: labrum. F, K: scutellum. G, L: pygidial plate. 

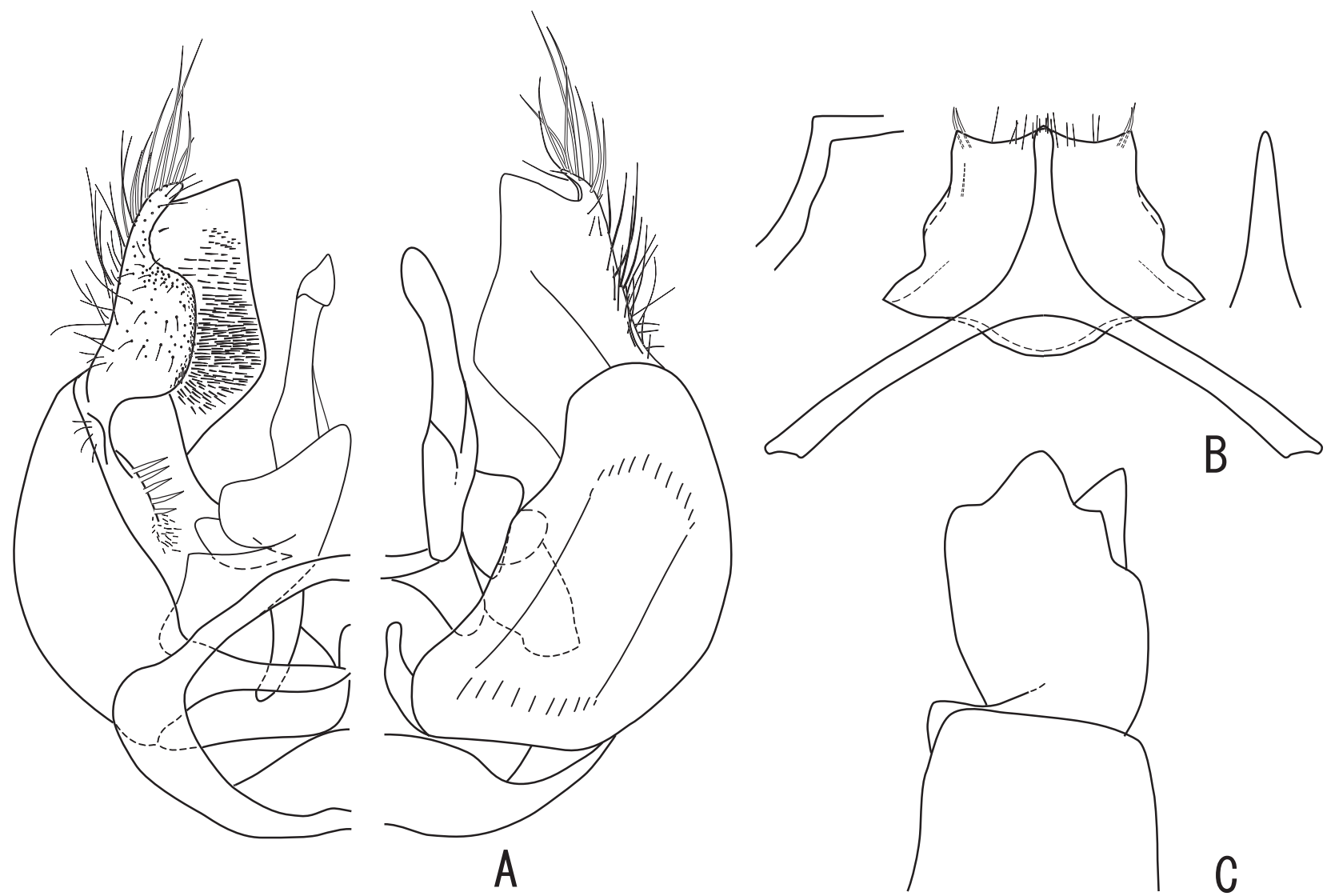

Fig. 31. Sphecodes silvicola Tsuneki, male. A: genital capsule (left, ventral view; right, dorsal view). B: 7 th and 8 th metasomal sterna, ventral view with variations of posterior portion of each sternum. C: gonostylus, lateral view (vestiture omitted).

roughly cylindrical, without velvet-like area. Hind femora slender, relative breadth to length of hind femur about 0.30. Apical process of hind tibia hardly produced. S7 slender, arrow-shaped. S8 with several fine setae on posterior margin which are bluntly tridentate to truncate, or slightly produced; anterior margin widely produced. Gonocoxite striate with shallow dorsal depression. Gonostylus with long setae on top and lateral surface; inner basal surface with dense setae finer downwards; dorsal lobe strongly curled inwards; basoventral lobe small with a few setae.

Distribution. JAPAN [Hokkaido, Honshu, Shikoku, Kyushu].

Specimens examined. Holotype [MNHAH], female with three labels as follows: "Yamagata, Mt Iide Entrance [in Japanese.] /Niigata, Japan/ 16. V. 1976 /K. Tsuneki, leg. [white rectangle with typed and handwritten letters], "Sphecodes / silvicola + / Tsuneki/ HOLOTYPE [red rectangle with handwritten letters]", and "B1-288301 [white rectangle with printed register-number of MNHAH and a bar-code]".

Other specimens: We have examined nearly 250 females and 50 males. The localities and phenology are shown in Table 6.

Biology. The flight period is from mid April to mid October in female, and from early July to early October in male.

Remarks. Tsuneki (1983) described S. shirozui based on males only, and described females in the supplemental part of the same paper. He reasoned about the combination from that one of the females was collected simultaneously with many of the $S$. shirozui males. However, among the specimens we examined we found the seven instance in which $S$. shirozui males and S. silvicola females have the same collecting data on labels, whereas only one such instance in which $S$. shirozui female (= S. coptis) and $S$. silvicola male have the same data. In addition, Mr. Nakamura (Tochigi Pref.) kindly allowed us to examine a couple of Sphecodes female and male, which were in copulation at collecting. Our examination showed that the female is $S$. silvicola, and the male is $S$. shirozui. From the above reasons, we conclude the males Tsuneki (1984) described as $S$. shirozui is that of $S$. silvicola and is synonymized under the latter. 
Table 6. Seasonal change in number of the captured individuals of S. silvicola in Japan (E: early, M: mid, L: late).

\begin{tabular}{|c|c|c|c|c|c|c|c|c|c|c|c|c|c|c|c|c|c|c|c|c|c|c|}
\hline \multirow{2}{*}{ Main Island } & \multirow{2}{*}{ Prefecture } & \multicolumn{3}{|c|}{ April } & \multicolumn{3}{|c|}{ May } & \multicolumn{3}{|c|}{ June } & \multicolumn{3}{|c|}{ July } & \multicolumn{3}{|c|}{ August } & \multicolumn{3}{|c|}{ September } & \multicolumn{3}{|c|}{ October } \\
\hline & & $\mathrm{E}$ & $\mathrm{M}$ & $\mathrm{L}$ & $\mathrm{E}$ & $\mathrm{M}$ & $\mathrm{L}$ & $E$ & $\mathrm{M}$ & $\mathrm{L}$ & $\mathrm{E}$ & $\mathrm{M}$ & $\mathrm{L}$ & $\mathrm{E}$ & $\mathrm{M}$ & $\mathrm{L}$ & $\mathrm{E}$ & $\mathrm{M}$ & $\mathrm{L}$ & $\mathrm{E}$ & $\mathrm{M}$ & $\mathrm{L}$ \\
\hline \multicolumn{23}{|l|}{ FEMALE } \\
\hline Hokkaido & & & & & 3 & 4 & 17 & 12 & 8 & 13 & 12 & 4 & 6 & 3 & & & & & 2 & 2 & 2 & \\
\hline $\begin{array}{l}\text { Honshu } \\
\text { [Tohoku] }\end{array}$ & $\begin{array}{l}\text { Aomori } \\
\text { Iwate } \\
\text { Miyagi }\end{array}$ & & & 1 & 3 & $\begin{array}{l}4 \\
4\end{array}$ & $\begin{array}{l}3 \\
2\end{array}$ & $\begin{array}{l}3 \\
4\end{array}$ & $\begin{array}{c}11 \\
6\end{array}$ & $\begin{array}{l}1 \\
3\end{array}$ & 1 & 4 & 1 & 1 & 1 & 2 & \multicolumn{3}{|c|}{1} & \multicolumn{3}{|l|}{1} \\
\hline [Kanto] & $\begin{array}{l}\text { Tochigi } \\
\text { Gumma } \\
\text { Saitama } \\
\text { Tokyo } \\
\text { Kanagawa }\end{array}$ & & & 6 & 4 & $\begin{array}{l}1 \\
2 \\
8 \\
1 \\
1\end{array}$ & $\begin{array}{l}5 \\
1 \\
\end{array}$ & $\begin{array}{l}1 \\
1 \\
1 \\
1\end{array}$ & & & 3 & 1 & $\begin{array}{l}1 \\
2 \\
\end{array}$ & $\begin{array}{l}2 \\
1 \\
\end{array}$ & & & & & & & & \\
\hline [Chubu] & $\begin{array}{l}\text { Niigata } \\
\text { Toyama } \\
\text { Ishikawa } \\
\text { Fukui } \\
\text { Yamanashi } \\
\text { Nagano } \\
\text { Gifu } \\
\end{array}$ & & 1 & & 1 & $\begin{array}{l}6 \\
2\end{array}$ & 10 & $\begin{array}{l}1 \\
1\end{array}$ & 1 & 1 & $\begin{array}{l}1 \\
2\end{array}$ & $\begin{array}{l}1 \\
3\end{array}$ & & & $\begin{array}{l}2 \\
1\end{array}$ & 3 & & & & & & \\
\hline [Chugoku] & Hiroshima & & & 1 & & & & & & & & & & & & & & & & & & \\
\hline Shikoku & Ehime & & & & 1 & 1 & & & & & & & & & & & & & & & & \\
\hline Kyushu & $\begin{array}{l}\text { Fukuoka } \\
\text { Oita } \\
\text { Miyazaki } \\
\text { Kagoshima }\end{array}$ & & & $\begin{array}{l}2 \\
9\end{array}$ & 1 & 2 & & & & & 1 & & 1 & 3 & & & & & & & & \\
\hline \multicolumn{23}{|l|}{ MALE } \\
\hline Hokkaido & & & & & & & & & & & & 1 & 5 & 4 & & & 1 & 2 & 4 & 1 & & \\
\hline $\begin{array}{l}\text { Honshu } \\
\text { [Tohoku] }\end{array}$ & Aomori & & & & & & & & & & 1 & 5 & 1 & 1 & 1 & 3 & 2 & 1 & & 1 & & \\
\hline [Kanto] & $\begin{array}{l}\text { Saitama } \\
\text { Kanagawa } \\
\end{array}$ & & & & & & & & & & 1 & 1 & $\begin{array}{l}2 \\
1 \\
\end{array}$ & & & & 1 & & & & & \\
\hline [Chubu] & $\begin{array}{l}\text { Fukui } \\
\text { Yamanashi }\end{array}$ & & & & & & & & & & & & 1 & 1 & 1 & & 1 & 1 & & & & \\
\hline Shikoku & Kochi & & & & & & & & & & & & & & & 1 & & & & & & \\
\hline Kyushu & Fukuoka & & & & & & & & & & & & & 3 & & & & & & & & \\
\hline Total: female & & 0 & 1 & 19 & 16 & 37 & 38 & 25 & 26 & 18 & 20 & 13 & 11 & 10 & 4 & 9 & 0 & 1 & 2 & 3 & 2 & 0 \\
\hline Total: male & & 0 & 0 & 0 & 0 & 0 & 0 & 0 & 0 & 0 & 2 & 7 & 10 & 9 & 2 & 4 & 5 & 4 & 4 & 2 & 0 & 0 \\
\hline Total & & 0 & 1 & 19 & 16 & 37 & 38 & 25 & 26 & 18 & 22 & 20 & 21 & 19 & 6 & 13 & 5 & 5 & 6 & 5 & 2 & 0 \\
\hline
\end{tabular}

\section{Sphecodes simillimus Smith, 1873}

[Japanese name: Esaki-yadori-kohanabachi]

(Fig. 32-33, Table 7)

Sphecodes simillimus Smith, 1873, Trans, Ent. Soc. London, 1873: 199 [Holotype: Female. Type locality: Hiogo, Honshu, Japan]; Tsuneki, 1983, Spec. Publ. Jap. Hymenopt. Assoc., (26): 30 [redescription].

Sphecodes esakii Strand et Yasumatsu, 1938, Mushi, 11: 78[Holotype: Male. Type locality: Chikuzen, Fukuoka Pref., Kyushu, Japan], synonymized by Tsuneki, 1983: 30.

\section{Redescription.}

\section{Female.}

Color: Head and mesosoma black except the following: mandible red apically; apical several flagellar segments sometimes blackish brown. Usually T1-2, and T3 basally red, often T1 basally darkened, and T3 wholly black. Legs black.

Sculpture: Clypeus deeply punctate-reticulate with median furrow; interpunctural surface sometimes finely rugose. Supraclypeal area as clypeus. Frons areolate until lateral ocelli. Vertex near preoccipital ridge and genal area coarsely rugose, partially areolate; Vertex with a longitudinally carinate behind lateral ocelli. Scutum moderately punctate, punctures separated generally by up to two puncture diameters apart; interpunctural surface scattered with punctules. Scutellum punctate as scutum or slightly more densely. Mesepisternum areolate shallowly. T1-4 shiny with scattered, fine punctules basally; puncture especially sparse, virtually impunctate on T1, slightly denser on T2-4. Pygidial plate wide, 1.6-1.8 times as wide as width of FL3; apex widely rounded; surface usually 
shiny, flat or slightly convex medially.

Vestiture: Vestiture on face white or slightly yellowish, sparse, moderately long, thin, not densely plumose.

Structure: Body length 7-9 mm. Head 0.75-0.80 times as long as wide. Labrum 0.6-0.7 times as long as wide; apex usually shallowly emarginate, degree of emargination variable, sometimes apical margin truncate. Interantennal elevation highly raised; median carina ends as sharp edge. Vertex behind lateral ocelli developed upward slightly beyond lateral ocelli in frontal view. Genal area much narrower than compound eye in lateral view, about 0.5 times as wide as compound eye. Exposed portion of pedicel about 1.5 times as long as FL1. Relatively length of FL1 $: 2: 3=1.0: 1.4-1.5: 1.4-1.6$, and F1 0.7 times as long as width, FL2 and FL3 0.8-0.9 times, and remaining segment roughly equal to width except the last. FL1 and FL2 densely shagreen, matt. Undersides of FL3 and the following segments slightly

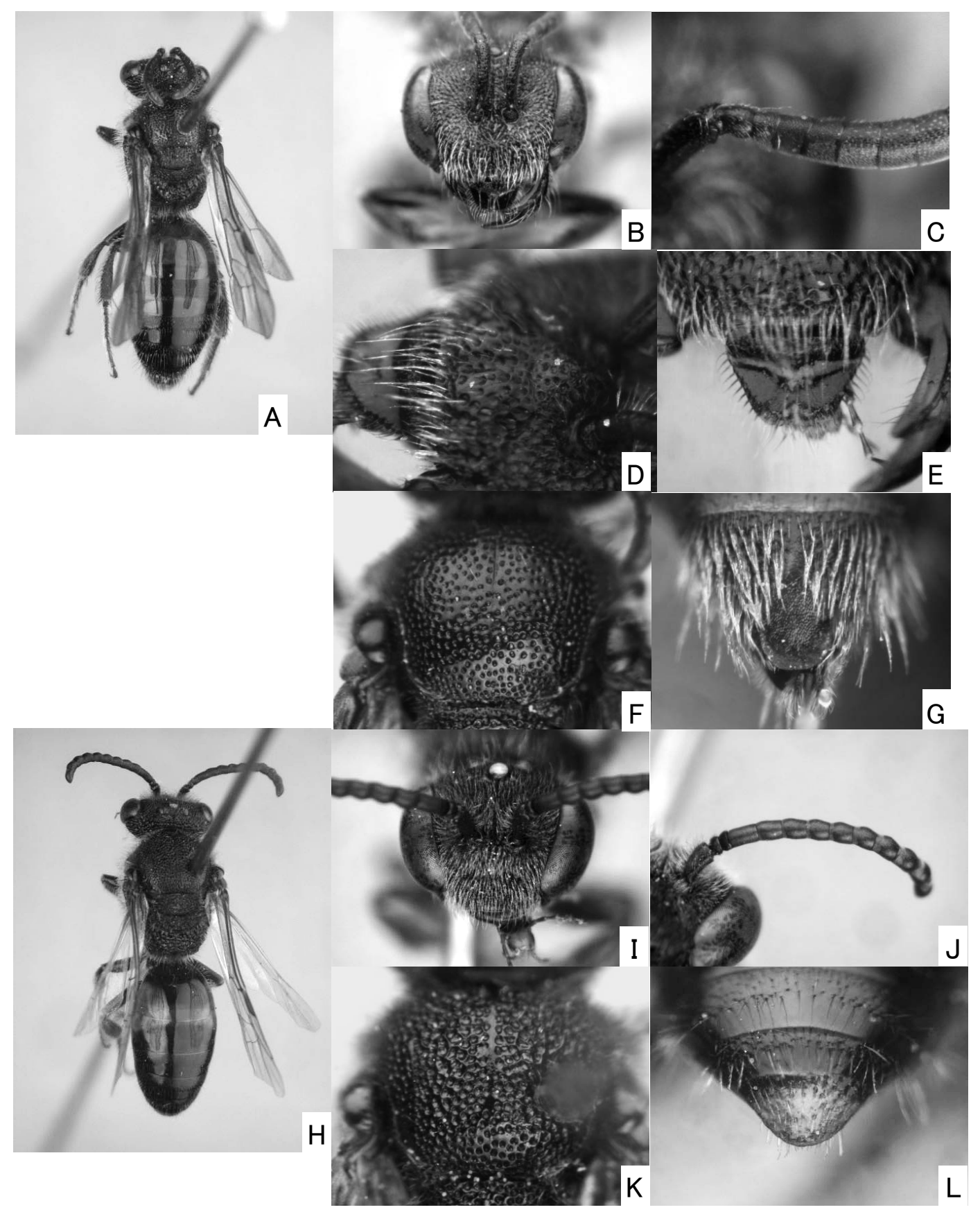

Fig. 32. Sphecodes simillimus Smith, Female: A-G. Male: H-L. A, H: habitus, dorsal view. B, I: head. C, I: antenna. D: clypeus. E: labrum. F, K: scutellum. G, L: pygidial plate. 

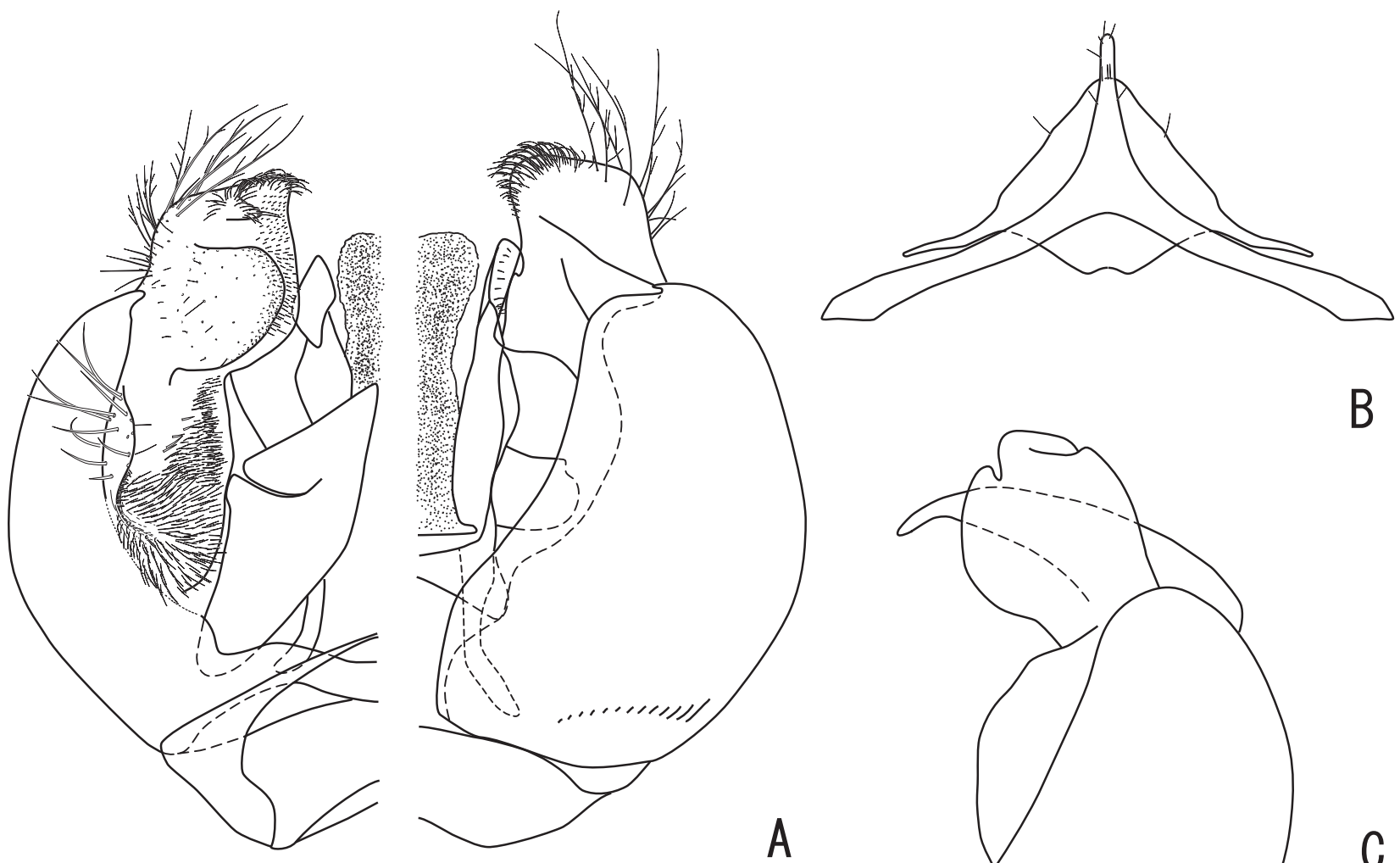

A

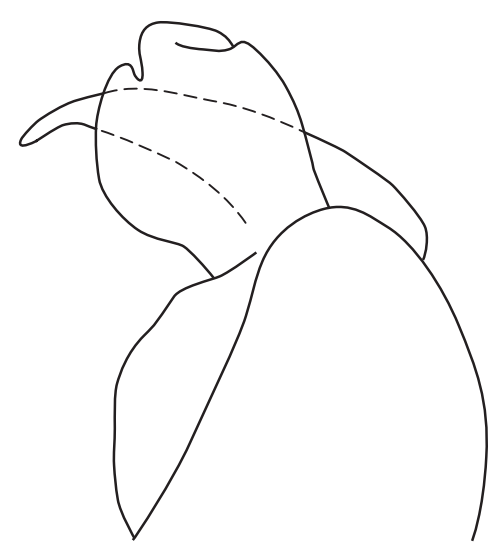

B

Fig. 33. Sphecodes simillimus Smith, male. A: genital capsule (left, ventral view; right, dorsal view). B: 7th and 8th metasomal sterna, ventral view. C: gonostylus, lateral view (vestiture omitted).

shiny. Collar sharply angulate between frontal and lateral sides. Pronotum with lateral ridge highly raised and produced anteriorly beyond anterolateral margin of pronotum. Scutellum flat. Hind femora moderate in breadth, relative breadth to length of hind femur about 0.35 . Apical process of hind tibia narrowly oblong. Hook on hind wing 5 in number.

Male.

Color: Body black except the following: mandible red apically; flagellar segments reddish brown beneath; usually T1 apically and T2 wholly red, sometimes T3 basally red. Legs black.

Sculpture: Clypeus similar to that of female but slightly denser. Generally as female, but somewhat coarser. Scutum and scutellum areolate; partitions of cavities often connected to appear longitudinal line medially on scutellum. Scutum and scutellum scattered with small punctures. T1 polished wholly with very scattered fine punctules, virtually impunctate; apical depressed margin not indicated. T2 polished with scattered punctules. T3-6 coriarious without punctures. Apical portion of T7 always polished and widely produced with apical margin obtuse-angled.

Vestiture: Vestiture on lower face white, moderately dense, densely plumose and appressed, not concealing integument, but obscuring that to some extent.

Structure: Body length 6-8 mm. Head about 0.8 times as long as wide. Genal area much narrower than compound eye in lateral view, about 0.4 times as wide as compound eye. Exposed portion of pedicel longer than FL1. Relative length of FL1 : $2: 3=1.0: 3.4: 3.0$. FL1 0.4-0.5 times as long as width, FL2 1.4 times, FL3 1.2 times, and remaining segments gradually shorter on more following segments; last several segment about equal to width. Each segment after FL2 distinctly swollen medially. Undersides of FL3 and the following segments with distinct velvetlike areas. Velvet-like area on FL3 confined to basal narrow margin of segments, reaching one-third of the segment; those on more the following segments wider developed up to beyond basal one-third of width on last five segments. Hind femora slender, relative breadth to length of hind femur about $0.28-0.3$. Apical process of hind tibia shortly triangular or rounded. S7 slender, arrowshaped. S8 with triangularly produced posteriorly; lateral margin not wavy; anterior margin triangularly produced anteriorly with small emargination at apex. Gonocoxite striate without dorsal depression. Gonostylus short, with long, plumose setae on top and lateral surface; inner basal 
Table 7. Seasonal change in number of the captured individuals of S. simillimus in Japan (E: early, M: mid, L: late).

\begin{tabular}{|c|c|c|c|c|c|c|c|c|c|c|c|c|c|c|c|c|c|c|c|c|c|c|c|c|c|}
\hline \multirow{2}{*}{ Main Island } & \multirow{2}{*}{ Prefecture } & \multicolumn{3}{|c|}{ March } & \multicolumn{3}{|c|}{ April } & \multicolumn{3}{|c|}{ May } & \multicolumn{3}{|c|}{ June } & \multicolumn{3}{|c|}{ July } & \multicolumn{3}{|c|}{ August } & \multicolumn{3}{|c|}{ September } & \multicolumn{3}{|c|}{ October } \\
\hline & & $\mathrm{E}$ & $\mathrm{M}$ & $\mathrm{L}$ & $E$ & $\mathrm{~L}$ & $\mathrm{M}$ & E & $\mathrm{L}$ & $\mathrm{M}$ & E & $\mathrm{L}$ & $\mathrm{M}$ & $\mathrm{E}$ & $\mathrm{L}$ & $\mathrm{M}$ & $\mathrm{E}$ & $\mathrm{L}$ & $\mathrm{M}$ & $\mathrm{E}$ & $\mathrm{L}$ & $\mathrm{M}$ & $\mathrm{E}$ & $\mathrm{M}$ & $\mathrm{L}$ \\
\hline \multicolumn{26}{|l|}{ FEMALE } \\
\hline Hokkaido & & & & & & 1 & & 5 & 36 & 11 & 48 & 4 & 10 & 4 & 37 & 7 & 6 & 1 & & 8 & 2 & & 3 & 2 & \\
\hline $\begin{array}{l}\text { Honshu } \\
\quad[\text { Tohoku] }\end{array}$ & $\begin{array}{l}\text { Aomori } \\
\text { Iwate } \\
\text { Miyagi }\end{array}$ & & & & & & & $\begin{array}{l}4 \\
7\end{array}$ & $\begin{array}{l}7 \\
8\end{array}$ & $\begin{array}{l}3 \\
7\end{array}$ & $\begin{array}{l}2 \\
5\end{array}$ & $\begin{array}{l}4 \\
1 \\
2\end{array}$ & $\begin{array}{l}2 \\
3\end{array}$ & 2 & 1 & $\begin{array}{l}1 \\
6\end{array}$ & & 1 & 1 & & $\begin{array}{l}2 \\
1\end{array}$ & 1 & $\begin{array}{l}4 \\
1\end{array}$ & & \\
\hline [Kanto] & $\begin{array}{l}\text { Tochigi } \\
\text { Gumma } \\
\text { Saitama } \\
\text { Kanagawa }\end{array}$ & & & & 1 & $\begin{array}{c}8 \\
20 \\
12 \\
1\end{array}$ & $\begin{array}{l}1 \\
5\end{array}$ & $\begin{array}{l}1 \\
6 \\
1 \\
\end{array}$ & $\begin{array}{l}2 \\
2 \\
9\end{array}$ & 3 & 2 & 1 & 3 & 1 & & 2 & & & 1 & & & & & 1 & \\
\hline [Chubu] & $\begin{array}{l}\text { Niigata } \\
\text { Toyama } \\
\text { Ishikawa } \\
\text { Fukui } \\
\text { Yamanashi } \\
\text { Nagano } \\
\text { Shizuoka }\end{array}$ & & & & $\begin{array}{l}1 \\
1 \\
3\end{array}$ & $\begin{array}{l}1 \\
3\end{array}$ & $\begin{array}{l}1 \\
3 \\
1\end{array}$ & $\begin{array}{l}1 \\
1 \\
8 \\
4 \\
1 \\
3\end{array}$ & $\begin{array}{c}14 \\
4\end{array}$ & $\begin{array}{l}2 \\
1 \\
1 \\
6 \\
2 \\
3\end{array}$ & $\begin{array}{l}2 \\
1 \\
1\end{array}$ & $\begin{array}{l}3 \\
1\end{array}$ & 3 & 1 & $\begin{array}{l}1 \\
1\end{array}$ & & 1 & 1 & & & & $\begin{array}{l}1 \\
1\end{array}$ & 1 & & \\
\hline [Kinki] & $\begin{array}{l}\text { Kyoto } \\
\text { Hyogo } \\
\text { Nara } \\
\text { Wakayama }\end{array}$ & & & & & 1 & & 1 & 1 & 3 & & & & & & & & & & & & & & & \\
\hline [Chugoku] & $\begin{array}{l}\text { Tottori } \\
\text { Shimane } \\
\text { Hiroshima }\end{array}$ & & & & & $\begin{array}{l}1 \\
3\end{array}$ & 2 & 2 & & & & & & & & & & & 1 & & 1 & & & & \\
\hline Shikoku & $\begin{array}{l}\text { Tokushima } \\
\text { Kochi }\end{array}$ & & & & & 1 & $\begin{array}{l}1 \\
1 \\
\end{array}$ & 1 & & & & & & & & & & & & & & & & & \\
\hline Kyushu & $\begin{array}{l}\text { Fukuoka } \\
\text { Saga } \\
\text { Nagasaki } \\
\text { Kumamoto } \\
\text { Oita } \\
\text { Miyazaki } \\
\text { Kagoshima }\end{array}$ & & & 1 & 6 & $\begin{array}{l}4 \\
1\end{array}$ & $\begin{array}{l}6 \\
1 \\
1\end{array}$ & 3 & 4 & 8 & 1 & & 2 & & 1 & 1 & & & & & & & 1 & & \\
\hline \multicolumn{26}{|l|}{ MALE } \\
\hline Hokkaido & & & & & & 1 & & & 1 & & & 2 & & & 3 & & 5 & 5 & & 25 & 16 & 7 & 20 & 6 & \\
\hline $\begin{array}{l}\text { Honshu } \\
\text { [Tohoku] }\end{array}$ & $\begin{array}{l}\text { Aomori } \\
\text { Iwate } \\
\text { Miyagi } \\
\text { Fukushima }\end{array}$ & & & & & & & & & & & & & 1 & 2 & & 2 & $\begin{array}{l}5 \\
1 \\
1\end{array}$ & 1 & $\begin{array}{l}3 \\
4\end{array}$ & $\begin{array}{l}7 \\
6\end{array}$ & $\begin{array}{l}5 \\
5\end{array}$ & 6 & 1 & \\
\hline [Kanto] & $\begin{array}{l}\text { Tochigi } \\
\text { Saitama }\end{array}$ & & & & & & & & & & & 1 & & & 1 & & & & 1 & $\begin{array}{l}1 \\
1\end{array}$ & 1 & 1 & & & \\
\hline [Chubu] & $\begin{array}{l}\text { Niigata } \\
\text { Fukui } \\
\text { Yamanashi } \\
\text { Nagano }\end{array}$ & & & & & & & & & & & & & & & 1 & 1 & $\begin{array}{l}1 \\
2 \\
3\end{array}$ & & 1 & 1 & \begin{tabular}{l|} 
\\
3 \\
2
\end{tabular} & & 1 & \\
\hline [Chugoku] & Tottori & & & & & & & & & & & & & & & & 1 & 1 & & & & & 1 & & \\
\hline Total: female & & 0 & 0 & 1 & 12 & 62 & 23 & 45 & 52 & 53 & 14 & 14 & 13 & 14 & 4 & 10 & 2 & 3 & 3 & 0 & 4 & 3 & 7 & 1 & 0 \\
\hline Total: male & & 0 & 0 & 0 & 0 & 0 & 0 & 0 & 0 & 0 & 0 & 1 & 0 & 1 & 3 & 1 & 4 & 14 & 2 & 10 & 15 & 17 & 7 & 2 & 0 \\
\hline Total & & 0 & 0 & 1 & 12 & 62 & 23 & 45 & 52 & 53 & 14 & 15 & 13 & 15 & 7 & 11 & 6 & 17 & 5 & 10 & 19 & 20 & 14 & 3 & 0 \\
\hline
\end{tabular}

surface widely with dense fine setae; basoventral lobe carinate with several long setae.

Distribution. JAPAN [Hokkaido, Honshu, Shikoku, Kyushu].

Specimens examined. We have examined nearly 340 females and 180 males. The localities and phenology are shown in Table 7.

Biology. The flight period is from late March to mid
October in female with most records from April to July, and from late April to mid October in male. The host is Lasioglossum duplex (Maeta et al., 1996).

Remarks. In Japan, this species is unique in having a carina on vertex, and, therefore, easily separable from the congeners. 


\section{Sphecodes sulcifera Tsuneki, 1983}

[Japanese name: Mizo-yadori-kohanabachi]

(Fig. 34-35)

Sphecodes sulcifera Tsuneki, 1983, Spec. Publ. Jap. Hymenopt. Assoc., (26): 36 [Holotype: Male. Type locality: Mt. Akausagi, Fukui Pref., Honshu, Japan].

\section{Redescription.}

\section{Female.}

Color: Head and mesosoma black except the following: labrum paler apically; mandible red apically. T1and T2 red, in some specimens T2 strongly dark medially. Legs black to dark brown, usually tarsi paler.

Sculpture: Clypeus without median furrow; punctures shallow or subobsolete, and sparse, generally two to three puncture diameters apart medially, denser peripherally; apical margin feebly furrowed. Supraclypeal area as clypeus. Frons punctate-reticulate narrowly medially, sparser laterally and toward vertex, where punctures three or more puncture diameter apart. Vertex near preoccipital ridge and genal area costate. Scutum scattered very sparsely with moderate sized punctures; usually mesoscutal and parapsidal lines deep. Scutellum punctate as scutum, sometimes punctures subobsolete. Upper margin of posterior vertical face of propodeum (immediately below transverse carina) smooth transversely without sculpture. Mesepisternum areolate shallowly. T1-2 polished wholly with very scattered, fine punctules, or virtually impunctate; apical depressed margin not indicated. T3-4 polished with scattered punctules. Pygidial plate 0.9-1 times as wide as width of FL3; surface usually shiny, flat or slightly turned upward peripherally.

Vestiture: Vestiture on face slightly yellowish, short, sparse, not densely plumose.

Structure: Body length 6-7 mm. Head about 0.8 times as long as wide. Labrum roughly semicircular, short 0.5 times as long as wide. Vertex behind lateral ocelli not developed upward beyond lateral ocelli in frontal view. Genal area narrower than compound eye in lateral view, about 0.6 times as wide as compound eye. Exposed portion of pedicel longer than FL1. Relative length of FL1 $: 2: 3=1.0: 1.0-1.1: 1.2$, and F1 0.6 times as long as width, FL2 0.7 times, FL3 0.8 times, and remaining segment slightly longer than width. FL1-2, and basal half of beneath of FL3 densely shagreen, matt. Undersides of FL4 and the following segments slightly shiny. Collar gently curved between frontal and lateral sides. Pronotum with lateral ridge lowly raised, indistinct. Scutellum flat. Hind femora moderate in breadth, relative breadth to length of hind femur about 0.35 . Apical process of hind tibia shortly rounded. Hook on hind wing 5-6 in number, exceptionally 8 on left hind wing in one specimen.

Male.

Color: Body black except the following: mandible red apically; flagellar segments brown or wholly black; terga black or dark brown, sterna as same as terga. Femora and tibiae slightly blackish brown, tarsi paler.

Sculpture: Clypeus densely punctate-reticulate, relatively highly and roundly convex without median furrow. Supraclypeal area as clypeus. Frons densely punctatereticulate, much denser than that of female, without interpunctural surface until lateral ocelli. Vertex behind lateral ocelli and genal area costate, the costae more irregular than those of female. Scutum punctate densely on anterior one-third to fourth; punctures generally about a puncture diameter apart, sparser posteriorly; interpunctural area scattered with punctules. Scutellum punctate as scutum; sometimes some punctures on medial area subobsolete. Mesepisternum areolate shallowly. T1-4 shiny with scattered fine punctules basally. T7 shagreen, sparser apically with apical margin truncate or emarginate, and turned upward.

Vestiture: Vestiture on face slightly yellowish, shorter than that of female, sparse, not densely plumose.

Structure: Body length 5-6.5 mm. Head about 0.85 times as long as wide. Genal area narrower than compound eye in lateral view, about 0.6-0.7 times as wide as compound eye. Exposed portion of pedicel shorter than FL1. Relative length of FL1 : $2: 3=1.0: 1.5: 1.2-1.3$. FL1 0.7-0.8 times as long as width, FL2 1.0-1.2 times [usually about 1.1], FL3 1.0-1.1 times, and remaining segments about same in proportion to FL3. Each segment after FL2 not swollen medially, roughly cylindrical. Undersides of FL5 and the following segments with distinct velvet-like areas, sometimes FL3 and FL4 with rudimentary one. Velvet-like area on FL5 confined to basal narrow margin of segments; those on the more following segments slightly wider, but at most reaching basal onefourth of each segment. Hind femora slender, relative breadth to length of hind femur about 0.30 . Apical process of hind tibia shortly triangular. Hook on hind wing 5 in number. S7 V-shaped. S8 with posterior margin truncate or produced posterolaterally; posterolateral corner with a few setae; lateral margin moderately wavy; anterior margin produced roundly. Gonocoxite striate with dorsal depression. Gonostylus terminated by an obtuse lobe, with long setae on the lobe and with much finer, very sparse, short setae on lateral surface; inner basal surface with not dense setae finer downwards; basoventral lobe small but distinct with a few setae.

Distribution. JAPAN [Honshu, Shikoku, Kyushu]. 
Specimens examined. Holotype [MNHAH], male with three labels as follows: "Akausagiyama [in Japanese], Ohno/ Fukui, Japan/ 14. IX. 1975/ Y. HANEDA [white rectangle with handwritten letters]", "Sphecodes/ sulcifera/ Tsuneki $\delta /$ HOLOTYPE [red rectangle with handwritten letters]", and "B1-288305 [white rectangle with printed register-number of MNHAH and a bar-code]".

Other specimens: We have examined 17 females and 30 males. Some of them are listed as follows: JAPAN
[Honshu] Aomori: + , Mt. Kuromori (Kuroishi), 6. vi. 1985 (M. Yamada, APM); đ, Mt. Hirai (Shingoh), 28. ix. 1986 (M. Yamada, APM); ðૈ, Natsusaka (Takko), 15. ix. 1986 (M. Yamada, APM); đૈ, Tukusimori (Towadako), 4. x. 1986 (M. Yamada, APM); 2ð, Mt. Ohkuromori (Takko), 30. viii. 1987 (M. Yamada, APM); O, Mt. Ohkuromori (Takko), 30. viii. 1987 (M. Yamada, APM); Õ, Mt. Ohkuromori (Takko), 30. viii. 1987 (M. Yamada,

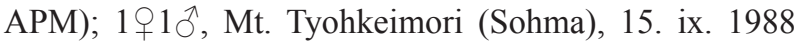

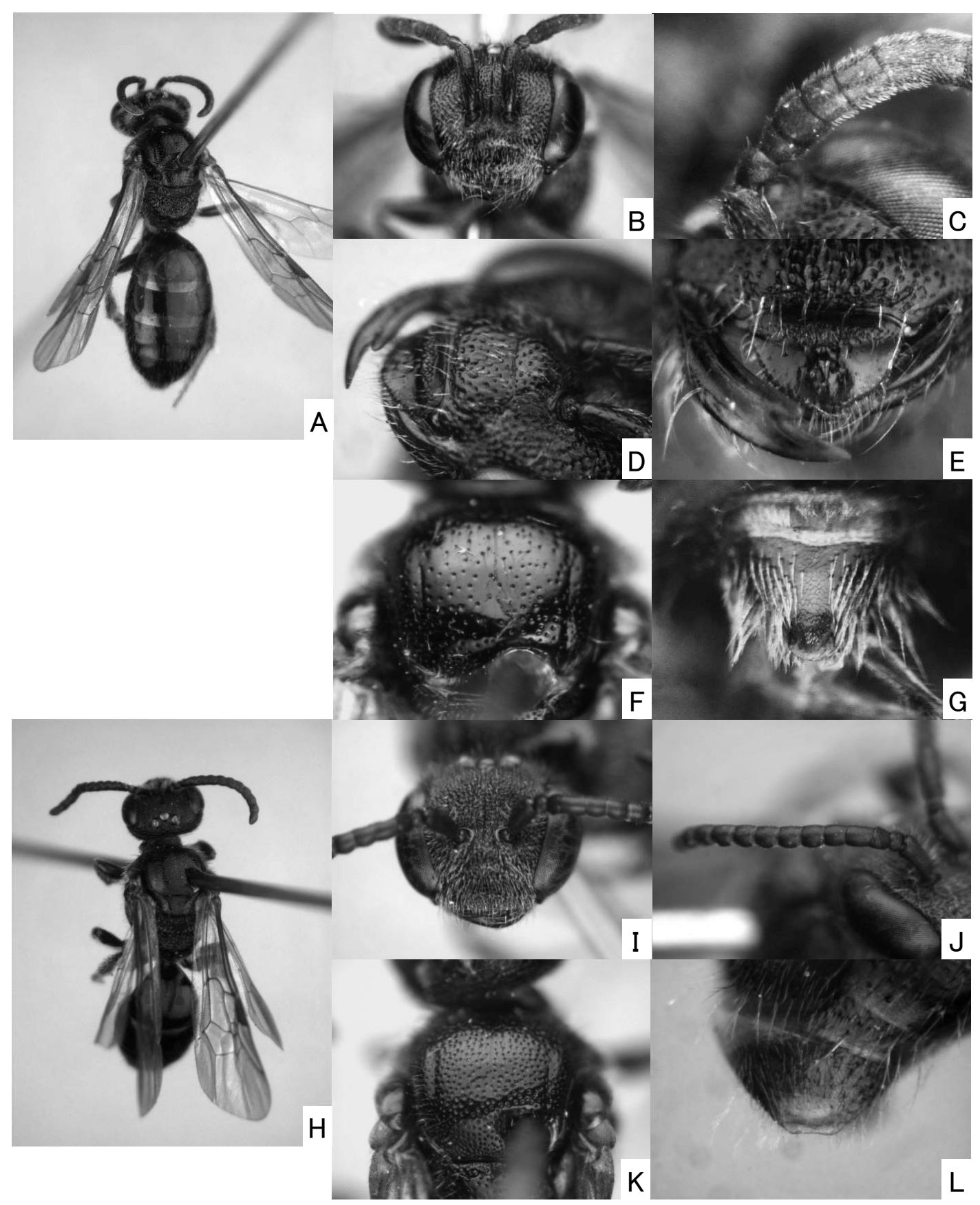

Fig. 34. Sphecodes sulcifera Tsuneki, Female: A-G. Male: H-L. A, H: habitus, dorsal view. B, I: head. C, I: antenna. D: clypeus. E: labrum. F, K: scutellum. G, L: pygidial plate. 

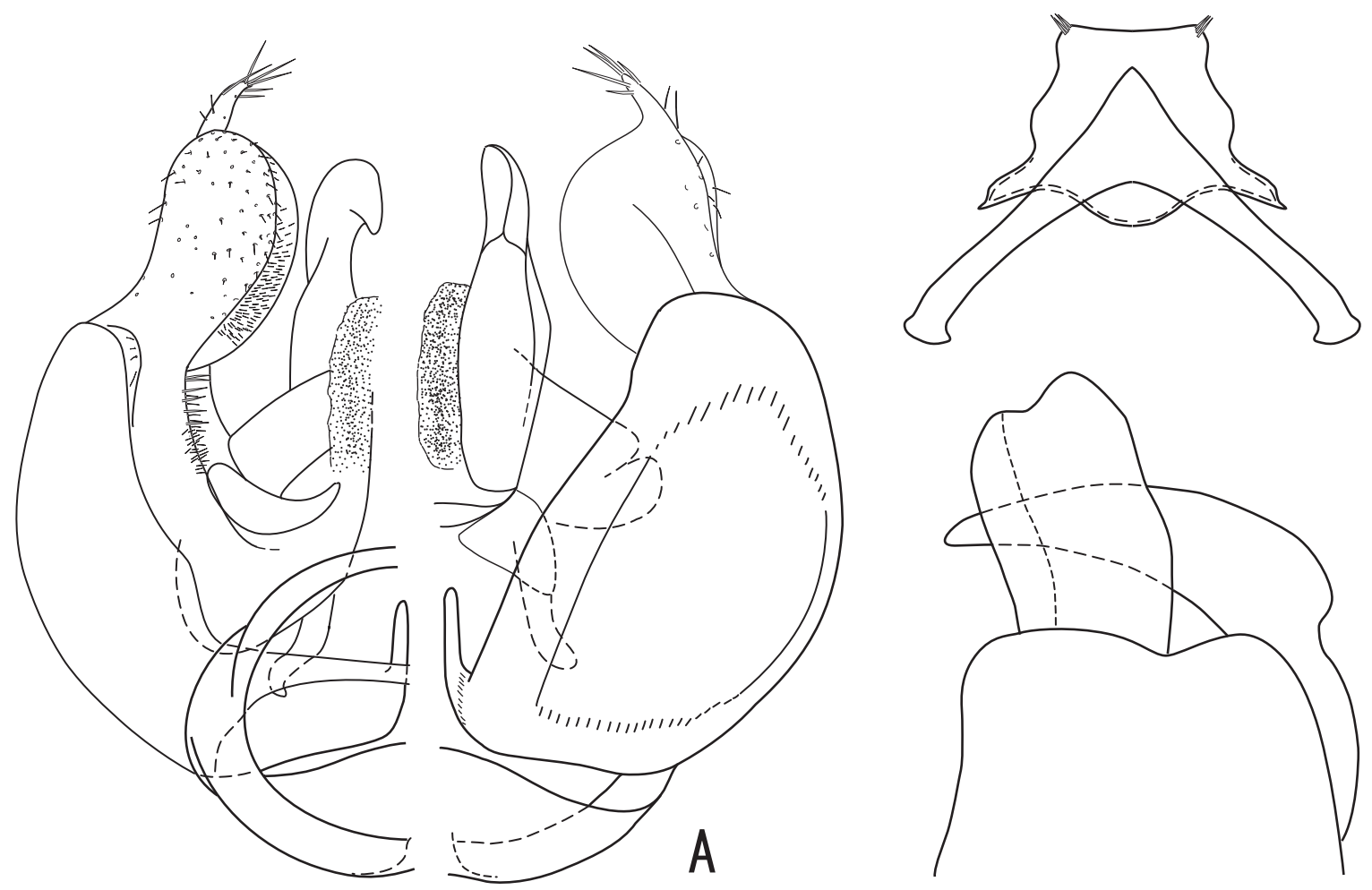

B

Fig. 35. Sphecodes sulcifera Tsuneki, male. A: genital capsule (left, ventral view; right, dorsal view). B: 7th and 8th metasomal sterna, ventral view. C: gonostylus, lateral view (vestiture omitted).

(M. Yamada, APM); ㅇ, Mt. Tyohkeimori (Sohma), 15. ix. 1988 (M. Yamada, APM); đ̃, Mt. Tyohkeimori (Sohma), 15. ix. 1988 (M. Yamada, APM); ठ̃, Zenkohzitai (Hiraka), 10. ix. 1988 (M. Yamada, APM); 11ㅅ, Itinoatari (Hirosaki), 13. ix. 1989 (M. Yamada); \&, Itinoatari (Hirosaki), 13. ix. 1989 (M. Yamada, APM); ठ̀, Itinoatari (Hirosaki), 13. ix. 1989 (M. Yamada, APM); ô, Mt. Chohkeimori (Sohma), 24. ix. 1989 (M. Yamada, APM); 2̧̄, Sukayu (Aomori), 26. viii. 1989 (M. Yamada, APM); §, Sukayu (Aomori), 26. viii. 1989 (M. Yamada, APM); §, Sukayu (Aomori), 26. viii. 1989 (M. Yamada, APM); +, Mt. Tashiro (Kuroisi), 26. v. 1990 (M. Yamada, APM); ㅇ, Hakkoda-IS (Aomori), 2. x. 1997 (M. Yamada, APM); ふ, Tsuta (Towadako), 29. viii. 1997 (M. Yamada, APM); Iwate: $192 \hat{\jmath}$, Ashiro, 26. ix. 1973 (Y. Maeta, EBSU); 우, Ashiro, 26. ix. 1973 (Y. Maeta, EBSU); đ̃, Ashiro, 22. ix. 1974 (Y. Maeta, EBSU); ô, Ashiro, 19. ix. 1979 (Y. Maeta, ELKU); đ̃, Isagozawa, Morioka C., 24. viii. 1991 (Ya. Chiba, FFPRI); ð̊, Matsukawa Spa, Matsuo V., 3. x. 1992 (H. Chiba, FFPRI). Tochigi: ㅇ, Takio Shrine, Nikko, 23. v. 1980 (K. Nakamura); 3ㅇ, Nikko Nat. Park, Odashirogahara, 26. ix. 1983, K. Nakamura); 2ð, Nasukogen, Nasu Town, 26. viii. 1991 (H. Suda). Gumma: ふૈ, Haruna-Kogen, Gunma Gun, 1. ix. 1987 (H. Suda). Saitama: ô, Tochiomoto, Chichibu, 4. ix. 1954 (H.
Nagase). Toyama: 1이, Arimine-kohan Seinangan, Toyama-shi, 10. ix. 2005 (H. Kurokawa). Fukui: + , Ifuriyama, Ohno, 10. v. 1964 (Y. Haneda); ๆ, Fukui, Shimouchinami, Ohno, 25. viii. 1973 (Y. Haneda); $\widehat{\partial}$, Arashi-Ohno, 16. viii. 1979 (H. Kurokawa, Y. Haneda's coll.); +, Arashima-dake, Oono-shi, 6. vi. 1982 (T. Tano, Y. Haneda's coll.); +, Nogo-Hakusan, Oono-shi, 8. vi. 1982 (Y. Haneda); ô, Mt. Akausagiyama, Ohno, 31. viii. 1986 (Y. Haneda); +, Obara-Toge, Katsuyama-city, 15. ix. 1995 (C. Nozaka); †, Suwara, Ohno, 10. ix. 1997 (Y.

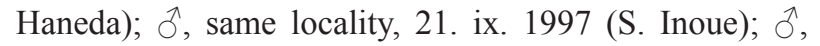
same locality, 30. viii. 1999 (Y. Haneda); 29, Kamikoike, Ono-shi, 14. v. 2002 (K. Mitai). Nagano: †, Sengataki, Karuizawa, 27. ix. 1972 (H. Suda, ELKU). [Shikoku] Ehime: ふૈ, Mt. Kamegamori, 26. ix. 1999 (Y. Maeta, EBSU). [Kyushu] Miyazaki: ô, Mt. Wanitsuka, 900m, 3. viii. 1994 (S. Ikudome).

Biology. The flight period is from early May to early October in female and male.

Remarks. Tsuneki (1983) mentioned in his original description that this species has the deeply impressed scutal and parapsidal lines. This character state is important for recognizing this species. However, it is rather misleading because this character is very variable from deep to shallow or obscure. The not-deeply impressed scutal 
and parapsidal lines, normal for Sphecodes, are usual among the specimens of $S$. sulcifera, rather than the deeply-impressed ones. Contrarily, the deeply impressed lines occur sometimes in other Sphecodes species. As for females of this species, they are also unique in having the smooth narrow upper margin of posterior vertical face of propodeum. As for males, this characteristic is less distinct, the smooth area is narrower than that of females. The males can be separated from the Japanese species by the weakly plumose vestiture on face, the antenna with narrow velvet-like area, and the apically truncate 7 th tergum.

\section{Sphecodes tanoi Tsuneki, 1983}

[Japanese name: Tano-yadori-kohanabachi] (Fig. 36-37)

Sphecodes tanoi Tsuneki, 1983, Spec. Publ. Jap. Hymenopt. Assoc., (26): 49 [Holotype: Male. Type locality: Mt. Haku, Iwama Spa., Ishikawa Pref., Honshu, Japan].

Sphecodes mutsu Tsuneki, 1983, Spec. Publ. Jap. Hymenopt. Assoc., (26): 22 [Holotype: Male, Type locality: Towada, Aomori Pref., Honshu, Japan]. Syn. Nov.

Sphecodes fukuiensis Tsuneki, 1983, Spec. Publ. Jap. Hymenopt. Assoc., (26): 44 [Holotype: Male. Type locality: Imajo, Tochinoki Pass, Fukui Pref., Honshu, Japan]. Syn. Nov.

Sphecodes fudzi Tsuneki, 1983, Spec. Publ. Jap. Hymenopt. Assoc., (26): 45 [Holotype: Male. Type locality: Mt. Fudzi, Narusawa, Yamanashi Pref.,
Honshu, Japan]. Syn. Nov.

Sphecodes chichibuus Tsuneki, 1983, Spec. Publ. Jap. Hymenopt. Assoc., (32): 46 [Holotype: Male. Type locality: Tochimoto Village, Chichibu mountain region, Saitama Pref., Honshu, Japan]. Syn. Nov.

\section{Redescription.}

Male.

Color: Body black except the following: mandible dark yellow or red apically; apical several flagellar segments slightly paler; terga and sterna black, or apical margins of terga tinged with dark red. Femora black, fore tibiae beneath yellowish and other tibiae yellowish partially, tarsi yellowish brown.

Sculpture: Clypeus punctate-reticulate with few punctules on thin interpunctural area, without median furrow. Supraclypeal area as clypeus. Frons minutely areolate until lateral ocelli. Vertex near preoccipital ridge and genal area coarsely rugose. Scutum punctate-reticulate, somewhat sparser medially. Scutellum areolate. Mesepisternum areolate densely. T1 polished wholly with very scattered fine punctules, virtually impunctate; apical depressed margin not indicated. T2 polished with scattered punctules. T3-5 impunctate on exposed areas. T7 densely shagreen, sparser apically, well produced; apical margin not well produced, but broadly rounded and turned upward.

Vestiture: Vestiture on lower face white, moderately dense, densely plumose and appressed, but short so that integument beneath visible to some extent.

Structure: Body length 6-7 mm. Head about 0.83 times as long as wide. Vertex behind lateral ocelli not

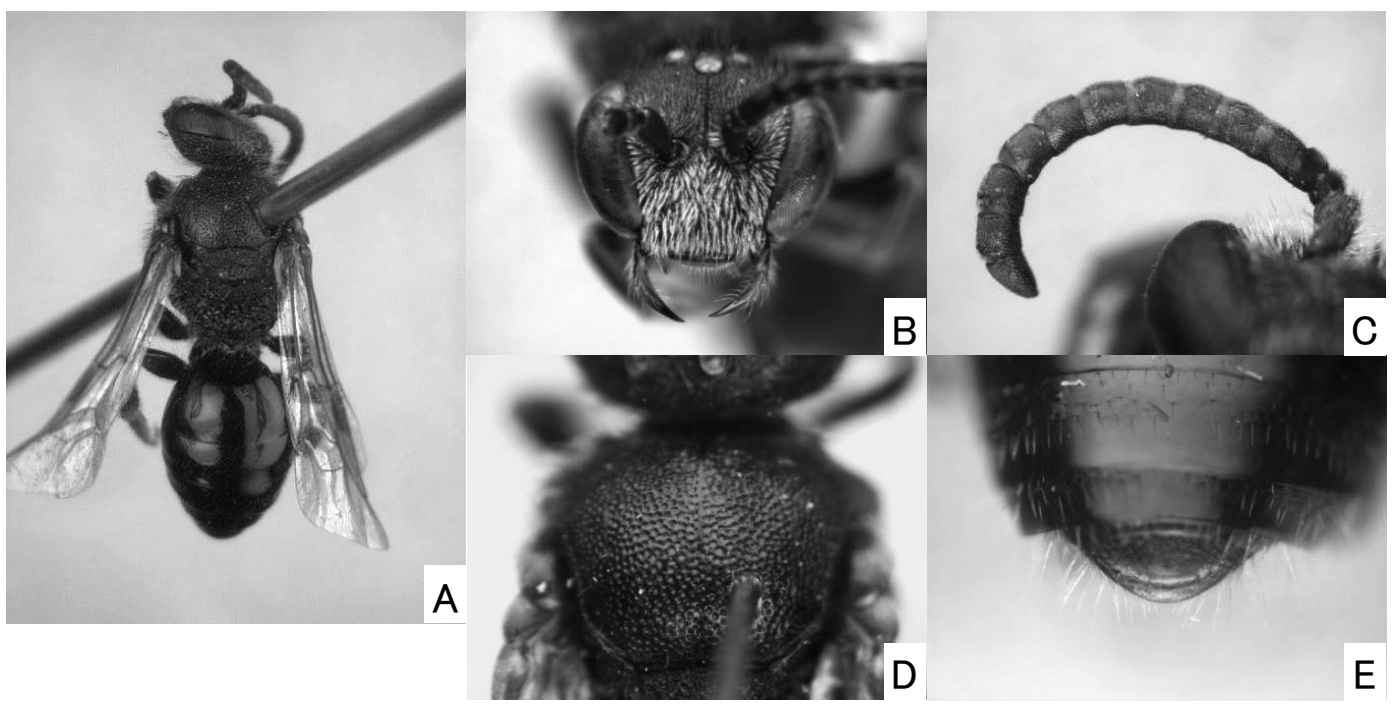

Fig. 36. Sphecodes tanoi Tsuneki, male. A: habitus, dorsal view. B: head. C: antenna. D: scutellum. E: pygidial plate. 

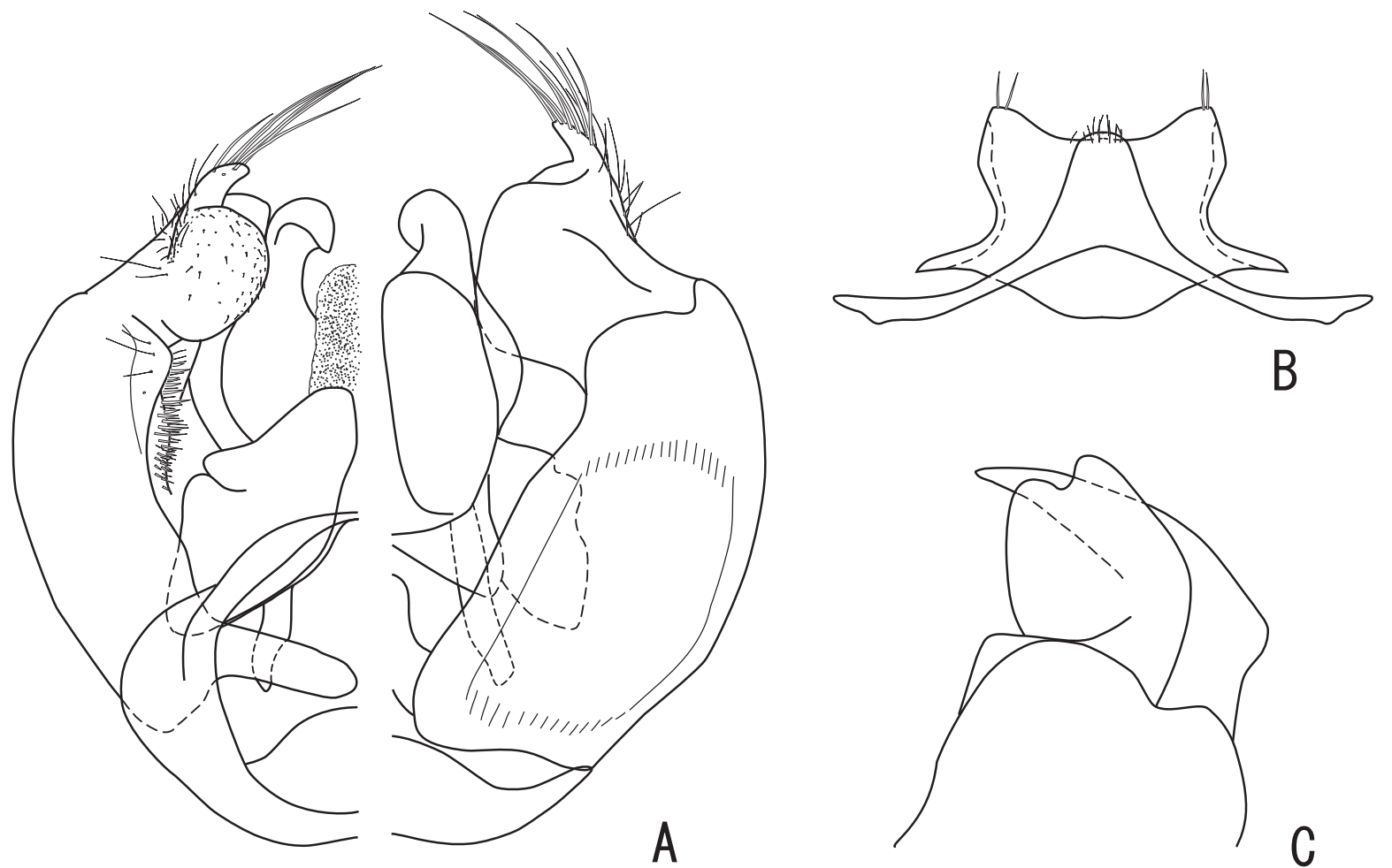

Fig. 37. Sphecodes tanoi Tsuneki, male. A: genital capsule (left, ventral view; right, dorsal view). B: 7th and 8th metasomal sterna, ventral view. C: gonostylus, lateral view (vestiture omitted).

developed upward beyond lateral ocelli in frontal view. Genal area narrower than compound eye in lateral view, about 0.5 times as wide as compound eye. Exposed portion of pedicel as long as FL1. Relative length of FL1 $: 2: 3=1.0: 1.4: 1.4$. FL1 0.8 times as long as width, FL2 1.1 times, FL3 1.0-1.1 times, and remaining segments about as long as width. Each segment after FL1 swollen medially. Undersides of FL2 and the following segments with distinct velvet-like areas [sometimes FL2 with rudimentary one] basally and apically. Basal velvet-like area on FL3 reaching near middle; those on the following segments much wider, developed upwards beyond the middle of each segment. Apical velvet-like area roughly similarly shaped on all segments. Collar gently curved between frontal and lateral sides. Pronotum with lateral ridge indistinct, at most lowly raised. Scutellum flat. Hind femora slender to moderate, relative breadth to length of hind femur about 0.32 . Apical process of hind tibia hardly produced or rather shortly rounded. Hook on hind wing 5 in number. Disc of S7 moderately wide, gently narrower posteriorly. S8 with posterior margin emarginate with a few setae on posterolaterad corner and on bottom of emargination; lateral margin wavy; anterior margin roundly produced anteriorly. Gonocoxite striate with dorsal depression. Gonostylus terminated by an obtuse lobe, with long setae on top of the lobe and with short fine setae on lateral surface; inner basal surface with dense setae finer downwards; basoventral lobe distinct with several setae.

Distribution. JAPAN [Hokkaido, Honshu, Kyushu].

Specimens examined. Holotype [MNHAH], male with three labels as follows: "IWAMA/ ISHIKAWA, Jap/ 25. VII. 1959/ T. TANO [white rectangle with handwritten letters]", "Sphecodes/ tanoi/ Tsuneki ő/ HOLOTYPE [red rectangle with handwritten letters]", and "B1-288310 [white rectangle with printed register-number of MNHAH and a bar-code]".

Other specimens: We have examined 20 males. Some of them are listed as follows: JAPAN [Hokkaido] $\hat{\sigma}$, Yukomanbetsu, 6. ix. 1967 (T. M., ELKU); Ô, same locality, 8. viii. 1967 (collector unknown, ELKU); ふૈ, Soranuma, 2. x. 1968 (collector unknown, ELKU); ふૈ, Moiwa, 13. vii. 1972 (Kawano); 2ð, Otarunai, 6. ix. 1973 (H. Fukuda, ELKU); ふै, Mt. Upepesanke, 700m alt., Tokachi, 16. ix. 1986 (M. Usui, K. Nakamura's coll.). [Honshu] Aomori: §̊, Oh-Kawa (Nishimeya), 23. ix. 1985 (M. Yamada, APM); స̃, Tukusimori (Towadako), 4. x. 1986 (M. Yamada, APM); đ̄, Nagasaka (Kuroishi), 15. vii. 1989 (M. Yamada, APM). Tochigi: ふૈ, Nikko Nat. Park, Yumoto Spa, 26. viii. 1983 (M. Terayama, K. 
Nakamura's coll.). Tokyo: đ̃, Shinmachi, Oume, 19. vii. 1990 (H. Takahashi). Toyama: ふૈ, Lake Arime Dam, 21. vii. 2007 (T. Tano). Fukui: ふૈ, Monjusan, Fukuishi, 16. vi. 2004 (H. Kurokawa). Yamanashi: ふ̂, Yakeyama road, Makioka Town, 29. vii. 1986 (H. Suda); Õ, KoyodaiGokodai, Narusawa V., 29. viii. 1989 (H. Suda); đ̃, Kouyoudai, Narusawa-mura, 10. viii. 1991 (H. Takahashi). Nagano: đ̊, Karuizawa, 6. ix. 1949 (R. Ishikawa, ELKU). Gifu: Ô, Sandani, Shoukawa-mura. Ohno-gun, 20. viii. 2002 (K. Mitai, ELKU). [Kyushu] Fukuoka: ふૈ, Inugatake (Buzen), 14. vii. 1938 (Hori, Kawahara \& Yasumatsu, ELKU).

Biology. The flight period is from mid June to early October with most records from mid July to early September.

Remarks. This species is similar to $S$. okuyetsu in having a similar structure of antenna, but can be easily separated from the latter by the shorter FL2 [1.1 times as long as width], the less produced apical margin of 7th tergum, contrasted with the longer FL2 [1.4-1.5 times as long as width] and the well-produced apical margin of 7 th tergum in S. okuyetsu.

\section{Supplementary comments on the fauna of Sphecodes in Japan}

Japan is composed of four main islands (Hokkaido, Honshu, Shikoku and Kyushu) and several thousand small islands, most of which are located on the eastern margin of the Palearctic Region. The series of southern islands that lie between Kyushu and Taiwan is called the Nansei Islands, and is the northwestern part of the Oriental Region. There are eight species which we identified in the present study from all four main islands of Japan: $S$. coptis, S. koikensis, S. nippon, S. nipponicus, S. okuyetsu, S. scabricollis, S. silvicola, and S. simillimus. All Japanese species inhabit the Palearctic part of Japan, and only two of them, S. amakusensis and S. nipponicus, are also recognized in the Oriental part.

Three species, S. nipponicus, S. scabricollis, and $S$. simillimus are each represented by roughly 700 specimens, and the combined number of them makes up more than half of all examined specimens from Japan. They could be said to be common species in Japan. Next to them, S. okuyetsu was nearly $10 \%$ of all specimens.

As is evident from the species descriptions, nine Japanese species are still known only by one sex. If the combinations of females and males are clarified, the number of species inhabiting in Japan will decrease. In Sphecodes, it is difficult to elucidate the sexual combination by the morphology. Decisions based on a few cases of co-occurrences in the field may well lead to incorrect conclusions about sexual combinations. Hence, the matter remains to be proven in the future by DNAbarcoding, etc. Here, we consider the sexual combinations of some species with circumstantial evidence.

In $S$. ikudomei and $S$. nambui, their females are unknown in the present study. The males of these two species and S. scabricollis are similar each other, and the differences among them are in the morphology of antennae and the color of hair on the face. Possibly we failed to find the differences among females of these three species and identified all of them as S. scabricollis, or there is a possibility that the females of $S$. ikudomei and $S$. nambui still have not been collected because these two species are rare.

Some females of $S$. ohdeyamanus with the male unknown were collected with females of $S$. silvicola in some instances. The females of these two species are similar although they can easily be recognized by external morphological characters. In this case too, we may well fail to recognize males of $S$. ohdeyamanus among males of $S$. silvicola.

The two species with the male unknown, namely $S$. coptis and S. koikensis are not rare in number, and it is, therefore, unlikely that their males have not yet been collected. Probably S. coptis and S. koikensis are females of any of four female-unknown species: $S$. dyozankeanus, $S$. hanedai, S. murotai, or S. tanoi.

\section{Acknowledgments}

We would like to express our sincere thanks to Mr. M. Schwarz (Linz) and Prof. Emeritus Y. Hirashima (Fukuoka) for his continuous guidance for study, and also to Assoc. Prof. L. J. Westover, Assoc. Prof. S. Kamitani (Kyushu University) and Mr. D. Yamaguchi (Kyushu University) for their kind support in many ways. Special thanks are due to the following entomologists for their encouragement and kindness in providing the valuable materials: K. Goukon (Miyagi), Y. Haneda (Fukui), S. Ikudome (Kagoshima Women's Junior College), E. Katayama (Tochigi), H. Kurokawa (Fukui), Y. Maeta (Shimane), T. Matsumura (Ibaraki), R. Miyanaga (Shimane University), R. Murao (Kyushu University), T. Murota (Fukui), K. Nakamura (Tochigi), H. Nagase (Kanagawa), T. Nambu (Saitama), H. Negoro (Toyama Science Museum), C. Nozaka (Fukui), H. Suda (Chiba), A. Shinohara (NSMT), H. Takahashi (Tokyo), T. Tano (Fukui), M. Yamada (Aomori), S. Yamauchi (Aomori Pref. Museum), K. Yasuda (NIAES). This work was supported in part by the Environment Research and 
Technology Development Fund (S-9-2(8)) of the Ministry of the Environment, Japan (Head Investigator: Osamu Tadauchi). This is a contribution from the Entomological Laboratory, Faculty of Agriculture, Kyushu University, Fukuoka (Ser. 6, No.117).

\section{Literature cited}

Amiet, F., A. Müller \& R. Neumeyer, 1999. Fauna Helvetica. Apidae 2. (Colletes, Dufourea, Hylaeus, Nomia, Nomioides, Rhophitoides, Rophites, Sphecodes, Systropha). Centre suisse de cartographie de la faune, Neuchâtel.

Cockerell, T. D. A., 1911. Bees in the collection of the U. S. National Museum. I. Proc. U. S. Nat. Mus., 39: 635-658.

Maeta, Y. et al., 1996. Host records of cleptoparasitic bees in Japan (Hymenoptera, Apoidea). Jap. J. Ent., 64: 830-842.
Meyer, R., 1922. Nachtrag zur Bienengattung Sphecodes Latr. Arch. Naturgesch., Abt., 88A 8: 165-174.

Michener, C. D., 2007. The Bees of the World, 2nd ed. John Hopkins University Press, Baltimore and London.

Tsuneki, K., 1983. A contribution to the knowledge of Sphecodes Latreille of Japan (Hymenoptera, Halictidae). Spec. Pub. Jap. Hym. Assoc., (26): 1-72.

Tsuneki, K., 1984. On some species of Sphecodes of Japan, with descriptions of new species (Hym., Apoidea). Spec. Pub. Jap. Hym. Assoc., (30): 1-10.

Tsuneki, K., 1986. New species and subspecies of the Aculeate Hymenoptera from East Asia with some synonyms, specific remarks and distributional data. Spec. Pub. Jap. Hym. Assoc., (32): $1-60$.

Yasumatsu, K. and Hirashima, Y., 1951. Zwei neue SphecodesArten aus Japan nebst Beschreibung des Weibchens von Sphecodes esakii Strand et Yasumatu. Ins. Mats., 17: 3-4. 